


\section{EDITORIAL POLICY}

Papers must be submitted with the understanding that they have not been published elsewhere (except in the form of an abstract or as part of a published lecture, review, or thesis) and are not currently under consideration by another journal published or any other publisher. The submitting (Corresponding) author is responsible for ensuring that the article's publication has been approved by all the other coauthors. It is also the authors' responsibility to ensure that the articles coming from a particular institution are submitted with the approval of the necessary institution. Only an acknowledgment from the editorial office officially establishes the date of receipt. It is a condition for submission of a paper that the authors permit editing of the paper for readability. All enquiries concerning the publication of accepted papers should be addressed to ejournal.assist @tau.edu.gy.

\section{PEER REVIEWERS}

Dr. Madhu Bala, Department of Commerce, D.A.V. College for Girls.

Dr. Abraham, Professor, Synergy University, Dubai Campus. 


\section{ABOUT PLAGIARISM}

Plagiarism is the use or close imitation of the language and ideas of another author and representation of them as one's own original work. Duplicate publication, sometimes called self-plagiarism, occurs when an author reuses substantial parts of his or her own published work without providing the appropriate references. This can range from getting an identical paper published in multiple journals, where authors add small amounts of new data to a previous paper.

Plagiarism can be said to have clearly occurred when large chunks of text have been cut and pasted. Such manuscripts would not be considered for publication in TIJMG Journal. But minor plagiarism without dishonest intent is relatively frequent, for example when an author reuses parts of an introduction from an earlier paper. The editors will judge any case of which they become aware (either by their own knowledge of and reading about the literature, or when alerted by referees) on its own merits.

The paper containing the plagiarism will be obviously returned back to the author's for review, but we earnestly request the authors to avoid submitting plagiarized. 


\section{DISCLAIMER}

Texila International Journal of Management (TIJMG) make every effort to ensure the accuracy of all the information (the "Content") contained in its publications. However, the TIJMG and its agents make no representations or warranties whatsoever as to the accuracy, completeness or suitability for any purpose of the Content and disclaim all such representations and warranties whether express or implied to the maximum extent permitted by law. Any views expressed in this publication are the views of the authors and are not necessarily the views of the Editor's or Texila International Journal of Management. 


\section{TABLE OF CONTENT}

1 Lessons Learned from the Quality of Care Project

Roy Chikwem

2 Employees Perspective on Internal Branding Mechanisms. Case Study of a 11 Multinational Organization in Ghana

Mary Akweley Cobblah

3 The Role of Internal Branding for Corporate Success. Employees

Perspective from a Multinational Organization in Ghana

Mary Akweley Cobblah

4 Costing and Financial Management: The Financial Impact of Investment of Technology in Motors Manufacturers (T) LTD

Fatema Rehman

5 Implications of Water Development Projects on Community Welfare; The

Case of Eloumden I Mbankomo Sub Division, Mefou and Akono Division

Roosevelt

6 A Critical Analysis of the Effects of Strategic Management on Small Scale 56 Businesses; A case study of Patent Medicine Stores in Abuja, Nigeria 


\title{
Lessons Learned from the Quality of Care Project
}

\author{
Roy Chikwem \\ Texila American University \\ E-mail: rchikwem@gmail.com
}

\begin{abstract}
Each year 40,000 women die during pregnancy and childbirth, and over 250,000 babies die in their first month of life in Nigeria. Save the Children International worked to improve the lives and health status of an estimated 435,000 mothers and their babies in Lagos and Jigawa over a period of three years through its Quality of Care (QoC) project in Nigeria. This integrated project drew on existing partnerships with national, state and global experts to strengthen essential training, improve the clinic environment including supervision and monitoring, develop and disseminate communication messages for behaviour change as well as advocate for implementation of transformative policies. A combination of document review, qualitative and quantitative data collection approaches were adopted. These data were then triangulated to respond to the objectives of the evaluation. The findings show that the project has changed the way healthcare is provided in target facilities in Jigawa and Lagos as a result of their participation on the project.
\end{abstract}

Keywords: project monitoring and evaluation, maternal and child health, project management, public health.

\section{Introduction}

Nigeria is the sixth most populous country in the world (Aluko, 2004). With a population of over 167 million, Nigeria is Africa's most populous country and has the highest annual number of maternal and new-born deaths across the continent (Olusegun, Ibe \& Michael, 2012). Each year 40,000 women die during pregnancy and childbirth, and over 250,000 babies die in their first month of life (Adedokun \& Uthman, 2019). Haemorrhage and hypertension are the leading causes of maternal deaths, and for newborns, complications during childbirth, preterm birth, and infections contribute to hundreds of thousands of lives being needlessly lost (Olusegun, Ibe \& Michael, 2012). Children in the poorest families carry more than four times the risk of dying compared to counterparts in the richest families. Most of these deaths are caused by conditions that are preventable or treatable. There has been some progress made to reduce these deaths over the past decade, the rate of change has not been fast enough for Nigeria to meet the Millennium Development Goal (MDG) 4 for child survival, or MDG 5 for maternal health.

According to the World Health Organization (2014), key interventions and packages that could prevent $70 \%$ of new-born deaths in
Nigeria exist, but coverage is low. For example, in Nigeria, half of all mothers are vaccinated against Tetanus Toxoid, only 39\% of mothers deliver in the presence of a skilled attendant and $30 \%$ of women breastfeed their new-borns within the first hour of life (Findley, Cometto, \& Afenyadu, 2013). The policies are in place; however, action is needed at state and local levels to increase coverage and quality of lifesaving interventions while closing the equity gap for the poorest families. The Nigerian health care has suffered several down-falls. Despite the Nigerian's strategic position in Africa, the country is greatly underserved in the health care sphere. Health facilities (health centres, personnel, and medical equipment) are inadequate in the country, especially in rural areas. There are various reforms have been put forward by the Nigerian government to address the wide-ranging issues in the health care system, they are yet to be implemented at the state and local government area levels.

Save the Children International in partnership with Unilever committed to making a real difference in the lives of women and new-born babies in Nigeria; by giving mothers the care they need, and babies the right start to a healthy life; one that they deserve. Through Unilever's support over three years, Save the Children International planned to improve the lives and 
health status of an estimated 435,000 mothers and their babies; 112,000 mothers and babies in 13 Health facilities across 6 Local Government Areas (LGAs) in Jigawa state, and 323,000 mothers and babies in 27 facilities in 7 LGAs and Local Council Development Area (LCDAs) in Lagos state. The Quality of Care (QoC) project also committed to building the capacity of 1,000 health care workers to provide quality health services and appropriate care to mothers and their babies as well as increased awareness among mothers and access to quality maternal and newborn health services. This integrated programme drew on existing partnerships with national, state and global experts to strengthen essential training, improve the clinical environment including supervision and monitoring, develop and disseminate communication messages for behaviour change as well as advocate for the implementation of transformative policy.

\section{Materials and Methods}

This study was evaluative in nature and it employed a qualitative method of data collection to gather necessary information. A combination of data sources was used in this assessment to answer the evaluation questions. This included a review of the project documents and the collection of both qualitative data. These data were triangulated to respond to the structured research questionnaires for in-depth interviews (IDIs) and key informant interviews (KIIs) and focus group discussions (FGDs). Several documents were reviewed; this included baseline reports, project proposal, project annual reports and other related research conducted during the project implementation.

\section{Data Collection}

Data collection involved the search for relevant information that will proffer a solution to specific problems. Every research effort, therefore, centred on the search for such information which could be obtained either from primary or secondary sources. But for this research, data for this study was gathered through primary and secondary sources.

- Beneficiary women in-depth interview

- Community leaders' in-depth interview

- Spouses of beneficiary women in-depth interview
- Trained Community Health Extension Workers (CHEW) in-depth interview

- Project staff in-depth interview

- Ministry of health officials' in-depth interview

- Schools of midwifery and health technology in-depth interview

- Health facility audit questionnaire

- Healthcare provider questionnaire

- Woman exit questionnaire

\section{Results and discussion}

The Quality of Care (QoC) project was intended to reduce maternal and neonatal morbidity and mortality ratio and rates by 2015 , through significantly improve care for mothers and babies at the time of birth and the immediate postnatal period in Lagos and Jigawa states by 2015. The table below shows key project goals of the Quality of Care (QoC) project;

\begin{tabular}{|c|c|c|}
\hline Objective 1 & Objective 2 & Objective 3 \\
\hline $\begin{array}{l}\text { Creation of an } \\
\text { enabling } \\
\text { clinical } \\
\text { environment in } \\
20 \text { health } \\
\text { facilities, and } \\
\text { effective } \\
\text { referral system } \\
\text { to increase } \\
\text { access to } \\
\text { quality } \\
\text { healthcare at } \\
\text { the time of } \\
\text { birth and in the } \\
\text { immediate } \\
\text { postnatal } \\
\text { period. }\end{array}$ & $\begin{array}{l}\text { Ensuring } \\
1000 \text { health } \\
\text { workers } \\
\text { have the } \\
\text { skills and } \\
\text { support they } \\
\text { need to } \\
\text { provide } \\
\text { quality } \\
\text { health } \\
\text { services to } \\
\text { mothers and } \\
\text { babies. }\end{array}$ & $\begin{array}{l}\text { Ensuring that } 2 \\
\text { states and its } \\
\text { local decision- } \\
\text { makers } \\
\text { implement key } \\
\text { national } \\
\text { policies at state } \\
\text { and local levels } \\
\text { and enable } \\
\text { communities to } \\
\text { realize their } \\
\text { right to quality } \\
\text { Maternal and } \\
\text { Newborn } \\
\text { Health } \\
\text { services. }\end{array}$ \\
\hline
\end{tabular}

Source: Quality of Care Project Implementation Plan, 2012.

The lead researcher reviewed the existing literature and gaps where they explicitly propose an evaluation methodology. The evaluation met the principles of participation in involving children and adults and making sure that men and women are represented in the data collection. The evaluation process included the following key steps: 
- Secondary data review: Review of relevant literature related to the Quality of Care (QoC) project, this included; the baseline health facility assessment report, project annual reports, project inception report, project monitoring data barrier analysis, referral study, facility assessment, community-based study of neonatal mortality in Lagos, and the report of the ongoing pilot for provision of postnatal home visits.

- Draft inception report with a summary of literature review and detailed evaluation study design including the application of appropriate data collection tools (e.g. questionnaire, checklist etc.) for interviews and discussions with stakeholders including Save the Children International staff.

- Field Data Collection by using: Quantitative and qualitative methods was used (including focal group discussions and key informant interviews) with appropriate groups/individuals including beneficiaries, health workers, ward development committees (WDC) and community development committees (CDC) members, policymakers and government officials at local government area (LGA) and state level. Health facility assessment using similar research methodology as baseline assessment including observation of service provision in health facilities, assessments of equipment, commodities and infrastructure.

- Reviewed the current status of maternal, newborn, and child health (MNCH) related policies and strategies as outlined in the project log frame, as compared to their status at the inception of the project e.g. child health policy and the integrated maternal, newborn, and child health (IMNCH) strategy.

- Ensured that all outcome indicators in the project log frame are assessed.

\section{Evaluation Results Considering Project Objective One}

One of the most important achievements of the Quality of Care (QoC) project was the fact that it exceeded it target in terms of the number of target facilities reach 100\% from 20 to 40, of its original target. Within the two states, Lagos and Jigawa, where the intervention took place, the project supplied equipment and supplies and also carried out basic improvements on healthcare infrastructures based on evidence from the health facility assessment that was conducted early in the second year of the project. These procurements included about 189 infant resuscitators, 1,300 mucus bulb syringe extractors and 49 digital baby weighing scales to target health facilities in Jigawa and Lagos states within the three years in which this project was implemented as a form of response to the shortages noted by the assessment.

As part of the evaluation, the lead researcher conducted an end line facility assessment, to assess the current level of availability of this equipment at the project sites and also explored how this may have affected and impacted the way services are provided in these facilities. The results showed that there is a significant increase in the proportion of health facilities that reported availability of equipment and supplies before and after participation in the project in Jigawa and Lagos states. While the availability of these equipment and supplies increased significantly in both states as a result of their participation in the project, Jigawa experienced a lot more of these changes when the lead researcher compared with Lagos. This is perhaps because of the level of availability of this equipment and supplies was lower at baseline in Jigawa when compared with Lagos. The data collected in the health facility assessment did not only assess how equipment and supplies may have changed between baseline and end line, the data further explored how the project may have changed how care is being provided in these target facilities.

Figure 1.1 and 1.2 below captures the main highlights of these results. An appreciable proportion of health facilities have now started providing different types of services that target mothers and babies and they are now that they are receiving the quality of service that is possible within this immediate postpartum period and beyond. Some of these services range 
from prevention and management of sepsis in babies, provision of care for neonates in the first week of life, resuscitation for neonates and the for mothers, the use of the anti-shock garment, management of postpartum haemorrhage, use of pantograph among others. More than half in Jigawa and more than two-thirds in Lagos reported that they now provide care for low birth babies as a result of their participation in the project. All these are no doubt lifesaving services and techniques that have great potentials to reduce mortality and avert deaths of neonates and their mothers, especially at the immediate postpartum period.

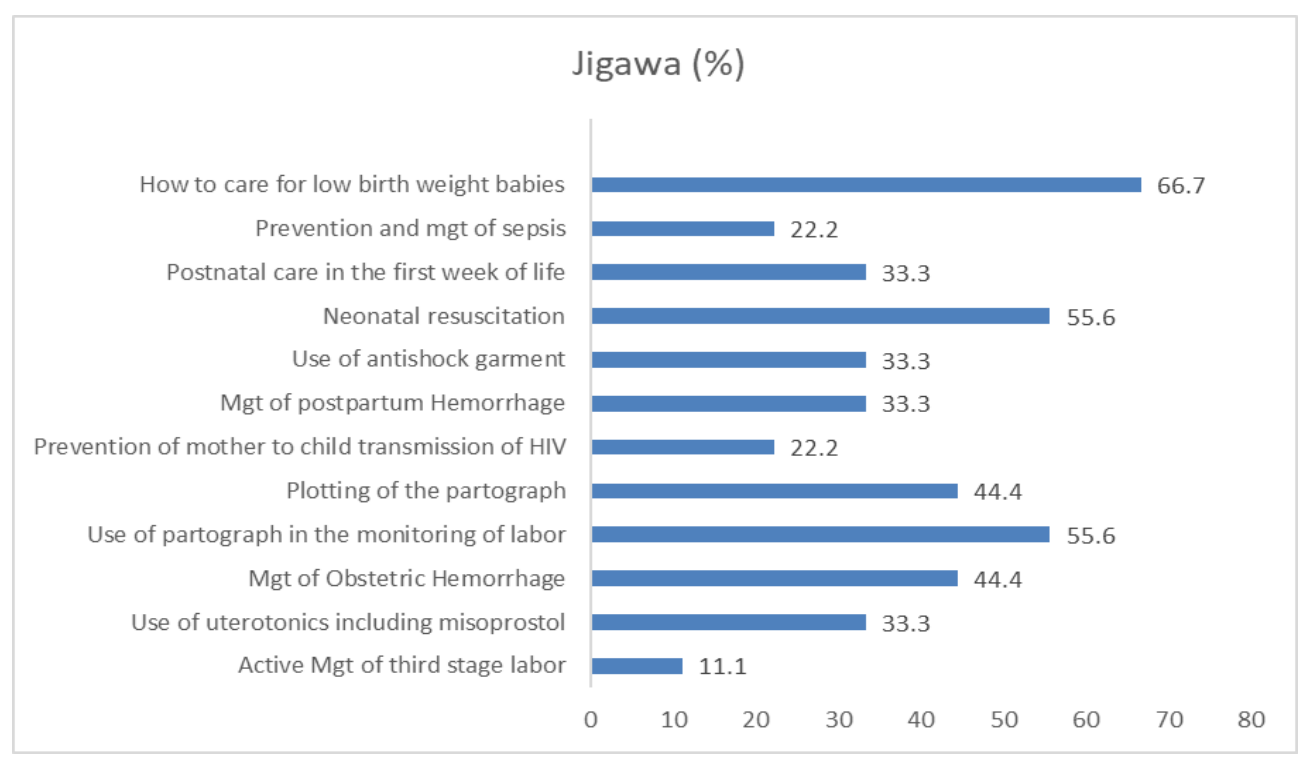

Figure 1.1. Proportion of facilities that started providing and using lifesaving services and techniques as a result of project intervention in Jigawa, Project End line Evaluation, 2019

In Jigawa, about two-thirds of the facilities reported they now offer care for low birth weight babies as a result of their participation in the intervention. Neonatal resuscitation is a care that more than half of the facilities in Jigawa said they now provide. Other care and services that facilities in Jigawa are offering as a result of the intervention are shown in Figure 1.1 and 1.2 above.

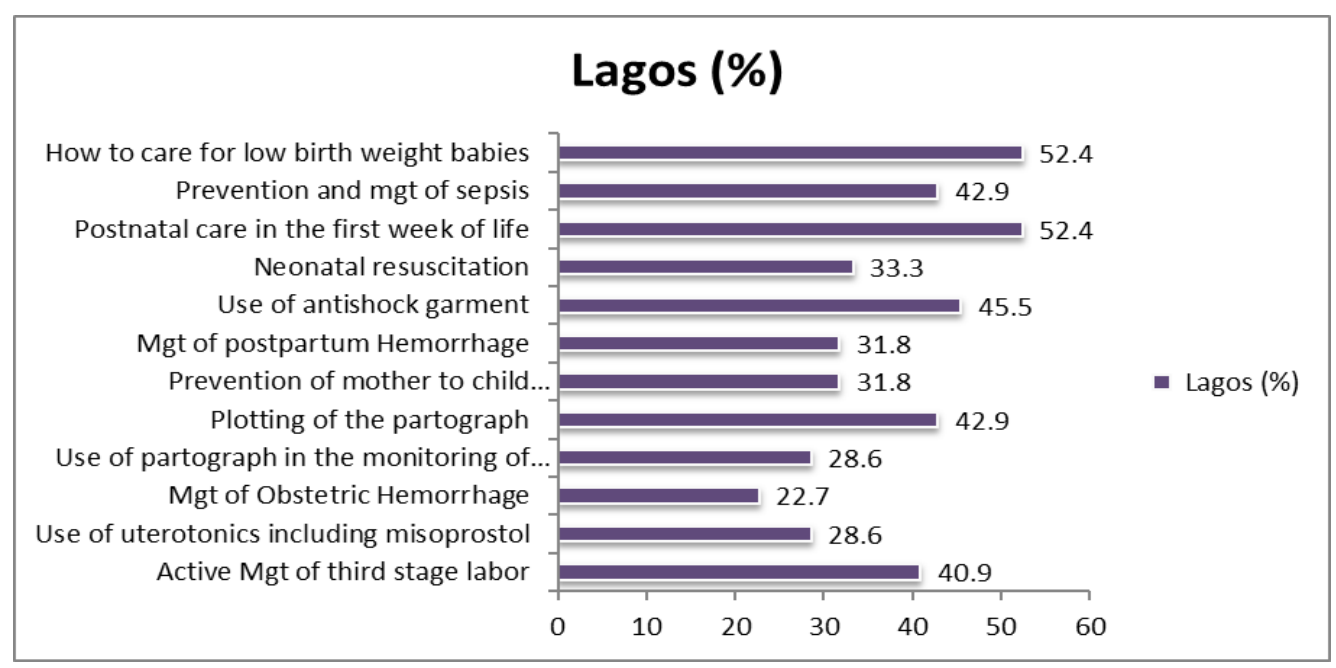

Figure 1.2. Proportion of facilities that started providing and using services and techniques as a result of project intervention in Lagos, Project End line Evaluation, 2019

Another key output under this objective is the need to strengthen the referral linkages between Primary Healthcare Centre (PHCs), secondary and tertiary facilities and in target Local
Government Area (LGAs) in the two states. For example, a woman who has just given birth and is beginning to haemorrhage may die within two hours if she is not treated for this obstetric 
complication. This timeframe should be enough for her to reach the emergency obstetric and neonatal care (EmONC) she needs. To better understand the current referral system as at the time of the project start-up, the project conducted an assessment of the system to understand the challenges and identify a plan of action that can help in achieving an improved referral system in the target states. Based on these findings, the project worked with the State Ministries of Health, LGAs and the health facilities to revise existing referral systems and ensure that women and newborns experiencing complications access advanced care as soon as possible.

Current barriers in the referral process include lack of transportation and limited systems to indicate the nearest available bed space. The project has since engaged the government using different platforms within its reach. Through advocacy, the project made efforts to ensure that all recommendations offered in the report are implemented by the government. Part of the project included advocating for the improvement of existing ambulance services provided by the
State Government. This effort has made the government to put in place functional ambulances in all the eight-flagship health centres in the focused LGAs which in turn has provided immediate access to emergency treatment for mothers and their babies. The project has also used the monthly health facility data review meetings to provide an avenue for the retraining of health workers on the application of the two-way referral system using referral tools in both Lagos and Jigawa states.

A review of the project documents showed that in Lagos, the number of referrals has increased from 64 to 92 between August 2014 and January 2015 and from 92 to 98 between January 2015 and June 2015. During the conduct of the health facility survey, the facilities reported that about the existence of referral system operationalized in the form of a plan of action for referral for women and babies requiring more specialized care in their facilities, our results showed that $92 \%$ of the facilities in Jigawa and $100 \%$ of those in Lagos reported that that they have a functional referral system in place.

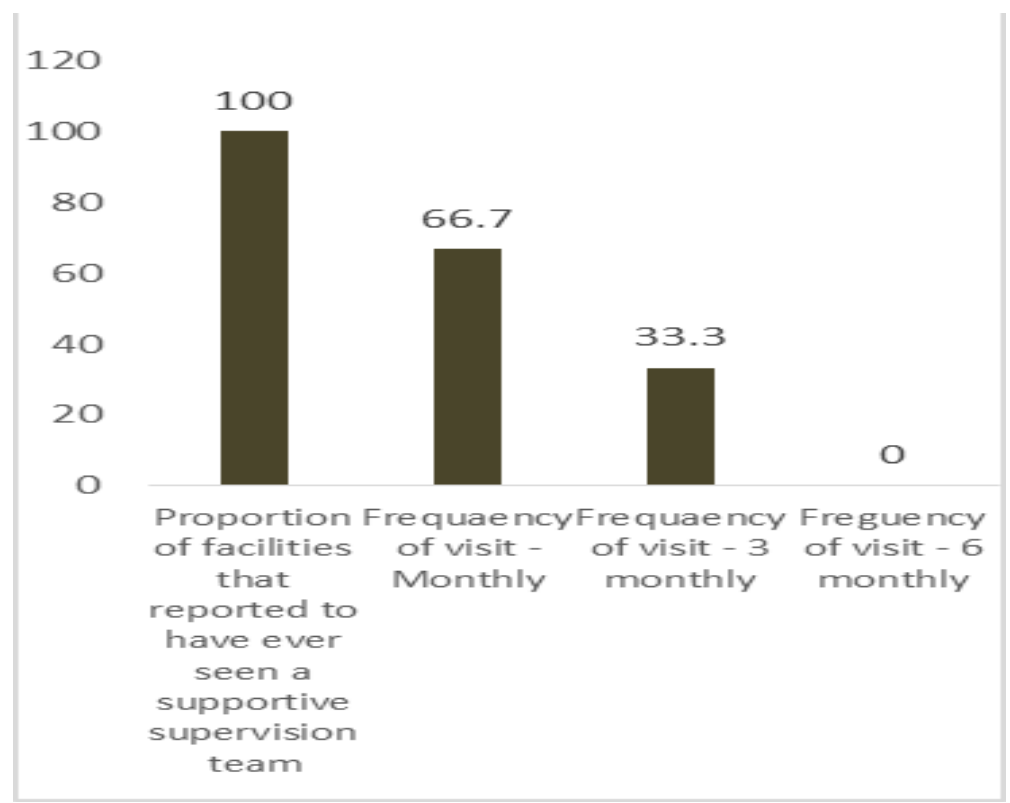

Figure 1.3a. Supportive supervision in target facilities in Jigawa state, Project End line Evaluation, 2019 


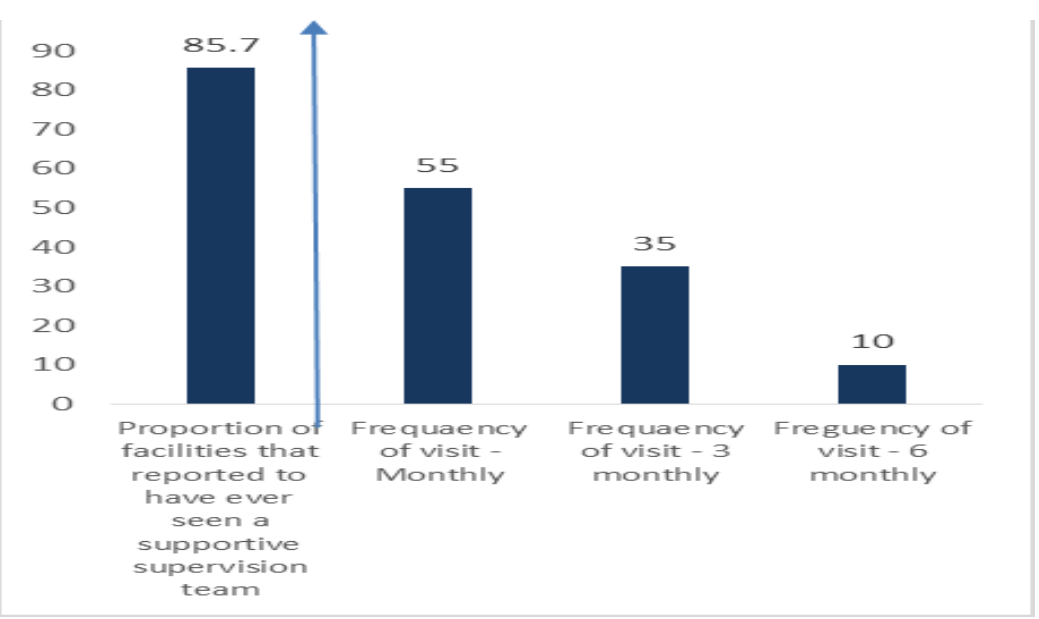

Figure 1.3b. Supportive supervision in target facilities in Lagos state, Project End line Evaluation, 2019

Several studies have shown that training alone is not enough; health care providers always require additional support on an ongoing basis to get full reward of training interventions, and in ensuring that trained providers can put their skills to use. Based on this knowledge, the project implemented a supportive supervision activity based on what is obtainable in the two states. In the assessment, the facilities reported they have seen a team of supportive supervisor as well as the frequency of times they have seen such a supervision team. Figures $1.3 \mathrm{a}$ and $1.3 \mathrm{~b}$ above showed that $100 \%$ of the facilities in Jigawa and $85.7 \%$ (about 9 out of 10) in Lagos reported that they have seen a supportive supervision team visit their facilities before. Facilities in Jigawa appear to have been more visited when compared to that of Lagos.

A further review of the project documents showed that the Quality of Care project has provided technical support to health workers in the target health facilities by engaging them in discussions on skills acquired during trainings to ensure that skills acquired are put to appropriate use. To ensure that this happens systematically, the Jigawa State Ministry of Health implemented an Integrated Supportive Supervision (ISS) framework conducted by the State Ministry of Health (MOH). The purpose of the framework was to ensure coordination in the conduct of integrated supervisory activities among partners within the state. The Quality of Care project made use of rare opportunities during these monitoring visits to address some of the challenges faced by the health workers at work. This had ultimately helped to improve the quality of maternal and newborn health services provided in the supported health facilities. In
Jigawa, there were more supportive supervision visits in 2015 compared to Lagos. For example, in Jigawa, the facilities there saw more monthly and quarterly supportive supervision visits compared to those in Lagos that reported to have a supportive supervision team in up to six months ago as shown in figure $1.3 \mathrm{a}$ and $1.3 \mathrm{~b}$ above). The implementation of this supportive supervision was collaborated during one of the key informant interviews conducted with one of the key partners of the Quality of Care project.

A referral in the health system context is a process by which a health worker at one level of the health system seeks the assistance of a facility at the same or higher level to assist in or take over the management of the client's case. Patient referral services constitute an integral part of any well-functioning health system. The goal of a referral service is to ensure that a patient is attended to at the appropriate level health facility and receive cost-effective and quality management. Also, a referral serves to provide linkages between primary, secondary and tertiary care centres. This Quality of Care project implemented a study that reviewed the current referral system in Lagos state and found that only 10 out of the 22 facilities surveyed had a functional ambulance. Based on this the project engaged the government of Lagos, both the State Ministry of Health and Local Government Authorities to alert them on the lack of ambulances and drivers and requested them to address this critical gap. At the time of this evaluation, the results showed that $100 \%$ of the facilities in Jigawa and $92 \%$ of those in Lagos reported that they have a referral system that helps transfer women to a higher level of care. 
Save the Children International support has contributed to the provision of Maternal and Newborn Health services in the facilities to 308,678 mothers and newborns in focused Local Government Areas in Lagos. Save the Children International worked to improve the availability of lifesaving equipment for newborns and their mothers and had procured and distributed to public healthcare centres and 3 general hospitals -100 infant resuscitators with masks, 1000 suction bulb mucus extractors, 200 penguin mucous extractors, 12 digital baby weighing scales and 8 resuscitation tables.

Save the Children International have contributed to a successful Maternal Newborn and Child Health $(\mathrm{MNCH})$ week campaign in the 3 focused LGAs, having leveraged the supply of 9,500 capsules of Vitamin A 100,000 iu, 717,500 capsules of Vitamin A 200,000iu and 717,500 tablets of Albendazole, from Vitamin A Angels in support of MNCH weeks in focus LGAs. Save the Children International supported the state government during the period of Ebola scourge to distribute over 745, 000 antiseptic soaps to public schools and health facilities. This was through the support of Unilever. This was to ensure the prevention of the spread of the Ebola virus disease (EVD). Save the Children International provided the flagship health centres in focused LGAs with curtains and Newborn resuscitation tables. The curtains were mainly for the delivery rooms and lying wards. Sango PHC, Oregun PHC, Ifako PHC, Kola PHC, Ogba PHC, Alausa PHC, Ojodu PHC are some the PHCs that benefited from this.

\section{Evaluation Results Considering Project Objective Two}

To reduce infant and maternal mortality, a major challenge is making sure that the required human and infrastructure resources are available. The lead researcher was made to understand through literature review that the best interventions for avoiding and resolving those complications in low-resource environments are: access to a skilled attendant at birth, access to emergency obstetrical and neonatal care in the event of complications, and a functional referral system that guarantees emergency care if it becomes necessary. However, in many developing countries, even the most basic of these interventions is available to only a negligible fraction of the population. Constantly improving and broadening available care is one of the best ways to reduce infant and maternal mortality. Building capacity helps health providers take concrete steps towards reducing morbidly and mortalities when they are needed most.

The Save the Children International Quality of Care project was intended to provide health care providers with the necessary knowledge and skills they need to provide timely care to mothers and babies especially during delivery and the immediate postpartum period. Under this objective, the project has trained 1,001 health care providers of varying cadres (exceeding its target of 1,000) and in different skills relevant to mothers and infants, these trainings were informed by the findings of the health facilities assessment that was conducted by the project in its second year of implementation. These trainings focused mainly on gaps in health workers' knowledge and skills identified during the assessment. From the review of project documents and analysis of the qualitative data collected, the Save the Children Quality of Care project has accomplished much in its work towards improving access to quality services for mothers and babies at the time of birth and the immediate postpartum period in Jigawa and Lagos states.

The School of Nursing and Midwifery and School of Health Technology located in Lagos have also benefited from the generous donations from Unilever through this project. They have been provided with training mannequins (4mamanatalie and 20 Neonatal) for improved quality of pre-service training for their students. During project implementation, Save the Children had trained 744 health workers (nurses, doctors and medical record officers) in Lagos on various Maternal Newborn Health (MNH) interventions- Essential newborn care, Helping Babies breathe, Active Management of the Third Stage of Labour (AMTSL), Respective maternal care, National Health Management Information System (NHMIS) training for record officers.

\section{Evaluation Results Considering Project Objective Three}

This objective is crucial for mobilizing the necessary support for improved maternal and child health services in the target states and Nigeria as a whole. The Quality of Care project 
has made significant progress and contributions to the advocacy arena especially in the area of maternal and child health. From our synthesis, the project adopted two approaches in its advocacy work; Implementation and conduct of policy-relevant research to be used as an advocacy tool and engagement and dialogue with policymakers including partnership building with other stakeholders such as Ward Development Committees (WDC). The project's advocacy effort was informed and guided mainly from results from landmark researches conducted by the project. The project conducted key policy-relevant research on maternal and child health and related development issues in the two target states and across intervention LGAs. In the past years of its work in Lagos and Jigawa states, Save the Children Quality of Care project had engaged policymakers and other key stakeholders to achieve measurable policy impacts and ensure decision making across the state as informed by rigorous evidence-based research. The project has shared through several platforms such as presentations and published reports, key findings from his policy-relevant studies with the government of the two states.

Several reviews have shown relevant maternal, newborn and child health policies have been developed and adopted by the Federal Government, implementation at the state level continues to be a challenge. Save the Children Children's Quality of Care project has focused resources towards garnering the needed government support and political commitment for these health policies to be implemented by putting the discussion in the forefront of its advocacy strategies efforts. As part of its data use strategy to advocacy, the project in 2013 launched on a once a year publication of the Save the Children's titled global 'State of the World Mothers' to report current global statistics on the status mothers. The 2013 edition was launched by the Lagos State Government. This report provided information on the health of mothers across the globe and examines the way investments in healthcare, nutrition and education can make a difference for newborns and their mothers.

The launch was well attended and disseminated, the participation and collaboration of the project with the media in this regard ensured that this important information on maternal and child health continues to be available and accessible over a long time and to a wider audience. Another key policy-relevant research conducted by the project was in January 2012, the study assessed the "national and statelevel barriers to scaling up maternal and newborn healthcare interventions. Findings of this study were shared with the State Ministries for Health in Lagos and Jigawa. A key achievement of the project's advocacy work is that the Lagos State Ministry of Health made use of the findings from these studies to fine-tune the development of its strategy document to be implemented in the state. Learnings from some of the results have provided opportunities for the health workers in private clinics, including those providing maternal and newborn health services, to benefit from health worker trainings organized by the Government. Some of the findings have led to State Ministry of Health currently looking at strategies to scale up known evidence-based maternal and newborn health interventions in other Local Government Areas.

Save the Children International has States offices and national level office in the Federal Capital Territory, Abuja, this structure has made it possible to engage the Ministry of Health and other stakeholders at these two levels in a clear and distinctive manner. Through this direct engagement and partnership building approach, the project has been able to engage the State Ministry of Health, Local Government and Millennium Development Goals (MDGs) office in Jigawa State to complete the renovations in selected facilities including the provision of extensions for maternity units to ensure the maximum standard of service provision is achieved. Also, in Lagos, the engagement of government ministry of health has led to the recruitment of two retired midwives who were working in one of the supported health facilities in Agege LGA. In addition to this renovation work had been concluded in three of project supported flagship health centres. As the project kept the care for mothers and their babies at the front burner through its engagement with the ministry of health, the state has continued to pay adequate attention to the agenda. In late 2013, the project marked World Prematurity Day by participating in a three-day advocacy initiative organized by the Federal Ministry of Health called "Every Breathe Counts" as a means to bring attention to the challenges of premature babies and a call for action to stakeholders. The 
project also participated and contributed to the Lagos State health policy review workshop in June 2013 in collaboration with other partners, led by the advocacy team of the Quality of Care project during which health-related policy documents including the Lagos state health development plan and the health sector reform law were reviewed and recommendations made to improve the policies and implementation plans.

\section{Conclusion}

This project has no doubt improved the quality of service to mothers and babies at the immediate postpartum period in Lagos and Jigawa where it was implemented. The project carried out advocacy at all levels and achieved an enabling environment for this project in particular to succeed and general promotion of issues of maternal and child health in the target states. Other critical issues of sustainability for such programs include continued expressed commitment on the part of the government and maintaining and improving on the quality of care offered at the health facilities at all time. Save the Children International had made some progress towards the sustainability of the program and government partners and other NGOs are also beginning to show commitment to promote sustainability that will eventually lead to overall improvements of their health systems.

Given the significant contributions that the Quality of Care project has made to the health system in Jigawa and Lagos states in improving access to quality life-saving services to mothers and babies, the following recommendations will suffice for a more effective and client-centred intervention in future.

- Although community involvement is not part of the project design from the start, the lead researcher thinks that future interventions of this type needs to have strong community involvement to ensure increased service utilization by mobilizing the communities to target facilities where care is domiciled, this in future will increase return on investment. In addition to this, the plan that will scale up this intervention needs to carry out a mapping of the locations where it intends to carry out the intervention, this will allow for proper use of community resources and will help in documenting the other relevant indicators at the population level.

- In future, similar projects will need to explore different ways through which it can involve and engage the communities. This will need to incorporate Strategic Behaviour Change Communication (SBCC) in its engagement and communication plan. This will ensure that community cantered and effective communication agenda is developed and implemented.

- As a result of increased utilization of the services at the government facilities offering such services and as a step towards sustainability, government and other partners should make deliberate efforts to increase recurrent budgetary support for equipment and supplies. The government will need to support the training of more health care providers in other Local Government Areas across the States since Save the Children International resources cannot meet the ever-increasing and diversifying needs in this regard.

- Future projects may support more opportunities for Heads of Hospitals where such projects are implemented to meet more regularly at a central level. This will enable them to exchange experiences relating to such services and other management issues. The Heads of the hospital will begin to show more commitment to overseeing the implementation of these services. This type of interaction has the long-term potential of promoting integration since such management meetings will not restrict its discussion to just this component of the entire care offered.

- Advocacy initiatives such as the one set up by the project with Ward Development Committee's and others should be sustained and scaled up with more emphasis at the community level and with the appropriate actors in these communities. These include religious and traditional leaders and other key and influential people from these communities. Although the project did not show any problem in its monitoring and evaluation system, future projects of this type that will be expanded to include the community at a greater scale and a stronger behaviour change communication change 
content may require that project have a state-level monitoring and evaluation team.

- To scale up the postnatal home visit piloted in Lagos, the project needs to explore the use of other messages/service "carriers" such as community resource persons instead of Community Health Extension Workers (CHEWs). Although CHEWs are supposed to offer community-level services, the shortage of human resource for health at the facility level continues to make it impossible for CHEWs to leave the health facility as they are usually the main service provider in most places.

\section{References}

[1] Adedokun, S. T., \& Uthman, O. A. (2019). Women who have not utilized health Service for Delivery in Nigeria: who are they and where do they live? BMC pregnancy and childbirth, 19(1), 93.
[2] Aluko, M. E. (2004). Our Superlative Country called Nigeria. Retrieved from https://dawodu.com/aluko84.htm

[3] Findley, S. E., Cometto, G., \& Afenyadu, G. Y. (2013). Awareness of critical danger signs of pregnancy and delivery, preparations for delivery, and utilization of skilled birth attendants in Nigeria. Journal of health care for the poor and underserved, 24(1), 152-170.

[4] Olusegun, O. L., Ibe, R. T., \& Micheal, I. M. (2012). Curbing maternal and child mortality: The Nigerian experience. International Journal of Nursing and Midwifery, 4(3), 33-39.

[5] World Health Organization. (2014). Every newborn: an action plan to end preventable deaths. 


\title{
Employees Perspective on Internal Branding Mechanisms. Case Study of a Multinational Organization in Ghana
}

\author{
Mary Akweley Cobblah \\ PhD in Management, Texila American University \\ E-mail: mary.cobblah@gmail.com
}

\begin{abstract}
This study examines how employees are supported to acquire requisite knowledge and skills and build brand supportive behaviors for corporate success. The study was conducted in a manufacturing setup of a multinational organization in Ghana. Being an exploratory study, a qualitative approach was adopted, and primary data was collected from twenty respondents via face-to-face semi-structured interviews. Purposive sampling was employed as it enabled diversity to be explored and targeted personnel to be contacted and interviewed. Manual coding was used in analyzing data collected. The study findings identified various mechanisms that an organization can employ to help employees build brand supportive behaviors, and to get employees empowered to deliver on the brand promise. The findings revealed that internal branding initiatives such as employees perceived knowledge and capability building activities, internal communication, leadership support, and the work environment, acted as critical mechanisms that contributed to employees' empowerment and display of brand supportive behaviors. The study further notes that effective management and implementation of internal branding activities contributes greatly to employees' empowerment, employees' internalization of corporate values, and consequently employees' delivery on the brand promise. The study results confirm the significance of internal branding initiatives to employees' development and organizational growth and recommends that internal branding initiatives be promoted for sustained success. The research approach adopted however limits generalizability of the findings to other organizations. This study contributes to the scanty empirical literature on internal branding in Africa, and more importantly to the limited literature on internal branding in Ghana.
\end{abstract}

Keywords: Internal Branding (IB), Human Resource (HR), Employees Empowerment, Corporate Success, Brand Supportive Behaviors.

\section{Introduction}

In a keenly contested market place, businesses continue with their strife to gain competitive advantage through stakeholder involvement, cocreation activities, and provision of unique products and services deemed vital for business sustenance and also relevant for satisfying customer requirements (King, 1991; Vargo and Lusch, 2004; Merz et al., 2009). Researchers and practitioners the world over have suggested that branding initiatives be employed for the creation of distinctiveness and sustained organizational success. Scholars such as Aaker, 1991: Rooney, 1995; Madden et al. 2006; and Kapferer, 2012; for instance, argue that brands form part of organization's most valuable assets and a part of the major strategic management tools necessary for creating and maintaining sustained competitive advantage. Similarly, King and Grace (2008), assert that employees form part of an organization's brand and that investing in them is the strategic weapon for exceptional service delivery. Miles and Mangold (2005) also acknowledge the important role employees play for corporate success and posit that employees form part of an organization's valuable assets as they possess valuable knowledge and skills which when tapped into and managed effectively enhances an organization's image and promotes corporate success. Furthermore, Foster et al, (2010) and Patla and Pandit (2012), state that enhancing employee productivity and service delivery is critical for corporate success.

The above opinions endorse the importance of internal branding (IB) as a strategic initiative for enhanced service quality, distinctive performance, enhanced customer experience, 
corporate image, and reputation. Hence, the ability of the organization to differentiate its offering from that of competitors and to create distinctiveness in the marketplace for sustained success and competitive edge over rivals (De Chernatony and Dal'Olmo Riley, 1998; Thomson et al., 1999; Murphy, 1988; Jacobs, 2003).

A review of the academic literature on internal branding mechanisms however reveal that much more investigative studies have been conducted in the developed economies (UK, USA, Europe, and Asia) and secondly, such studies have mainly been in the service sector, with more than two or three studies exploring a particular industry within the service sector (example Hospitality, Banking, Insurance, Airlines, Tourism). In Europe for instance, studies such as Maxwell and Knox (2009) considered a non-profit sports organization, a specialist school, a film distribution, a television production, and a data analysis company; Wallstrom et al. (2008) investigated service firms; De Chernatony and Cottam (2006) examined financial services; and Burmann and Zeplin (2005) considered financial services, telecommunications, electronics, transport, and tourism sectors. Similarly in Asia, studies such as Punjaisri and Wilson (2011); King et al (2013); and Lee et al (2014) examined the hotel industry, whiles Patla and Pandit (2012), and Javannard and Nia (2011) considered the Banking industry, Ashraf et al. (2010) the telecommunication industry, Chong (2007) the Airline Industry, and Asha and Jyothi (2013) the telecommunications, Banking, IT, and Aviation sectors.

Thus, even though researcher interest has resulted in a plethora of investigative studies, very little empirical work has been done in Africa, and secondly that most studies have been conducted within the service sector leaving other sectors unexplored. Additionally, whereas some research works identify formal initiatives as crucial to success, others endorse both formal and informal initiatives. The scanty studies in Africa, and inconsistency noted in study results, calls for further studies to increase knowledgebase, and to clarify and validate existing research findings. Scholars such as King and Grace (2010), and Ashraf et al. (2011) have also requested that future empirical studies consider other sectors such as manufacturing settings to compare such findings with that of the service industry. Hence the contribution of this paper is threefold. Firstly, the study which is conducted within an African context contributes to the limited empirical literature on Internal branding in Africa. Secondly, the study focuses on IB mechanisms conducted from an 'employee perspective' in a manufacturing sector where very little consideration has been given, and also in a developing country (Ghana) to add to the limited studies besides the service sector in Africa. Thirdly, study findings will provide more comprehensive understanding of IB initiatives necessary for corporate success to enrich the knowledge base and corroborate earlier empirical findings.

This section which is the introductory part of the paper provides the study background. Next is a review of literature which entails prominent theories that underpin internal branding efforts, an overview of previous studies on internal branding mechanisms, and gaps identified which form the basis for the study. This is followed with the methodology, study findings, discussion section, study limitations and managerial implications, after which a conclusion is offered.

\section{Branding}

Branding efforts have generally been noted as crucial to organizations differentiating themselves from others, to attract, effectively engage and retain employees, and gain competitive advantage (Aaker 1991, Kapferer 2012). Aaker (1991), assert that building brand equity is necessary for sustained competitive advantage. Similarly, Kotler and Keller (2009) emphasize the importance of establishing a strong brand for sustained competitive advantage. Contributing to this discussion, Kapferer (2012), emphasizes that brands are now being recognized as strategic assets and part of a company's capital and as such must be exploited to realize their full potential. Kapferer (2012) further indicates that brands have the power to influence and therefore the more a brand commands trust, respect, community engagement, interconnectedness, and is shared by a lot of people, the more powerful it becomes. Other scholarly works such as Lee et al (2015) also point out that brands are strategic assets and thus branding activities are necessary for creating an identity, distinctiveness in the marketplace, and value for an organization. The opinions expressed by the various scholars suggest that business survival, growth, and ability to build and sustain brand equity is underpinned 
by branding efforts aimed at building the brands power.

Branding has evolved as a major component of marketing strategy with varied definitions offered by scholars as to what branding is. For instance, Rooney (1995:48) defines branding as "a technique to build a sustainable, differential advantage by playing on the nature of human beings". Similarly, Brown, (1992 cited in De Chernatony and Dal'Olmo Riley1998: 419) states that "a brand name is nothing more or less than the sum of all the mental connections people have around it". Taken together, these definitions portray branding as perceptions created by firms to gain sustained competitive advantage to promote a certain image, prestige, or lifestyle, and as a strategic tool, used to attract and retain people. The varied definitions also confirm assertions made by scholars such as Backhaus (2016), Cascio (2014), and Kapferer (2012), that branding initiatives are increasingly being considered by business organizations as an effective and powerful tool essential for corporate success. Additionally, branding initiatives are being adopted as strategic initiatives and so are targeted at both internal and external customers and aimed at differentiating a firm's brand from its rivals through the creation of desired images in people's minds. Thus, with the understanding that branding efforts are clearly strategic initiatives, the application of branding initiatives have been noted to extend beyond the marketing function to other departments such as Human Resources for corporate success (Mitchell, 2003, Aurand et al, 2005).

\section{Internal branding}

Employees identification with an organization has been noted as critical for corporate success. More importantly, employees have been noted as strategic assets that can be exploited for the delivery of an organization's brand promise (King and Grace, 2008). In line with this thinking, Internal branding mechanisms have been proposed as an approach worth adopting to promote an organization's brand internally, and ultimately deliver desired goals. Ind (2003), an advocate of organizations differentiating their brands to deliver success, remarked that brands are about people, as such, brand success can be attained by empowering employees to live the brand values and by so doing get them to align their attitudes and behaviors' with the overall corporate goal. Scholars such as Michell (2002), Maxwell and Knox (2009), also assert that equipping employees with knowledge and capabilities gives employees a sense of direction and purpose, gets them engaged, motivated, emotionally connected, and additionally inspires them to deliver desired goals through the exhibition of brand supportive behaviors. Similarly, Balmer and Gray (2003) and Miles and Mangold (2004) suggests that employees must be motivated and empowered to build brand supportive behaviors which should be consistently aligned with the corporate brand promise. Additionally, scholars such as Harris and De Chernatony (2001); Balmer and Gray (2003); and Hulberg (2006), have emphasized that internally oriented initiatives are vital for corporate success which suggests that effective management of the relationship and experiences an organization has with its employees helps shape their perceptions, attitudes and behaviors which have been identified as vital for corporate success. Hence the need for organizations in the twenty first century to focus on internally oriented initiatives and more importantly on employees to support the organization's brand to create distinctiveness for sustained competitiveness.

Whereas Bergstrom et al. (2002:135) indicates that IB refers to three things namely "communicating the brand effectively to the employees; convincing them of its relevance and worth; and successfully linking every job to delivery of brand essence", Punjaisri and Wilson (2011:1523) describe IB as "the activities undertaken by an organization to ensure that the brand promise reflecting the espoused brand values that set customers' expectations is enacted and delivered by employees", whiles Miles and Mangold (2004: 68) define IB as "the process by which employees internalize the desired brand image and are motivated to project the image to customers and other organizational constituents". MacLaverty et al. (2007:3) also define IB as "the set of strategic processes that align and empower employees to deliver the appropriate customer experience in a consistent fashion. These processes include, but are not limited to, internal communications, training support, leadership practices, reward and recognition programs, recruitment practices and sustainability factors". A common feature inherent in their viewpoints is the important role of employees, and a 
consideration of strategic measures to facilitate employee value internalization for the achievement of desired goals. It also suggests that internal branding activities are critical for corporate success and thus challenge organizations to pay attention to valuable assets such as its human capital for the creation of distinctive products and services for organizational success.

\section{Theories Underpinning Internal Branding Initiatives}

Several theories have been proposed to support Internal Branding Activities and to offer better understanding of the adoption of IB practices. Prominent amongst them is Social Identity Theory which highlights the effect of the individual's identification with the social group and the Resource-based view which emphasizes a firm's exploitation of its strategic assets to its best advantage. Social Identity Theory proposes that an individual's sense of self-worth depends on groups that he/she associates with or belongs to (Ashforth and Mael, 1989). The notion of selfworth being linked to membership of certain groups confirms the importance of the social environment and the individual's willingness to associate with and support group work. Punjaisri et al, (2009), indicate that internal branding activities enhances employees' sense of belonging as it fosters employee identification with an organization's brand, and motivates employees to exhibit brand-supportive behaviors that enhance group goals.

Similarly, the resource-based view advocates that firms are endowed with a unique bundle of resources, capabilities, and competencies which when strategically managed creates sustainable competitive advantage for the organization. Barney, (1991) argues that competitive advantage could be gained from organizational resources that are valuable, rare, imperfectly imitable, and non-substitutable. Valuable resources Barney (1991) notes exploit opportunities and overcomes threats in a firm's environment, and nonsubstitutable and imitable resources he indicates are knowledge-based. Thus, the strategic use of a firm's human resources Barney (1991) notes, creates distinctiveness which is essential for corporate success. This suggests that effectively managing and consciously exploiting the skills and capabilities of an organization's workforce to its competitive advantage cannot be underestimated. Penrose (1959, cited in Kor and Mahoney 2004), also argues that development of the capacities of the workforce create distinctiveness in work practices, products and services offered thus making an establishment more attractive to applicants and existing employees. Altogether, these theories suggest that a firm can develop and manage its strategic human assets to its advantage thus making more relevant internal branding strategies as necessary initiative to be adopted by organizations to create distinctiveness and corporate success.

\section{Internal Branding Mechanisms: Overview of Previous Research}

Empirical studies conducted from the employee perspective have identified numerous mechanisms for equipping employees to build brand-supportive behaviors, and to gain employees commitment and loyalty (Bowden, 2000; Begley and Boyd, 2000; Vallaster and de Chernatony 2005; LePla, 2013). Miles and Mangold's (2004) study for instance identified communication, employee recruitment programs, employee training and development programs, recognition and rewards schemes, work culture, leadership and co-worker support as mechanisms building brand supportive behaviors. Similarly, Asha and Jyothi's (2013) study in India which is similar to that of King and So's (2015) study in China, identified IB mechanisms such as; recognition and rewards; trainings and developmental initiatives; leaderships concern for employee growth; employee empowerment via employee participation in decision making; informal socialization with management and coworkers; and finally multidimensional communication by management, as contributing to employee development of brand-supportive behaviors. Their findings suggest a blend of both formal and informal socialization process as necessary initiatives for employee knowledge and skills acquisition, and for building brandsupportive behaviors.

Conversely, Punjaisri and Wilson's (2011) study in Thailand share some similarities with empirical studies such as Ching, (2007), Ashraf et al. (2013), Lee et al. (2014), and Yang et al. (2015). These studies, unlike the earlier studies discussed, highlight formal sources only as key mechanisms for building brand-supportive behaviors. Punjaisri et al's (2011) study identified internal communication, training 
programs, the work environment, and personal variables as key mechanisms for IB initiatives. Lee et al's (2014) study in South Korea identified HR activities such as internal communication, training programs and reward schemes as initiatives vital for building employee brand supportive behaviors. Similarly, Yang et al's (2015), study in Taiwan identified formal initiatives such as brand training/ orientation programs, meetings, briefing sessions, and daily reporting amongst others as necessary initiatives for building employee commitment and brand supportive behaviors.

Taken together, one can conclude that although study findings suggest the need for brand-centered HR activities as necessary initiatives for building employee brandsupportive behaviors, study findings differ as to which programs are crucial for corporate success. Whiles some studies suggest that brand-centered formal initiatives increase employee skills and knowledge base, other studies portray both formal programs and informal socialization processes such as leadership influence, co-worker support and conducive work environment, as crucial initiatives for employee building of brandsupportive behaviors. Besides the inconsistencies recorded in study findings, majority of these studies have been conducted in Europe, Asia, and USA, with very little studies conducted in Africa. Furthermore, focus of most IB studies have been on service organizations leaving other sectors unexplored. The afore-mentioned reasons provide justification for further investigation hence the need to conduct this study.

\section{Research Aim and Design}

This study conducted in Africa, specifically Ghana, and within a manufacturing set up, examines internal branding mechanisms from employees' perspective. A case study approach was adopted, and a multinational organization considered for the study. Based on recommendations made by Saunders et al (2007), and Bryman and Bell (2011), a qualitative approach was adopted to explore perceptions of the workforce on mechanisms employed to empower them to acquire brand supportive behaviors and deliver on the brand promise. The study employed purposive sampling and face-toface semi-structured interviewing technique to collect data from 20 respondents in the selected multinational organization. The choice of sampling approach was influenced by the study's aim of consciously engaging employees at all levels. Additionally, selecting respondents via purposive sampling was appropriate for the study as it enabled diversity to be explored and targeted personnel to be contacted and interviewed. Furthermore, due to the exploratory nature of the study, face-to-face semi-structured interviews was considered appropriate as it allowed for flexibility and a better understanding of opinions expressed, and to unearth new findings. The interviewing technique adopted also promoted dialoguing with informants to further probe and prompt when necessary to clarify issues. Also, the technique helped to delve deeper and to uncover unknown phenomenon (Walker and Myrick, 2006).

In analyzing data collected from respondents, the grounded theory approach was adopted. Bell and Bryman (2011), notes that the technique is by far the most prominent approach for analyzing qualitative data. The grounded theory approach involved coding, identification of themes, and textural explanation of feedback obtained from respondents. Research question posed was as follows; - In what ways do employees perceive the organization as empowering them to internalize its corporate values?

\section{Findings}

With the objective of understanding internal branding initiatives that promote corporate success, data assessment revealed four common themes as necessary mechanisms employed by the organization to empower employees internalize corporate values and to deliver on the brand promise. Themes identified which will be discussed next were knowledge and capability building activities, internal communication, leadership support, and the work environment.

\section{Knowledge and Capability Building Activities}

Respondents unanimously revealed that the organization provided different forms of training to enhance their knowledge base and equip them to perform their jobs. Respondents identified induction, refresher and on-the-job training, as IB initiatives consciously organized by human resource (HR) for employees, and all geared towards employees' understanding and inculcation of the corporate values. For instance, respondents mentioned that new recruits go 
through induction training to learn what the company stands for and to align their values to that of the company. Subsequently specific training programs which are mandatory, on-line courses, and on-the-job training are organized to reinforce employee understanding and compliance with the corporate values. Some respondents also mentioned that the on-line courses were interesting as they tend to use real life situations (scenarios) to reinforce knowledge gained, after which employees are assessed so as to make information acquired more relevant and meaningful to employees' day to day work activities. Mentoring and coaching programs done by leadership and peers also helped employees align their attitudes and behaviors to that of the organization, and to encourage and reinforce expected values. This is evidenced by the following statements:

Respondents' views suggest that training programs are crucial to employees' display of brand supportive behaviors and this finding is consistent with studies such as Burmann and Zeplin (2005); and Punjaisri and Wilson (2011) as they established that training and developmental programs enhance employees' brand knowledge and skills, and helps build brand-supportive behaviors.

\section{Internal Communication (Formal and Informal)}

Majority of the respondents perceived internal communication championed by $\mathrm{HR}$ as contributing to employee brand knowledge and awareness, and their ability to perform assigned duties. For instance, respondents mentioned that management consistently reminded employees of the values and updated them on on-going activities through sources such as meetings, briefings, internal memos, manuals, and e-mails. Respondents also acknowledged that informal sources such as conversations and interactions with superiors and peers have also enhanced their brand knowledge and ability to align individual values to that of the organization which is evidenced by the following statements:

The opinions expressed suggest that internal communications both formal and informal sources reinforce brand messages, guide employees' actions, and assists in building brand supportive behaviors. This finding is consistent with studies such as Chong (2007); and King and Grace (2008) as they identified internal communication to build employee brand awareness and brand supportive behaviors.

\section{Leadership Support}

Respondents acknowledged that Leadership plays a key role in employees' inculcation of the corporate values. For instance, respondents acknowledged that at forums such as employee meetings and briefing sessions, leadership interacts with them, reminds, encourages, and inspires them to live up to expected values. This is evidenced by the following statements:

The opinions expressed suggest that leadership support tends to strengthen work relationships as it directs, motivates, and inspires employees to remain committed and loyal to their jobs and achieve desired goals. This finding is consistent with studies such as Kaufmann et al., (2012); and Wallace et al., (2013) as they found that leadership's support motivates and inspires employees to act as ambassadors.

\section{Work environment}

Respondents perceived the work environment as influencing their inculcation of the corporate values. For instance, respondents acknowledged that work practices, work culture, employee interactions, and co-worker behaviors and attitudes influence what they do. Also, with the help of colleagues, new recruits adjust and are also able to fit into the system and perform assigned tasks. This is evidenced by the following statements:

Respondents' feedback suggests that besides the management systems and processes, policies and procedures, the informal socialization process reinforces brand messages received and influences employee brand - building behaviors and attitudes. This finding is consistent with studies such as Asha and Jyothi (2013); and King and Grace (2008) as they identified the work environment assisting employees perform assigned tasks.

\section{Discussion}

Whereas most of the existing studies on internal branding from the employee perspective have focused on the service sector and in the developed economies, this study has considered internal branding mechanisms from the employee perspective in a manufacturing setting in a developing economy. The research findings revealed that employees working with the 
multinational organization under study in Ghana perceived their empowerment to internalize corporate values as emanating from internal communications, knowledge and capability building activities, leadership support, and the work environment. Employees also perceived their establishment as promoting brand supportive behaviors due to HR's consistent training and communication programs, which was deemed relevant for employee understanding of the corporate values, and leadership's encouragement and reinforcement of the values for employee display of brand-supportive behaviors. Knowledge and capability building programs such as orientation training for new employees had a major influence on the initial socialization process and this was buttressed with subsequent training programs and on-the-job training to help build brand-supportive behaviors as they internalize and reinforce corporate values. Additionally, internal communication which included face-to face communication with employees during employee meeting and briefing sessions, as well as internal memos and email exchanges were noted as critical as it furnished employees with the requisite information and knowledge on the organization's corporate values to enable them deliver on the brand promise. The findings are consistent with the views of scholars such as Yang et al, (2015), Lee et al (2014), Burman and Zeplin (2005), and Punjaisri et al (2008), who acknowledge that internal communication and training programs are internal branding mechanisms critical for corporate success and they help employees exhibit brand-supportive behaviors.

Leadership's influence was also noted as significant as it impacted employee performance, which suggests that the informal socialization process is pivotal to IB success. The informal socialization process supported employee acceptance of the corporate values, helped establish the desired employer-employee relationship, and to build employee confidence to live and to deliver required goals. The study findings concur with the views of studies such as King and Grace (2012); Wallace et al. (2013); and Xiong et al. (2013) who assert that besides HR practices which equip employees with the requisite knowledge and skills, the work culture, and 'care factor' championed by leadership reinforces and motivates employees to live the brand. More importantly, the results also suggest similarities in IB mechanisms identified in empirical literature on the services sectors discussed which implies that there are similarities in relation to IB mechanisms employed in the manufacturing industry studied in the developing economy and the services industries in the developed countries discussed in this study.

\section{Limitations and Managerial Implication}

Some limitations of study must be acknowledged. The study adopted a qualitative approach and employed purposive sampling (a non-probability sampling technique) to collect data from a sample size of 20 respondents. The study also focused on one organization (a manufacturing set up). The approach adopted, the sampling technique employed, and the unrepresentative nature of the sample size limits generalization of the study findings.

With regards to the managerial implications of the study, the paper seeks to draw management's attention to the impact of internal branding initiatives. That is, its positive influence on employees, and additionally the important role of employees in the delivery of an organization's brand promise. Hence, internal branding efforts must not be overlooked but rather promoted in business organizations that seek to attain corporate success and sustained competitive advantage.

\section{Conclusion and Recommendation for Future Research}

The study findings have demonstrated how internal branding mechanisms support employee empowerment, employee internalization of corporate values, employee exhibition of brandsupportive behaviors and consequently employee delivery on the brand promise. This imply that internal branding initiatives when effectively implemented would positively influence employees, get them more committed to the organization, help them identify and associate with the corporate brand, and consequently exhibit a sense of belonging for corporate success. The paper thus concludes that employees would exhibit brand-supportive behaviors if they are trained, coached, socialized, and empowered to do so. The study results also endorse the results of previous empirical findings which posit that internal branding initiatives when effectively deployed enable employees acquire brand- 
supportive behaviors which is deemed critical for corporate success.

The paper further emphasizes the similarities in internal branding initiatives in the manufacturing set-up investigated in a developing economy and in-service industries in the developed countries which arguably suggests that internal branding initiatives identified can be applied in both manufacturing and services setups. But more importantly, the effective management and implementation of both formal and informal programs are critical for the realization of desired results. Drawing from the fact that much studies have not been undertaken in other sectors besides the service sector, the paper recommends that more investigative studies be conducted in other industries to test for similarities and differences in IB mechanism that promote success.

\section{References}

[1]. Aaker, D. A. 1991, Managing Brand Equity (The Free Press. New York London Toronto Sydney).

[2]. Ashraf, H., Khalid, M., Maqsood, S., Kashif, M., Ahmad, Z., and Akber, I. 2011, Internal Branding in Telecommunication Sector of Pakistan: Employee's Perspective. Asian Journal of Business Management, 3 (3), 161-165.

[3]. Asha, C. S. and Jyothi, P. 2013, Internal Branding: A Determining Element of Organizational Citizenship Behaviour. The Journal Contemporary Management Research, 7(1), $37-57$.

[4]. Ashforth, b. E., and Mael, F. 1989, Social Identity Theory and The Organization. Academy of Management Review, 14(10),20-39.

[5]. Aurand, T. W., Gorchels, L., and Bishop, T. R. 2005, Human Resource Management's Role in Internal Branding: An Opportunity for Cross Functional Brand Message Synergy. The Journal of Product and Brand Management, 14 (2/3), 163-169.

[6]. Backhaus, K. 2016, Employer Branding Revisited. Organization Management Journal, 13(4), 193-201.

[7]. Balmer, J. M. T. and Gray, E. R. 2003, Corporate Brands: What Are They? What of Them? European Journal of Marketing, 37(7-8), 972-997.

[8]. Barney, J. B. 1991, Firm Resources and Sustained Competitive Advantage. Journal of Management, 17,99-120.

[9]. Begley, T. M. and Boyd, D. P 2000, Articulating Corporate Values through Human Resource Policies. Business Horizons, 8-12.
[10]. Bergstrom, A., Blumenthal, D., and Crothers, S., 2002. Why Internal Branding Matters: The Case of Saab. Corporate Reputation Review, 5(2/3), 133-142. [11]. Bowden, P. 2000, Delivering organizational excellence by employee values management. Total Quality Management, 11 (4-6), 636 -640.

[12]. Bryman, A. and Bell, E. 2011, Business Research Methods, (Third Edition, Oxford University Press Inc, New York).

[13]. Burmann C. and Zeplin S. 2005, Building brand commitment: A behavioral approach to internal brand management. Journal of Brand Management, 12 (4), 279-300.

[14]. Chong, M. 2007, The Role of Internal Communication and Training in Infusing Corporate Values and Delivering Brand Promise: Singapore Airlines Experience. Corporate Reputation Review, 110 (3), 201-212.

[15]. De Chernatony, L. and Cottam, S. 2006, Internal brand factors driving successful financial services brands. European Journal of Marketing, 40 (5/6), 611 $-633$.

[16]. De Chernatony L. and Dall'Olmo Riley 1998, Defining A Brand: Beyond the Literature with Experts Interpretation. Journal of Marketing Management.14 (5), 417-443.

[17]. Foster C., Punjaisri, K., and Cheng, R. 2010, Exploring the relationship between corporate, internal and employer branding. Journal of Product and Brand Management, 19 (6), 401 - 409.

[18]. Harris F. and De Chernatony, L. 2001, Corporate Branding and Corporate Brand performance. European Journal of Marketing, 35 (3/4), 441-456.

[19]. Hulberg, J. 2006, Integrating Corporate Branding and Sociological Paradigms: A Literature Study. Journal of Brand Management, 14 (1/2), 60-73. [20]. Ind, N. 2003, Inside Out: How Employees Build Value. Brand Management , 10 (6), 393-402.

[21]. Jacob, R. 2003, Turn Employees into Brand Ambassadors. ABA Bank Marketing, 35(3),22-26.

[22]. Javanmard, H. and Nia, E.N. 2011, Effect of Internal Branding on Brand Supporting Behaviors of Employees Regarding Customer Attraction in Islamic Banking. The IUP Journal of Brand Management, VIII (4),35-46.

[23]. Kapferer, J. N. 2012, The New Strategic Brand Management: Advanced Insights and Strategic Thinking (Fifth Edition).

[24]. Kaufmann, R.H., Vrontis, D., Czinkota, M., and Hadiono, A. 2012, Corporate Branding and Transformational Leadership in Turbulent Times. Journal of Product and Brand Management, 21 (3), 192-204. 
[25]. King, S. 1991, Brand building in the 1990s. Journal of Marketing Management, 7 (1), 3-13.

[26]. King, C. and Grace, D. 2008, Internal Branding: Exploring the employee's Perspective. Brand Management, 15 (5), 358-372.

[27]. King, C. and Grace, D. (2012) "Examining the Antecedents of Positive Employee Brand-Related Attitudes and Behaviors", European Journal of Marketing, 46 (3/4), 469 - 488.

[28]. King, C., So, K.K.F., and Grace, D. 2013, The influence of service brand orientation on hotel employees' attitude and behaviors in China. International Journal of Hospitality Management, $34,172-180$.

[29]. King, C., and So, K.K.F. 2015, Enhancing Hotel Employees' Brand Understanding and Brand-Building Behavior in China. Journal of Hospitality and Tourism Research, 39(4),492-516.

[30]. Kor, Y., and Y. and Mahoney, J. T. 2004, Edith Penrose's (1959) Contributions to the Resource-Based View of Strategic Management. Journal of Management Studies, 41, 183-191.

[31]. Lee, Y.K., Kim, S., and Kim, S.Y. 2014, The Impact of Internal Branding on Employee Engagement and Outcome Variables in the Hotel Industry. Asia Pacific Journal of Tourism Research, 19 (12), 1359-1380.

[32]. Lee, A., Yang, J., Mizerski, R., and Lambert, C., 2015, The Strategy of Global Branding and Brand Equity (London, New York).

[33]. LePla, F.G. 2013, The Impact of Internal Branding on Employee Motivation and Competitive Advantage. Employee Relations Today, 19-24.

[34]. MacLaverty, H., McQuillan, P., and Oddie, H. 2007, Internal Branding Best Practices Study. Canadian Marketing Association: 1-12.

[35]. Madden, T., Fehle, F., and Fournier, S. 2006, Brands Matter: An Empirical Demonstration of the Creation of Shareholder Value through Branding. Journal of the Academy of Marketing Science, 34(2), 224-235.

[36]. Maxwell, R. and Knox, S. 2009, Motivating employees to 'live the brand': a comparative case study of employer brand attractiveness within the firm. Journal of Marketing Management, 25 (9-10), 893907.

[37]. Merz, M.A., He, Y., and Vargo, S. 2009, The Evolving Brand Logic: A Service Dominant Perspective. Journal of the Academy of Marketing Science 37(3), 328 -344.

[38]. Miles, S.J. and Mangold, G. 2004, A Conceptualization of the Employee Branding Process. Journal of Relationship Marketing, 3(2-3), 65-87.
[39]. Miles, S.J. and Mangold, G. 2005, Positioning Southwest Airlines through Employee Branding. Business Horizons, (48):535-545.

[40]. Mitchell, C. 2002, Selling the Brand Inside. Harvard Business Review, 80 (1), 99-105.

[41]. Murphy, J. 1988, Branding. Marketing Intelligence and Planning, 6 (4), 4-8.

[42]. Patla, S. and Pandit, D. 2012, Internal Branding in an Indian Bank: An Initial Exploration. Journal of Management (XIMB),115-124.

[43]. Punjaisri K., Wilson, A., and Evanschitzky, H. 2008, Exploring the Influences of Internal Branding on Employees' Brand Promise Delivery: Implications for Strengthening Customer-Brand Relationships. Journal of Relationship Marketing, 7 (4), 407- 424.

[44]. Punjaisri, K., Evanschitzky, H., and Wilson, A. (2009) "Internal branding to influence employees' brand promise delivery: A case study in Thailand", Journal of Service Management, 20: 209-226.

[45]. Punjaisri, K. and Wilson, A. 2011, Internal branding process: Key Mechanisms, Outcomes and Moderating Factors. European Journal of Marketing, 45 (9/10), 1521 - 1537.

[46]. Rooney, J.A. 1995, Branding: a trend for today and tomorrow. Journal of Product and Brand Management, 4 (4), 48 - 55.

[47]. Saunders, M., Lewis, P., and Thornhill, A. 2007, Research Methods for Business Students, (Fourth Edition, Pitman Publishing Print).

[48]. Thomson, K., De Chernatony, L., Arganbright, L., and Khan, S. 1999, The Buy-In Benchmark: How Staff Understanding and Commitment Impact Brand and Business Performance. Journal of Marketing Management, 15, 819-835.

[49]. Vargo, S.L. and Lusch, R.F. 2004, Evolving to a New Dominant Logic for Marketing. Journal of Marketing, 68(1), 1-17.

[50]. Vallaster, C. and de Chernatony, L. 2005, Internationalization of services brands: The role of brand leadership during the internal brand building process. Journal of Marketing Management, 21 (1/2), 181-203.

[51]. Wallace, E., de Chernatony, L., and Buil, I. 2013, Building bank brands: How leadership behavior influences employee commitment. Journal of Business Research, 66, 165-171.

[52]. Walker, D. and Myrick, F. 2006, Grounded Theory: An Exploration of Process and Procedure. Quantitative Health Research, 547-559.

[53]. Wallstrom, A., Karlsson, T., and Salehi-Sangari, E. 2008, Building a Corporate Brand: The Internal brand building process in Swedish service firms. Brand Management, 16, (1/2), 40-50. 
[54]. Xiong, L., King, C., and Piehler, R. 2013, That's not my job: Exploring the employee perspective in the development of brand ambassadors. International Journal of Hospitality Management, 35, 348-359.
[55]. Yang, JT., Wan, CS., and Wu, CW. 2015, Effects of Internal Branding on Employee Brand Commitment and Behavior in Hospitality. Tourism and Hospitality Research, 15(4), 267-280. 


\title{
The Role of Internal Branding for Corporate Success. Employees Perspective from a Multinational Organization in Ghana
}

\author{
Mary Akweley Cobblah \\ PhD in Management, Texila American University \\ E-mail: mary.cobblah@gmail.com
}

\begin{abstract}
The study examined the role of internal branding to understand how the practice was used as a strategic tool to empower and support employees' building of brand supportive behaviors for corporate success. An inductive approach was adopted, and data was collected from twenty respondents via faceto-face semi-structured interviews. Purposive sampling was employed as this technique enabled the conscious engagement of targeted respondents (both senior and junior staff). The grounded theory approach was used in analyzing data collected. Study findings revealed that internal branding played both an enabler and a differentiator role. As an enabler, internal branding initiatives enhanced employees' brand understanding, facilitated employees' internalization of corporate values, and exhibition of brand-supportive behaviors. Additionally, the practice empowered them to act as brand ambassadors and inspired them to achieve desired goals. With regards to the differentiator role, internal branding efforts promoted the alignment of internal processes and culture with desired goals, which enhanced the identity, image, and reputation of the establishment. This suggests that internal branding practices contributes greatly to building strong brands as the practice helps provide the point of differentiation for the organization. The research approach adopted limits generalizability of the findings. It is suggested that future research consider a wider company or sector coverage and much larger sample size. The paper highlights the important role of internal branding initiatives for employees' acquisition and display of brand supportive behaviors for sustained competitiveness and corporate success. It thus contributes to the limited empirical literature on internal branding in Africa.
\end{abstract}

Keywords: Branding, Internal Branding (IB), Brand Performance, Employee Brand Supportive Behaviors.

\section{Introduction}

The increased competition amongst businesses has resulted in organizations adopting diverse strategies to better position themselves in the market for survival and growth (Urde, 1994). A widely recognized approach by academics and researchers the world over is for firms to adopt branding strategies for enhanced performance (King, 1991; Aaker, 1991/1996; Harris, 2007; Figiel, 2012) The concept of branding has evolved as a major component of marketing strategy and is increasingly being adopted by organizations as a strategic tool and a powerful approach to enable firms differentiate themselves from others, and to gain competitive advantage (Urde, 1994; Aaker, 1996; Khan, 2009). Brands are increasingly being considered as part of an organization's valuable resource and a part of the major strategic management tools necessary for building strong brands for enhanced overall business performance (Aaker 1996; King and Grace 2008; Urde et al 2013). Branding activities when effectively implemented have also been noted to enhance employees' commitment and engagement, and organizational image and reputation (Kapferer, 2012). Ind (2003), and Punjaisri et al. (2009), assert that managing an organization's brand should be considered from both an internal and external viewpoint, but more importantly, an organization should focus on aligning employees' attitudes and behaviors with corporate values for branding and corporate success.

Today, the application of branding principles as a strategic tool is been noted to extend beyond the marketing function to other departments such as Human Resources for corporate success (Punjaisri and Wilson, 2007). The initiative which targets both internal and external 
customers, is aimed at differentiating a firm's brand from its rivals through the creation of desired images in people's minds (Aurand et al, 2005). This is because organizations are increasingly realizing the need to invest in both their internal and external customers for enhanced brand performance and sustained success (Mitchell, 2002). Employees are increasingly being recognized as valuable assets of every establishment and thus require that organizations treat them as internal customers to ensure employee satisfaction and commitment, and increased customer consciousness for improved performance across the business (King and Grace, 2008/2012). Employees' acquisition of brand knowledge via internal management of the brand, results in the enhancement of brand equity (King and Grace, 2010; Yang et al, 2015). Also, employees' values alignment with that of the organization influences their attitudes and behaviors, and results in their empowerment to deliver on the brand promise. The enhancement of employees' knowledgebase and skills also promotes the building of mental associations and images in the minds of employees, and the development of emotional connectivity and relationships (Punjaisri and Wilson, 2007; King and Grace, 2008). These activities tend to inspire and empower employees, and positively influence the power of the brand, hence, rendering internal branding (IB) activities as necessary measures for strategic goals to be realized (Iyer et al, 2018).

Despite the importance attributed to IB efforts, a review of empirical literature show that majority of IB studies have focused on understanding mechanisms and outcomes with very little known about the role IB plays with regards to employees' empowerment and display of brand-supportive behaviors for corporate success (Punjaisri and Wilson, 2009; Santos Vijande et al, 2013). Secondly, most of these studies have been conducted from a non-African context as studies from Europe, Asia and the USA dominate extant literature (Amegbe, 2016). Additionally, the very few studies that reflect the role of IB have approached the subject from slightly different perspectives (Iyer et al, 2018: Punjaisri and Wilson, 2008). Towards this end, this paper examines the role of IB from the employees' perspective in an African setting. Specifically, it examines how IB practices tend to motivate and empower employees to deliver on the brand promise, and ultimately corporate success. This paper's contribution to IB literature is thus in two folds. From a theoretical standpoint, this study contributes to the limited empirical literature on IB in Africa. It demonstrates the important role employees play via internal brand building efforts, and its impact on the brand and overall business performance. Additionally, study findings provide unique insights from a manufacturing set up in an African setting to enrich knowledgebase on the role IB plays for corporate success. From a managerial perspective, this study draws attention to the positive influence of IB on employees' attitudes and behaviors and endorses the practice as crucial to employees' internalization of corporate values and empowerment, and delivery of an organization's brand promise.

This first section forms the introductory part of the paper. Sections 2 presents the literature review, specifically, rationale and role of IB, theories underpinning IB efforts, and empirical literature relevant to the study. Section 3 outlines the research aim and design, and section 4 presents study findings. This is followed with the discussion section, study limitations and managerial implications, and finally a conclusion is offered.

\section{Literature Review}

\section{Internal Branding (IB)}

There is increasing emphasis on IB efforts as a necessary measure for building strong brands and corporate success (Keller, 2009: King and Grace, 2010). Punjaisri and Wilson (2011: 1523) define Internal Branding as "activities undertaken by an organization to ensure that the brand promise reflecting the espoused brand values that sets customer's expectations is enacted and delivered by employees". Similarly, Miles and Mangold (2004:68) define internal branding as "the process by which employees internalize the desired brand image and are motivated to project the image to customers and other organizational constituents". These definitions portray IB as a strategic approach to consciously increase employees brand understanding and get them to align their attitudes and behaviors to that of the brand. Some researchers (Punjaisri and Wilson, 2008/2011; LePla, 2013; Iyer et al, 2018) have suggested the need to invest in activities that help align employees behaviors and attitudes with corporate values, so that they could act as brand 
ambassadors for the achievement of desired organizational goals. Within the academic literature, scholars such as Burmann and Zeplin (2005), King and Grace (2008/2010), and Xiong and King (2013/2015/2019), have identified IB as a strategic initiative targeted at employees to promote the brand from inside the organization. They indicate that IB efforts facilitate the creation of a right mindset and right processes for corporate success as the practice is based on the notion that investing in the right personnel and creating desired images in the minds of employees is necessary for building brand supportive behaviors, and enhanced business performance (Punjaisri et al, 2009). Similarly, scholars such as Golant (2012), Srivastava and Thomas (2010), Maxwell and Knox (2009), and Mitchell (2002) all advocates of IB practice, acknowledge employees as key stakeholders due to the important role they play in brand building for distinctive performance and sustained competitiveness. Miles and Mangold (2005), and Dickson (2015), emphasize the need to equip employees with the requisite skills and knowledgebase to create the desired uniqueness for increased competitiveness and organizational excellence. They recognize IB initiatives to positively influence employees' brandsupportive behaviors which ultimately enhance an organization's image and reputation. Furthermore, Punjaisri et al (2008), point out that employees' internalization of corporate values shapes their perceptions and reflects in their attitudes and behaviors, which translates into how employees project the organization, and consequently how they meet or address customer concerns. Employees' values alignment with that of the organization gets them better equipped to deliver on the brand promise and ensures that their mind set and actions are all geared towards fulfilling the organization's promise (De Chernatony, 2002; Keleman and Papasolomou, 2007). Employees also tend to act as brand ambassadors via the display of brand supportive behaviors which makes them feel confident to deliver the appropriate customer experience for corporate success (Bergstrom et al, 2002; De Chernatony and Cottam, 2006; Mohart et al, 2009). Strategically, managing employees to effectively deliver corporate goals also results in superior brand performance (Khan, 2009). Scholars such as Aurand et al (2005), Patla and Pandit (2012), and Foster et al (2010), have also argued that IB practices positively impacts employee productivity and satisfaction, which are very necessary for delivering exceptional customer experience, and an enhanced corporate image and reputation. Equipping employees with knowledge and capabilities ultimately gives them a sense of direction and purpose, and gets them emotionally connected, engaged, and involved. Additionally, internal brand building activities results in employees' display of brand-supportive behaviors and inspires them to deliver desired goals (King and Grace, 2008; Maxwell and Knox, 2009). One can thus conclude that the viewpoints expressed suggest that IB initiatives increase employee skills and knowledgebase and promotes employees' building of brandsupportive behaviors for corporate success.

Bowen (2015) presents a theoretical perspective on the role of IB and indicates that the practice enables employees play different roles for corporate success. He points out that IB initiatives enable employees act as innovators when they are guided and empowered to display creative and innovative skills. The is based on the notion of exploitation of employees' creativity and innovative skills to enhance the organization's uniqueness, its competitive edge, and overall business performance. Bowen (2015) also indicates that IB efforts facilitate employees' brand-supportive behaviors, in that, the practice serves as powerful means of continuously educating, emotionally connecting, and guiding employees' actions to deliver desired organizational goals. Furthermore, Bowen (2015) notes that IB efforts make employees' play coordinator role due to their interdependencies, and differentiator role when they internalize the organizations corporate values. The acquisition of brand knowledge and the inculcation of corporate values he notes, promote employees' display of brand-supportive behaviors, and portray them as brand ambassadors. Bowen's (2015) assertion aligns with scholarly views such as Burman and Zeplin (2005), who remark that employees contribute to the credibility and image of an organization's brand when their interdependencies and display of consistent brand behaviors cut across all customer touch points. Additionally, scholars such as De Chernatony (1999), De Chernatony and Cottam (2006), and Madden et al (2006), have highlighted brand building, relationship building, and strengthening of the corporate identity and reputation as 
benefits organizations enjoy when employees are considered in promoting corporate values. Also, Kaufman et al. (2012), and Hatch and Schultz (2009), posit that when employee brand-building behaviors consistently align with desired values, it promotes growth, sustainability, and increases the organizations visibility, recognition, and reputation.

Taken together, the viewpoints expressed suggests that IB initiatives when effectively implemented enhances employees brand orientation and overall brand performance. As such, IB must be promoted for successful operations as it enables employees understand better management's expectations and actively work at delivering the brand promise (Santos Vijande et al, 2013). Improving employees' knowledgebase increases their understanding, boost their confidence, and motivates them to work towards desired goals. Empowerment of employees for the delivery of successful operations is crucial to brand success and thus cannot be underestimated (Maxwell and Knox, 2009). Effective management and implementation of IB activities result in the cocreation of value, increases employees' identification with the brand, and commitment and loyalty which is vital for corporate success (Punjaisri and Wilson, 2008/2011). Additionally, the practice better equips employees with relevant knowledge, values, and skills, and gets them empowered and motivated to deliver desired goals. Also, IB enables employees project a positive image of the organization to external customers via the exhibition of brand-supportive behaviors (King and Grace 2008/2010). Furthermore, IB initiatives facilitate employees' ability to deliver the brand promise to customers as the practice is aimed at building employees' brand understanding for successful delivery of desired organizational goals (Burmann and Zeplin, 2005). Hence, IB activities must be endorsed by businesses that expect to have competitive edge over their counterpart.

\section{Theoretical Underpinnings}

\section{Resource-Based View}

The resource-based view emphasizes the exploitation of a firm's strategic resources to its competitive advantage. This is based on the notion that firms are endowed with a unique bundle of resources, capabilities and competencies which when strategically managed create sustainable competitive advantage for the organization. According to Barney (1991), competitive advantage could be gained from valuable organizational resources that are intangible, non-substitutable and inimitable. Such valuable resources are mainly knowledgebased and can exploit opportunities and overcome threats in a firm's environment (Barney, 1991). This understanding suggests that the strategic management of human resource could create distinctiveness for a firm, an element which is very essential for corporate success. Hence, a firm must consciously manage and exploit workforce skills and capabilities to its competitive advantage. Scholars such as Penrose (1959, cited in Kor and Mahoney 2004), Grant (1991), and Wernerfelt (1984), have advanced arguments which corroborates Barney's (1991) viewpoint. They all emphasize the importance of deliberately developing and managing a firm's strategic human resource to its advantage. Thus, making more relevant IB strategies as necessary initiatives for establishments that seek to create distinctiveness in work practices and in the marketplace to sustain corporate success.

\section{Human Capital Theory}

This theory which shares similar thinking as the resource-based view emphasize resource heterogeneity as a vital foundation for performance differences across firms. Scholars such as Brymer et al (2014), Presbitero et al (2016), and Allen et al (2017), believe that firms can create distinctiveness through the mechanisms underlying human capital acquisition and accumulation. These processes which differ across firms result in the heterogeneous management of human capital and facilitate the development of tacit knowledge to a firm's advantage. Human Capital theory thus aligns with the resource-based view in that both theories are of the view that intellectual capital and knowledge management remain valuable assets of a firm. Therefore, they advocate for the exploitation of employees' skills and competencies to a firm's advantage. Additionally, they recognize also that individual competencies and capabilities enable an organization to differentiate itself from rivals. Hence, measures such as IB campaigns that exploit human capital to enhance firm differentiation must be encouraged and pursued. 


\section{Social Identity Theory}

Social Identity Theory also proposes that an individual's sense of self-worth depends on groups that he/she associates with or belongs to (Ashforth and Mael, 1989). This theory highlights the effect of the individual's identification with the social group as an important element for the attainment of selfsatisfaction. In other words, IB efforts promotes the individuals desire to associate with and to identify with groups they perceive as important in their quest for self-expression and belongingness. Punjaisri et al (2009), indicate that IB activities enhances employees' sense of belonging as it fosters employee identification with an organization's brand, and motivates employees to exhibit brand-supportive behaviors that enhance group goals. Altogether, the theories discussed promote IB efforts for enhanced brand performance and business success.

\section{Empirical Literature}

Despite the popularity of the subject area, there is very limited empirical literature that emphasizes the important role that IB plays for employees' empowerment and delivery of desired goals for corporate success. Very few studies such as Iyer et al (2018), and Punjaisri and Wilson (2007) reflect the role of IB in facilitating brand performance. Also, these studies have been conducted from a non-African context thus creating a gap worth exploiting to confirm study findings.

Iyer et al's (2018) study in the USA on IB was conducted from an organizational perspective to understand the role of employees in improving brand performance. A survey-based design and key informant approach (Qualtrics Panels) was used in collecting data from respondents mainly made up of Brand/ Marketing Managers, Product/Service Managers, and Assistant Managers. Questionnaires were distributed to 534 respondents out of which 218 responses, representing 218 organizations were used. Study findings revealed that IB was viewed as a mechanism for effectively executing the brand's vision and strategic brand plans over a period. Employees were noted as crucial in the creation and sustaining of strong brands. Accordingly, IB's role in brand management was linked to an activity that enhanced employees brand orientation mindset and ultimately brand performance. The results also highlighted the importance of brand orientation and strategic brand management initiatives which suggest that IB practice facilitates employees' alignment to brand and strategic plans. IB initiatives thus acted as an enabler (a bridge) for executing brand orientation values and strategic brand management goals.

Piehler et al's (2016) study in Australia which shares similarities with Xiong and King's (2015) study in USA, examined the dynamics of four important internal brand management outcomes (Brand understanding, Brand identification, Brand commitment and Brand citizenship behavior). Purposive sampling was employed, and data was collected via online survey using an Australian web-based market research list. The sample comprised of entry-level, supervisory, middle management, and senior management positions. 3,000 email invitations were sent out, and 678 responses were received out of which 375 valid responses were used. Study results revealed that brand understanding, a cognitive outcome of internal brand management (IBM), was an important antecedent of brand citizenship behavior (BCB). And BCB, a behavioral outcome of IBM was shaped by brand understanding through two-related routes, firstly through brand understanding which is the foundation for both, and secondly through both brand commitment and identification. The study identified brand understanding as fundamental to employees' identification with the brand and exhibition of brand commitment. Brand understanding and brand commitment were identified as two immediate antecedents of BCB. Brand identification was included in the study to show its indirect effect as personal interest was noted to drive connectivity to the brand. The study noted that brand understanding afforded employees the ability to identify with the brand after which brand commitment was achieved. This is so because when employees have sufficient brand knowledge, it boosts their emotional attachment and confidence as to what to do (role clarity) which leads them to exhibit brand-aligned behaviors (Piehler, 2016: 1588/1589). Employees act as brand ambassadors or brand champions when they know what to do and are committed to delivering desired goals. Which suggests that IB efforts facilitated brand understanding, brand identification and commitment and brand-aligned behaviors. 
Xiong and King's (2015) study in the USA examined how employees' motivation informed their brand performance. Specifically, the study explored how employees are motivated to act as brand champions/ambassadors. Data was collected via online self-reported survey from 202 US based hotel employees. The study identified employee perceived brand meaningfulness, and employee perceived brand value fit, as two key motivational drivers that underpinned employees' brand alignment and enhanced brand performance. Xiong and King (2015: 60/61) define employee perceived brand meaningfulness as "the extent to which employees perceive that delivering the brand is meaningful and valuable to them" which suggests that employee motivation (which is crucial to excellent service delivery) is underpinned by the brand's meaningfulness and personal relevance. Additionally, it is suggested that motivated employees exhibit brand-aligned behaviors for brand success. Employee perceived brand value fit was also defined as "the extent to which employees perceive their values are consistent with the brand's value" which also suggests that value congruence propels employees to act authentically as they feel a sense of belongingness which can be equated to employee empowerment. The study findings also imply that employees become brand ambassadors when they perceive the brand as meaningful and relevant, and their personal values aligned with that of the brand. Which suggests that IB efforts promoted brand meaningfulness and relevance and facilitated brand-aligned behaviors for enhanced brand performance.

Punjaisri and Wilson's (2007) study in Thailand which shares similarities with that of Punjaisri et al (2009) study also in Thailand, examined employees' perceptions towards their role and organizational practices that enabled them deliver on the brand promise. A mixed approach (Quantitative/Qualitative) was adopted, and study findings revealed that IB practices (mainly internal communication and training) influenced employees' actions and brand attitudes, and ultimately their service delivery. Employees' perceptions with regards to the role they play to enhance the brand's value were aligned to that of management. Employees' regarded their behaviors and actions as significant and crucial to brand and overall business performance, which suggests that IB efforts facilitated employees' brand understanding and brand-supportive behaviors for corporate success.

Even though research interest has resulted in a plethora of investigative studies on IB, majority of these studies have been conducted outside of Africa (Amegbe, 2016). Also, empirical studies conducted from the employees' perspective have largely focused on understanding IB mechanisms and outcomes rather than the role of IB (King and Grace, 2008/2010/2012). Furthermore, the very few studies that reflect the role of IB have approached the subject from a slightly different perspective as they do not clearly spell out the different roles IB efforts play in employee inculcation of brand values, their empowerment, and exhibition of brand-supportive behaviors (Iyer et al, 2018: Piehler et al, 2016; Xiong and King, 2015).The knowledge gap identified presents an opportunity to conduct a study from employees' viewpoint, and from an African context, to augment current literature and add to the limited studies in Africa. Hence, this paper examines the role of IB from the employees' perspective in a manufacturing set up in Ghana.

\section{Methodology}

Following recommendations by Saunders et al (2007), and Bryman and Bell (2011), a qualitative approach was adopted to explore employees perceptions on how IB efforts contributed to their acquisition of brand knowledge, empowerment and exhibition of brand-supportive behaviors for the delivery of brand promise. The sampling technique adopted was influenced by the study's aim of consciously engaging employees at all levels. Hence, purposive sampling was employed to enable data to be collected from both senior and junior staff to ensure the collection of diverse views, and to get the most information from the sample considered from the study. Face-to-face semi-structured interviewing technique was used to collect data from 20 respondents in the selected multinational organization. Face-to-face semistructured interviews was considered very appropriate as it allowed for flexibility and further probing to unearth new findings. It also promoted dialoguing with informants for better understanding and to clarify issues where necessary (Walker and Myrick, 2006: Saunders et al, 2007).

The grounded theory approach was adopted in analyzing data collected. This analytical 
technique is by far the most prominent approach for analyzing qualitative data and involved coding, identification of themes, and textural explanation of feedback obtained from respondent (Bryman and Bell, 2011). Firstly, face-to-face interviews recorded were transcribed after which responses were manually coded in a Microsoft excel spreadsheet. Data was then categorized based on clustering and thematic coding, and finally textural explanation of the information obtained. With the objective of understanding how IB was used as a strategic tool to empower and enhance employees' brandsupportive behaviors the following research question was posed: - How do employees perceive the role of internal branding in the organization's strategy formation?

\section{Findings}

Data analyses revealed two common themes, internal branding played 'an enabler' and a 'differentiator role' for corporate success. These will be discussed next.

\section{The "Enabler Role"}

Respondents unanimously revealed that IB activities championed by HR enhanced their knowledgebase, guided their actions, and equipped them to perform their jobs. For instance, respondents mentioned that new recruits go through induction training and specific training programs to learn what the company stands for and to align their values to that of the company. Leadership activities were also noted as playing significant role in employees' inculcation of corporate values for organizational success. Respondents indicated that leadership's directives, support, and interaction with them inspired and empowered them to build brandsupportive behaviors and to achieve desired goals. Leadership's influence guided their actions and supported employees' understanding and inculcation of corporate values.

Also, the attitude and behavior of the workforce (managers, supervisors, and colleagues) helped to implicitly inculcate brand values. Respondents indicated that interaction with peers also helped employees align their attitudes and behaviors to that of the organization and encouraged and reinforced the exhibition of expected values. Respondent's opinions arguably suggest that IB played an 'enabler "role as it supported employees' internalization of the corporate values, employees building of brandsupportive behaviors, and ultimate delivery on the brand promise. IB activities helped employees align their individual values with that of the organization and facilitated employee involvement and engagement. The practice also empowered them to act as brand ambassadors and to achieve desired goals. This is evidenced by the following statements.

Taken together, respondents' views suggest

"Looking around daily how employees go
about their processes, how they implement
these core values in their various day to day
operations. I believe the message has gone
down with every single one"
"Well the awareness and knowledge gained
is something that has moulded me to fit into
the organization. The knowledge gained
has actually helped me to fit myself into the
organization and whiles I get myself
relating well within the organization its
helping me to do my work as I am supposed
to do"

that IB initiatives enhance employee brand orientation and understanding which is crucial to employees' display of brand-supportive behaviors. The practice also contributed to building a strong brand and an enhanced overall business performance. The findings concur with studies such as Burmann and Zeplin (2005), and Punjaisri and Wilson $(2007 ; 2011)$, as they state that internally organized activities targeted at employees such as coaching, training and developmental programs, enhance employees' knowledgebase and skills, and helps build brandsupportive behaviors. The findings are also consistent with studies such as Iyer et al, (2018), who assert that IB efforts facilitated employees' alignment to brand and strategic plans. In that, the practice enhanced employees brand orientation mindset and reflected in their attitude and behaviors which ultimately enhanced the brands performance. The findings also concur with Xiong and King's study (2015) which identified perceived brand meaningfulness and perceived brand value fit as core elements that motivated employees to build brand-aligned behaviors and enhanced brand performance. Similarly, study 
findings confirm the results of Piehler et al (2016), as they also noted brand understanding as fundamental to employees' brand identification and commitment, and brand citizenship behaviors. Altogether, study findings suggest IB efforts to promote employee-based brand equity and exceptional service delivery which is consistent with scholarly views such as King and Grace (2010/2012). Respondents' views also imply that IB efforts support businesses to achieve desired goals and thus require effective implementation of such initiatives as they impact employee attitudes and behaviors, brand performance, and consequently ensure corporate success.

\section{The "Differentiator Role"}

Majority of the respondents perceived IB initiatives as contributing to the organization's attractiveness, enhanced image, and reputation. Respondents linked the organization's current overall outstanding performance to their alignment with the internal processes and culture which have been put in place by management. Respondents believed that their actions have contributed greatly to the outstanding performance, positive image, and enhanced reputation enjoyed by the firm. The respondents mentioned that the organization currently stands out due to employees' commitment and exhibition of brand-supportive behaviors. Respondents also felt proud to be a part of such a prestigious organization as their responses suggests identification with the company. For instance, respondents mentioned that living the corporate values has improved customer feedback and word-of-mouth communication about the company. Additionally, it has built trust, respect, increased credibility, enhanced identity, image, and reputation of the organization. This is evidenced by the following statements:

The opinions expressed by respondents suggest that IB initiatives helps to differentiate the organization from others. In that, the brand knowledge acquired contributed to the creative and innovative skills displayed by the workforce. IB efforts thus inspired and guided employees' actions and assisted in building brand-supportive behaviors which enhanced the organization's identity, attractiveness, distinctiveness, and sustained competitive advantage (De Chernatony and Cottam, 2006). The organization is perceived as unique via customer experience and interaction with employees. The findings also suggest that IB

"Currently you will realize that you would
not really hear any negativity in relation to
the company. Another thing too that you will
realize is that each and every individual tries
to live and abide by these values because we
get to understand from the very word go that
these values are core to your behavior and
conduct in the company".
"I was actually considering today about how
the values have driven the growth of the
company over the years. We don't joke when
it comes to the values and that is what sets us
apart from other companies."

efforts contribute to exceptional performance and competitive edge over rivals. It also contributed to the building of a strong brand equity which is reflected in the overall brand performance. Furthermore, IB practices exploit employees innovative and creative skills, and empower them to act as brand ambassadors. Consequently, the image and reputation of the establishment is enhanced via employees display of distinctive qualities. The findings also agree with Bowen's (2015) view that IB initiatives make employees display creative and innovative skills which enhances their brand knowledge and overall business performance.

\section{Discussion}

Whereas most of the existing studies on IB have been conducted outside of Africa and have largely focused on understanding mechanisms and outcomes, this study has considered the role of IB from an African context in a manufacturing set up, in Ghana. It is evident from the research findings that employees working with the multinational organization under study in Ghana perceived IB as playing two key roles: - an enabler role and a differentiator role. The enabler role emanates from the practice empowering them to internalize corporate values and build brand-supportive behaviors. Respondents indicated that HR's consistent training and communication programs increased their knowledgebase and understanding of the corporate values which equipped them to perform assigned tasks. HR trainings had a major influence on the socialization process as it 
positively impacted their brand understanding and promoted values alignment for corporate success.

Leadership's directives, support, and influence was also noted to have positively shaped employees' attitudes and behaviors and ultimately impacted employee brand performance. Leadership's continuous interactions, encouragement, and reinforcement of the values empowered employees to live the brand and to display brand-supportive behaviors. Leadership's influence also facilitated employeremployee relationship which was necessary for building employee confidence to live the brand and to deliver required goals. In other words, IB efforts equipped employees with the requisite knowledgebase and skills to deliver on the brand promise. This finding concurs with the views of scholars such as Bowen (2016), Iyer et al (2018) and Punjaisri et al (2008), who acknowledge that IB efforts facilitated employee empowerment and exhibition of brand-supportive behaviors which improved overall brand performance. Study findings also identified IB to have played a differentiator role as it increased the distinctive qualities of the organization and made it stand out. Employees noted IB efforts to have increased their creative and innovative skills which contributed greatly to the exceptional service delivery and distinctive overall business performance. The organization's attractiveness was linked to the enhanced identity, image and reputation enjoyed by the organization. This finding is consistent with Bowen's views (2016) on IB practices promoting creative and innovative skills to enhance brand performance and corporate success.

\section{Limitations/ Managerial Implications}

The study was conducted in only one establishment and was based on a small sample size thus limiting generalizability of the findings. It is suggested that future research consider a wider company or sector coverage and much larger sample size. The paper also seeks to draw management's attention to the positive influence of IB initiatives on employees' attitudes and actions. The study findings demonstrate the important role employees play in the delivery of an organization's brand promise. The study endorses the effective management and execution of IB programs, and the conscious exploitation of employees' skills and competencies for enhanced performance and realization of corporate goals.

\section{Conclusion and Recommendations for Future Research}

The study findings demonstrate how IB initiatives support strategic management decision making and ultimately brand performance. Employees would act as brand ambassadors if they are empowered to live the brand and exhibit brand-supportive behaviors. This is made possible when employees' skills and competencies are consciously exploited to exhibit distinctive skills and services. Having established that IB efforts positively influence employees' actions and gets them empowered to live the brand, this paper recommends that IB practices be encouraged for corporate success. The study also endorses the results of previous empirical literature that promote IB efforts as playing an enabler and a differentiator role. The enabler role is linked to equipping employees with the requisite knowledgebase and skills to empower them to live the brand. The differentiator role strengthens the corporate identity, reputation, and image of the establishment. Given that there is very scanty literature on the role IB plays in employees' empowerment and exhibition of brand-supportive behaviors, this paper recommends more studies be conducted from an African context to increase knowledgebase, and to guide and enhance the practice in Africa.

\section{References}

[1].Aaker, D. A. 1991, Managing Brand Equity (New York Free Press).

[2].Aaker, D. A. 1996, Building Strong Brands (New York Free Press).

[3].Allen, D. J., Bryant, P.C. and Vardaman, J. M. 2017, Retaining Talent: Replacing Misconceptions with Evidence-Based Strategies. Academy of Management Perspectives, Vol. 24(2):48-64.

[4].Amebge, H. 2016, Internal Branding Among SME's and Employee's Supporting Behaviors in Ghana. Journal of marketing and Consumer Research, Vol. 26: 65-72.

[5].Ashforth, B. E., and Mael, F. 1989, Social Identity Theory and The Organization. The Academy of Management Review, Vol. 14(1): 20 -39.

[6].Aurand, T. W., Gorchels, L., and Bishop, T. R. 2005, Human Resource Management's Role in Internal Branding: An Opportunity for Cross 
Functional Brand Message Synergy. The Journal of Product and Brand Management, 14 (2 /3): 163-169.

[7].Barney, J. 1991, Firm Resources and Sustained Competitive Advantage. Journal of Management, Vol (1): 99-120.

[8].Bergstrom, A., Blumenthal, D., and Crothers, S., 2002, Why Internal Branding Matters: The Case of Saab. Corporate Reputation Review, Vol. 5(2/3): 133142.

[9].Bowen, D. E. 2015, The Changing Role of Employees in Service Theory and Practice: An Interdisciplinary View. Human Resource Management Review, Vol, 26 (1):4-13.

[10].Bryman, A. and Bell, E. 2011, Business Research Methods, Third Edition, Oxford University Press Inc, New York.

[11].Brymer, R. A., Molly, J. C., and Gilbert, B. A. 2014, Human Capital Pipelines: Competitive Implications of Repeated Inter-Organizational Hiring. Journal of Management, 483-508.

[12].Burman C. and Zeplin S. 2005, Building brand commitment: A behavioral approach to internal brand management. Journal of Brand Management, Vol. 12 (4): 279-300.

[13].De Chernatony, L. 1999, Brand Management through narrowing the Gap between brand Identity and brand reputation. Journal of Marketing Management, Vo. 15 (1-3): 157-80.

[14].De Chernatony, L. 2002, Living the Corporate Brand: Brand Values and Brand Enactment. Would A Brand Smell any sweeter by a Corporate Name? Corporate Reputation Review, Vol. 5(2/3):114-132.

[15].De Chernatony, L. and Cottam, S. 2006, Internal brand factors driving successful financial services brands. European Journal of Marketing, Vol. 40 (5/6): $611-633$.

[16].Dickson, M. 2015, People are the Essential Element for Implementing and Delivering Strategy. PMI Today: 3-5.

[17].Foster C., Punjaisri, K., and Cheng, R. 2010, Exploring the relationship between corporate, internal and employer branding. Journal of Product and Brand Management, Vol. 19 (6): 401 - 409.

[18].Grant, R. M. 1991, The Resource-Based Theory of Competitive Advantage: Implications for Strategy Formulation. California Management Review, Vol. 33(3):114-135.

[19].Golant, B.D. 2012, Bringing the corporate brand to Life: The Brand Manager as Practical Author. Journal of Brand Management, Vol. 20(2):115-127. [20].Harris, P. 2007, We the People: The Importance of Employees in The Process of Building Customer
Experience. Brand Management, Vol. 15 (2): 102114.

[21].Hatch, M.J. and Schultz, M. 2009, Of Bricks and Brands: From Corporate to Enterprise Branding. Organizational Dynamics, 38(2): 117-130.

[22].Ind, N. 2003, Inside Out: How Employees Build Value. Brand Management Vol. 10 (6): 393-402.

[23].Iyer, P., Davari., A. and Paswan, A. 2018, Determinants of Brand Performance: The Role of Internal Branding. J. Brand Management, Vol. 25: 202-216.

[24].Kapferer, J. N. 2012, The New Strategic Brand Management: Advanced Insights and Strategic Thinking. $5^{\text {Th }}$ Edition, London, Kogan Page.

[25].Kaufmann, R.H., Vrontis, D., Czinkota, M., and Hadiono, A. 2012, Corporate Branding and Transformational Leadership in Turbulent Times. Journal of Product and Brand Management, Vol. 21 (3): 192-204.

[26].Keleman, M. and Papasolomou, I. 2007, Internal Marketing: A Qualitative Study of Culture Change in UK Banking Sector. Journal of Marketing Management, Vol. 23 (7/8): 745- 767.

[27].Keller, K. L. 2009, Building Strong Brands in A Modern Marketing Communications Environment. Journal of Marketing Communications, Vol. 15(2-3): $139-155$

[28].Khan, B.M. 2009, Internal Branding: Aligning Human Capital Strategy with Brand Strategy. Journal of Brand Management, Vol. VI (2): 22-36.

[29].King, S. 1991, Brand Building in the 1990's. Journal of Consumer Marketing, Vol 8(4): 43-51.

[30].King, C. and Grace, D. 2008, Internal Branding: Exploring the employee's Perspective. Brand Management, 15 (5), 358-372.

[31].King, C. and Grace, D. 2010, Building and Measuring Employee-Based Brand Equity. European Journal of Marketing, Vol. 44: 938-971.

[32].King, C. and Grace, D. 2012, Examining the Antecedents of Positive Employee Brand-Related Attitudes and Behaviors. European Journal of Marketing, Vol. 46 (3/4): 469 - 488.

[33].King, C., and So, K.K.F. (2015) "Enhancing Hotel Employees' Brand Understanding and BrandBuilding Behavior in China", Journal of Hospitality and Tourism Research, 39 (4):492-516.

[34].Kor Y. Y, and Mahoney J. T. 2004. Edith Penrose's (1959) contributions to the resource-based view of the firm. Journal of Management Studies 41(1): 183-191.

[35].LePla, F.G. 2013, The Impact of Internal Branding on Employee Motivation and Competitive Advantage. Employee Relations Today: 19-24. 
[36].Madden, T., Fehle, F., and Fournier, S. 2006, "Brands Matter: An Empirical Demonstration of the Creation of Shareholder Value through Branding. Journal of the Academy of Marketing Science, 34(2), 224-235.

[37].Maxwell, R. and Knox, S. 2009, Motivating Employees to Live the Brand: A Comparative Case Study of Employer Brand Attractiveness Within the Firm. Journal of Marketing Management, 25 (9-10): 893-907.

[38].Miles, S. J. and Mangold, G. 2004, A Conceptualization of the Employee Branding Process. Journal of Relationship Marketing, 3(2-3): 65-87.

[39].Miles, S.J. and Mangold, G. 2005, Positioning Southwest Airlines through Employee Branding. Business Horizons, (48):535-545.

[40].Mitchell, C. 2002, Selling the Brand Inside. Harvard Business Review, Vol. 80 (1): 99-105.

[41].Mohart, F.M., Herzog, W., and Tomczak, T. 2009, Brand-Specific Leadership: Turning Employees into Brand Champions", Journal of Marketing, 73:122 -142 .

[42].Patla, S. and Pandit, D. 2012, Internal Branding in an Indian Bank: An Initial Exploration. Journal of Management (XIMB):115-124.

[43].Piehler, R., King, C., Burmann, C., and Xiong, L. 2016, "The Importance of Employee Brand Understanding, Brand Identification and Brand Commitment in Realizing Brand Citizenship Behavior" European Journal of Marketing, Vol. 50 (9/10): 1575-1601.

[44].Presbitero, A., Roxas, B., and Chadee, C. 2016, Looking Beyond HRM Practices in Enhancing Employee Retention in the BPOs: Focus on Employee-Organization Value Fit. The International Journal of Human Resource Management, Vol. 27(6): 635-652.

[45].Punjaisri, K., and Wilson, A. (2007) "The Role of Internal Branding in The Delivery of Employee Brand Promise" Brand Management, Vol, 15 (1): 57-70.

[46].Punjaisri K., Wilson, A., and Evanschitzky, H. 2008, Exploring the Influences of Internal Branding on Employees' Brand Promise Delivery: Implications for Strengthening Customer-Brand Relationships. Journal of Relationship Marketing, Vol. 7. (4): 407424.

[47].Punjaisri, K., Evanschitzky, H., and Wilson, A. 2009, Internal branding: An enabler of employees brand supporting behaviors. Journal of Service Management, Vol. 20 (2): 209-226.

[48].Punjaisri, K., Evanschitzky, H., and Wilson, A. 2009, Internal branding to influence employees' brand promise delivery: A case study in Thailand. Journal of Service Management, 20: 209-226.

[49].Punjaisri, K. and Wilson, A. 2011, Internal branding process: key mechanisms, outcomes and moderating factors. European Journal of Marketing, Vol. 45 (9/10): 1521 - 1537.

[50].Rooney, J.A. 1995, Branding: a trend for today and tomorrow. Journal of Product and Brand Management, 4 (4): 48 - 55.

[51].Santos-Vijande, M.L., del Rio-Lanza, A. B., Suarex-Alvarex, 1., and Diaz-martin, A. M. 2013, The Brand Management System and Service Firm Competitiveness. Journal of Business Research, 66 (2): 148-157.

[52].Saunders, M., Lewis, P., and Thornhill, A. 2007, Research Methods for Business Students, Fourth Edition, Pitman Publishing Print.

[53].Srivastava, R. K and Thomas, G. M. 2010, Managing Brand Performance: Aligning positioning, execution, and experience. Journal of Brand Management, Vol. 17 (7): 465-471.

[54].Urde, M 1994, Brand Orientation- A Strategy for Survival. Journal of Consumer Marketing, Vol. 11(3):18-32.

[55].Urde, M., Baumgarth, C., and Marrillees, B. 2013, Brand Orientation and Market OrientationFrom Alternatives to Synergy. Journal of Business Research, Vol. 66(1):13-20.

[56].Vallaster, C. and de Chernatony, L. (2005) "Internationalisation of services brands: The role of brand leadership during the internal brand building process", Journal of Marketing Management, 21 (1/2): 181-203.

[57].Wallace, E., de Chernatony, L., and Buil, I. (2013) "Building bank brands: How leadership behavior influences employee commitment", Journal of Business Research, 66:165-171.

[58].Walker, D. and Myrick, F. 2006, Grounded Theory: An Exploration of Process and Procedure. Quantitative Health Research, 547-559.

[59].Wenerfelt, B. 1984, A Resource-Based View of the Firm. Strategic Management Journal, Vol. 5(2): 171-180.

[60].Xiong, L., King, C., and Piehler, R. 2013, That's not my job. Exploring the employee perspective in the development of brand ambassadors. International Journal of Hospitality Management, 35: 348-359.

[61].Xiong L., and King, C. 2015, Motivational Drivers That Fuel Employees to Champion the Hospitality Brand. International Journal of Hospitality Management, Vol. 44:58-69.

[62].Xiong L., and King, C. 2019, Aligning Employees Attitudes and Behaviors with Hospitality 
Brands: The Role of Employee Brand Internalization. Journal of Hospitality and Tourism Management, Vol. 40: 67-76.
[63].Yang, JT., Wan, CS., and Wu, CW. (2015) "Effects of Internal Branding on Employee Brand Commitment and Behaviour in Hospitality", Tourism and Hospitality Research, Vol. 15 (4):267-280. 


\title{
Costing and Financial Management: The Financial Impact of Investment of Technology in Motors Manufacturers (T) LTD
}

\author{
Fatema Rehman \\ MBA General, Texila American University \\ E-mail:fatema.rehman@yahoo.com
}

\begin{abstract}
This study examined the relative effects of investing in technology and its financial impact on the company. The analysis was based on primary data collected from the auditor of Motor Manufacturers (T) LTD which included the cash flow statement and income statements for the years 2015 to 2017. The review also included secondary data from previous researches in order to support the results and findings obtained. The findings of study show that companies investing in technology would bring a positive financial impact for the company. The results indicate that the company can bring higher returns and better liquidity through new technology however needs to maintain it throughout the years in order to bring constant improvement. In order to analyze the impact of investment in technology, the financial analysis would include the ratio analysis, budgeting, benchmarking, risk management and investment appraisal. The constantly changing environment increases the need of investing in technology however the negative financial impact becomes a concern for a company's management. This therefore causes the management in neglecting the idea of investing in technology which does not bring any positive impact that it could have brought to the company if the management would have forecasted its' financial and investment appraisal.
\end{abstract}

Keywords: Finance, Impact, Investment, Technology.

\section{Introduction}

Companies operate in an environment that keeps on changing from time to time which affects the company in one way or the other. In order to remain competitive and survive in the market, the company needs to bring about changes in its decisions and strategies. Sometimes the company can be required to invest in new technology in order to meet the standards of the market place.

Companies invest in technology to enable their employees to increase productivity as they are able to reduce time spent and increase their output simultaneously (Dewan and Kraemer 2000). The cost of investing in technology needs to be outbalanced by the benefits and profit of investing in the long-terms in order to prove to be beneficial to the company.

Investment in technology could bring about some benefits but could also bring negative effects if not implemented correctly. This research will therefore look at the benefits and disadvantages as well as the overall outcome of investing in technology in a local established company.

Motor Manufacturers is a medium-scale industry based in Tabora. The firm manufactures and designs agro-construction equipment and tools such as hullers, oxen carts, brick-lying machines and much more. The firm started its operations in 2012 with revenue of 5,976,875 only and faced losses in the first two years of operations.

The company started to do substantially well after the third year when it invested in technology with $10,000,000$ to create an innovative product of a watering machine for farmers that is operated through solar power. Currently the company has 80 employees and revenue of 29,470,769 which comes from the result of the investment in technology that met the rural farmers' needs and of the environment. The company is looking into expanding its business across different regions and reaching up to 200 employees by 2020 . 


\section{Research Questions}

1. Analyzing the financial impact of the decision of investment through financial ratios, techniques and data.

2. Evaluating the decision of investment to the company's profitability and growth.

3. Analyzing the progress of the company with its competitors' through best-in-class benchmarking.

4. Assessing the source of investment and its utilization.

5. Analyzing budgeting in relation to the decision of investment and its importance.

6. Assessing any risks associated with the decision of investment towards the company.

This review will determine the outcome of a decision for investment in technology within a company. The benefits, disadvantages, risk and impact will be discussed in this research in terms of both quantitative and qualitative appraisal.

\section{Literature Review\& Methods}

\section{Investment in Technology}

According to $\mathrm{Li}$ et al (2000), investment in technology does not directly enable the employees to increase their productivity though many researchers such as Gyampoh-Vidogah et al (1999) claims that investment in technology will improve the performance of the company in the long term. When the decision for investment in technology turns out to be successful, the company not only makes high returns from the decision but also becomes responsible for transformingtheir business as well as their industry sector (O’Brian 1999)

According to Irani et al (1999), the biggest problem in investing in technology arises when the company is unable to predict and analyze the benefits of the result. Different appraisal techniques such as the Net Present Value (NPV), payback period, Return on Investment (ROI) and Internal Rate of Return (IRR) are mostly used by companies when evaluating their decision of investment (Ballantine and Stray 1999).

\section{Quantitative Appraisal}

Evaluating the benefits of investing in technology through quantifiable terms could include using techniques such as the appraisal of investment through ROI, NPV and IRR or through the financial statement using ratios such as net profit margin, current ratio and more. The analysis of the budget is also included under this appraisal.

\section{Investment Appraisal}

The investment appraisal could be carried out using techniques such as ROI, NPV, IRR and the payback period. In order to get the exact amount of return and time spent, the NPV and IRR technique should be used however the project size is not measured which can cause conflicting or misleading answers.

The payback period is easy to use therefore is widely used despite its limitations of not effectively evaluating the project since it does not consider the returns the way it's used in other techniques (Brigham and Ehrhardt 2005).

In order to know the net gain or loss from the project companies should use ROI which helps to identify the project's outcome and detailed financial analysis (Botchkarev and Andru2011). Another option is NPV that is used to analyze the profitability of the decision where the decision/project with highest NPV is to be chosen (Brigham and Ehrhardt 2005).

\section{Financial Ratios Appraisal}

The financial data used to analyze the ratios includes the comprehensive statement (profit/loss statement), balance sheet and the cash flow statements which are not independent but are linked to the same system of finance in a company (Walsh 2003).

Financial data from the company are obtained in order to calculate the ratios and then analyze through comparison between different years. According to Pandey (2005), ratios are the relation of two or more mathematical outcomes and identified these ratios to be liquidity, leverage, activity and profitability.

\section{Budgeting}

According to Musaazi (1982), budget is the financial strategy where the objectives are put in place according to that financial strategy to turn it into reality. The allotment of financial resources to a company's activities, divisions and investment is known as the process of budgeting (Blumentritt 2006).

Flexible budgeting is preferred to be used since it allows adapting according to the environment as opposed to traditional budgeting 
which gives a rigid budget that employees have to maintain despite the changes in the environment. Budget is seen to be as a management control in the organizations' systems as stated by Otley (1978). Many researchers such as Abdel-Kader and Luther (2006) and Uyar (2009) have demonstrated to prove that budgeting is used as a control mechanism as well as a planning tool for an organization.

\section{Qualitative Appraisal}

Evaluating the investment in technology in terms of qualitative terms could include conducting the SWOT analysis of the company to understand the risks or opportunities to the company. The risk management, source of investment and benchmarking has also been carried out to evaluate the decision.

\section{Risks on Investment}

According to Lawrence (1976) risk can be defined as the measure of possibility of undesirable consequences arising. Risks are supposed to be communicated, consulted, analyzed and monitored once they are identified in order to ensure the risks do not adversely affect in the future (Risk Management ISO 2009).

\section{Benchmarking}

Benchmarking has been defined as the process of comparing one's performance with a competitor with the purpose of improving through adaption of best practice approach (Edith Cowan University 2011). According to Epper (1999), benchmarking could be successful for a company after it has done a self-analysis first in order to understand its own processes more clearly before it tries to understand its competitors. A company needs to be aware of the likely problems that could arise resulting the shortfall in results from its competitors and should be able to come up with a solution through agreed decisions and plans (Wilson et al 2000). Not only can the company compare itself with its competitor but also with the best in the industry; best in previous years or best in the market as stated by Johnson, Scholes and Whittington (2008).

\section{Source of Investment}

The source of investment depends on the project being invested in where the source can either be internal or external. Internal funding is mostly preferred to avoid the monitoring and checking resulting from external funding (Brealey et al 2001). Where the investment is huge or for expansion of operations then external funding is looked into. External funding is usually used when there is limited cash flow from the company's operations (Watson and Head 2007). Another option is the equity financing which is not preferred when compared to debt financing (Eckbo 2008).

\section{Research Gap}

Previous researchers such as Khan (2007) and Venkatesh et al (2010) have analyzed the benefits and challenges of investing in technology in many companies, however this research will be conducted on Motor Manufacturers and its investment in technology which has never been evaluated by previous researchers. The benefits, challenges and overall outcome will be analyzed in both quantitative and qualitative terms in order to determine the success or failure of investment in technology at the bank.

\section{Data Collection}

This review has used secondary method to obtain the information relating to the topic. The quantitative and qualitative methods were used where financial data and the evaluation of the strategic decision was carried out through the use of SWOT analysis.

\section{Data Management}

The data collected was ensured to be reliable since it was collected from sources that were considered reliable and authentic. The information and financial statements for Motor Manufacturers was derived from the company's management through emails and from auditor, Mr. Denis Demarco who was on a visit to Dares-Salaam through personal meetings. Therefore, all data derived is considered as valid and reliable.

\section{Findings and Analysis}

\section{Financial Analysis}

The analysis of the calculation of the ratios (Appendix 1) is as follows:

\section{ROCE}


The calculation shows an increase in ROCE after the year of investment from 1.9\% in 2015 to $4.2 \%$ in 2016 . This shows a good return on the capital employed following the investment in technology and a substantial increase in the profit before tax. However, the ROCE decreased in 2017 due to a slight decrease in profit before tax along with an increase in the capital employed. The decrease was not lower than the ROCE of 2015 where it was calculated to be $2.8 \%$ which still shows the result of an increase from the investment of technology.

\section{Current Ratio}

Motor Manufacturers' current ratio had an increase from 1.9 in 2015 to 3.0 in 2017. This shows that the company has been able to increase its current assets and the investment has not affected its liquidity. However, the increase needs to be managed where the current assets should be used efficiently and working capital could be used for other investments.

\section{Profit Margin}

There was an increase in profit margin from $19.6 \%$ in 2015 to $25 \%$ in 2016 which shows the investment in machinery has been able to improve the company's profitability and its margin over time. The profit margin however slightly decreased to $24.7 \%$ due to a decrease in profit before tax and revenue in that year (2017).

\section{Debt Ratio}

Despite the acquiring of debt for the investment in technology the debt ratio was maintained where it was 0.54 in 2015 and 2016 while it slightly reduced to 0.52 in 2017 . This shows that the company was able to slightly reduce its financial risk and the investment did not adversely affect the company through acquiring a debt.

\section{Best-in-class Benchmarking}

Simba Manufacturer is a competitor as well as the best-in-class for the agriculture industry in terms of the local firms. Motor Manufacturers and Simba Manufacturer were analyzed for the year 2017 with financial ratios (Appendix 4).

The analysis shows that Simba Manufacturer has better profitability in terms of the profit margin and ROCE. Simba Manufacturer has a higher profit as well as revenue which show that Motor Manufacturer is yet to achieve that target in order to be the best in the industry. However, in terms of liquidity Motor Manufacturers holds a better position than Simba Manufacturer where they are more prone to financial risk and are less likely able to get into more debts for future investments.

Motor Manufacturers despite the lower profitability than Simba Manufacturer has a better liquidity position and is able to invest through obtaining debt and therefore expand in the market with new projects.

\section{Budgeting}

The company has done substantially well in terms of maintaining low variance between forecasted and actual figures (Appendix 6). Motor Manufacturers used traditional budgeting method where figures were set before the start of the financial year and were not to be changed despite any change in the environment or market place. This could cause biased analysis where the budget was not altered according to the situation especially in a country where inflation is always on the rise. The variance however was not too high therefore showing that the company was able to mostly achieve the forecasted figures.

In terms of the investment, the forecasted figures were achieved with a positive variance for the revenue with $12 \%$ higher than forecasted figure. The expenses were lesser than forecasted by $-15 \%$ and therefore brought down the variance for profit to $-2 \%$ only. The forecasted figures in 2017 was not achieved the way it was in 2016 probably because of the overachievement in 2016 caused the company to set the budget for 2017 with higher figures than expected. 2017 in Tanzania was a year with inflation and tight economy therefore the figures were not easily achieved though expenses were less than predicted $(5 \%)$.

\section{Risk Management}

Motor Manufacturers knew the risk of investing in a new technology for a product carries more risk especially since it was after two years of being founded. The company had the risk of acquiring loan as well as using $20 \%$ of its own equity for the investment. This finance risk was however mitigated as the company benefitted from the investment in the next year with increasing revenue and profit.

The company had mitigated and solved the 
risk of not keeping with the market needs by investing in the technology and offering a new product that was introduced according to the advanced technology and convenience need in the market. The company also dealt with the risk of losing customers by introducing the new product through investment of technology which was not only convenient but also cost-effective.

The inflation risk as well as risk from change of policies from the government as stated in the SWOT analysis (Appendix5) shows that the company has to consider the economy of Tanzania and government decisions in order to make sure the operations are not negatively affected. Due the rise in costs in Tanzania, Motor Manufacturers obtained a minimum loan amount instead of a huge amount as it knew it would not be able to suffice with the profitability it achieves. This enabled Motor Manufacturers to reduce the negative risk of inflation by investing a small amount that would be recovered soon as well as avoid negative impact arising from changing government policies.

\section{Investment Appraisal}

The investment appraisal carried out for this project was analyzed through two common techniques; NPV and Payback Period (Appendix $2 \& 3)$.

The actual NPV was calculated to be lower than the forecasted NPV however the actual NPV turned to be positive which shows that the revenue from the project is higher than the costs. The actual Payback Period shows that the investment amount has been recovered within 23 months which is sooner than the forecasted payback period of 29 months.

This therefore shows that despite not being able to achieve the forecasted NPV it has been able to still obtain a positive amount as well as recover the investment amount within a shorter period of time. The analysis could be more detailed by using other techniques such as IRR however, due to lack of time and resources the analysis for the investment was carried out through NPV and Payback Period only.

\section{Source of Finance}

Motor Manufacturers obtained a loan for $80 \%$ of its investment while $20 \%$ was obtained from the company's equity.

This enabled the company to not place its risk of investment on one option only and could recover easily.

The company was able to recover the investment from its shareholders where the ROCE (Appendix 1) increased and the amount invested was recovered. The debt amount can be easily be recovered through the company's cash or assets since the current ratio (Appendix 1) is high and the invested amount has been recovered as shown in the Payback Period (Appendix 3).

\section{Conclusion and Recommendation}

\section{Conclusion}

Motor Manufacturers' investment in technology was successful as seen in the quantitative and qualitative analysis carried out in this review. The company was able to recover its investment in a shorter period of time and achieve higher profitability from the time it invested in the technology. The investment appraisal therefore was positive for the company and the financial data was analyzed with the outcome of favorable terms.

The company was able to manage its risks and invested with precaution through a small amount and dividing the source of income to equity and debt to mitigate the risk of financing. Motor Manufacturers were able to achieve some of its forecasted figures as well as reducing the variance which shows it was able to achieve a better position than before.

The company was not only able to increase its profitability, but also increased its customers of rural farmers since the new technology offered a cost-efficient machinery and convenient usage. The company was also able to expand its product base through the new technology and therefore increase its market share and also enabled the company to look into more projects for investment after experiencing the benefits for this particular investment of technology.

Motor Manufacturers however faced slightly lower profitability, ROCE and revenue in 2017 which could be due to external factors such as the tight economy and high inflation rates. The company also needs to improve itself to compete better with its competitors as seen in the benchmarking analysis where Simba Manufacturer is potentially better in profit and performance except for liquidity. 


\section{Limitation}

This review was limited due to time and resources where the author could not meet the management in person for company details but had to use email for communication. The author also faced the restriction of not getting information of the company from sources such as the websites or published annual reports since it is a locally established medium scale company. Local companies in Tanzania are hesitant in providing financial data of the company due to which personally meeting the auditor and obtaining information was not through reference sources but through authors' personal interaction with auditor.

\section{Recommendations}

In relation to the findings and conclusion, Motor Manufacturers needs to find ways of growing its profitability and revenue since it had faced a slight decrease in 2017. Since the investment in the technology proved to be successful in terms of higher ROCE, revenue, profit and overall performance in 2016, the company should invest in latest technology to meet the changing needs of the market. The

Appendix 1 company's liquidity is in good position where company has more current assets compared to its liabilities and previous investment has already been recovered, the company can therefore look into financing a new investment.

Moreover, Motor Manufacturers needs to adapt to flexible budgeting in order to avoid high variance due to change in environment or government rules which the company cannot control. This could be seen in 2017 where the inflation was high in Tanzania therefore the variance was high and forecasted figures were not achieved in contrast to 2016. The company needs to continue assessing its risks in order to successfully operate in the industry which it did well when assessing risks of the investment in terms of source of finance.

\section{Self-Evaluation}

This research has enabled the author to learn about the local company's financial stability as well as decisions of investment in terms of small yet largely impacting projects. The author learnt how to analyze financial data in relation to a certain decision as well as concluding the impact of that decision to the company.

\section{Ratio Analysis}

\begin{tabular}{|c|c|c|c|}
\hline Ratios & 2015 & 2016 & 2017 \\
\hline ROCE & $5,256,832$ & $16,916,851$ & $14,688,002$ \\
\hline Net profit before Interest and Tax & $\overline{278,004,501} \times 100$ & $\overline{403,332,698} \times 100$ & $\overline{533,030,809} \times 100$ \\
\hline Capital employed & $=1.9 \%$ & $=4.2 \%$ & $=2.8 \%$ \\
\hline Current Ratio & $233,346,282=19$ & $358,009,919$ & $481,762,370$ \\
\hline Current Assets & $\overline{117,800,358}=1.9$ & $\overline{168,009,938}=2.1$ & $\overline{160,159,099}=$ \\
\hline$\overline{\text { Current Liabilities }}$ & & & \\
\hline Profit Margin & $5,256,832$ & $16,916,851$ & $14,688,002$ \\
\hline Profit before interest tax & 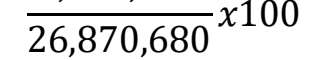 & $\frac{67,428,891}{6700}$ & $\overline{59,470,769} \times 100$ \\
\hline Revenue & $=19.6 \%$ & $=25 \%$ & $=24.7 \%$ \\
\hline Debt Ratio & $150,000,000$ & $218,659,170$ & $276,256,321$ \\
\hline Total Liabilites & $\overline{278,004,501}$ & $\overline{403,332,698}$ & $\overline{533,230,809}$ \\
\hline Total Assets & $=0.54$ & $=0.54$ & $=0.52$ \\
\hline
\end{tabular}

Appendix 2

\section{Forecasted NPV}

\begin{tabular}{|l|l|l|l|}
\hline Year & Cash Flow & Discount Rate (8\% ) & Present Value \\
\hline Investment (2015) & $10,000,000$ & 1.00 & $(10,000,000)$ \\
\hline 2015 & $2,500,000$ & $(1+0.08)^{\wedge} 1$ & $2,314,815$ \\
\hline 2016 & $4,890,800$ & $(1+0.08)^{\wedge} 2$ & $4,193,073$ \\
\hline 2017 & $6,980,770$ & $(1+0.08)^{\wedge} 3$ & $5,541,560$ \\
\hline NPV & & & $2,049,448$ \\
\hline
\end{tabular}




\section{Actual NPV}

\begin{tabular}{|l|l|l|l|}
\hline Books & Books & Books & Books \\
\hline Investment (2015) & $10,000,000$ & 1.00 & $(10,000,000)$ \\
\hline 2015 & $5,927,762$ & $(1+0.08)^{\wedge} 1$ & $5,488,669$ \\
\hline 2016 & $4,564,448$ & $(1+0.08)^{\wedge} 2$ & $3,913,279$ \\
\hline 2017 & $2,096,120$ & $(1+0.08)^{\wedge} 3$ & $1,663,968$ \\
\hline NPV & & & $1,065,916$ \\
\hline
\end{tabular}

\section{Appendix 3}

\section{Forecasted Payback Period}

\begin{tabular}{|l|l|l|}
\hline Books & Books & Books \\
\hline Investment (2015) & $10,000,000$ & $-10,000,000$ \\
\hline 2015 & $2,500,000$ & $-7,500,000$ \\
\hline 2016 & $4,890,800$ & $-2,609,200$ \\
\hline 2017 & $6,980,770$ & $4,371,570$ \\
\hline \multicolumn{2}{|l|}{ Payback Period: 29 Months } \\
\hline
\end{tabular}

\section{Actual Payback Period}

\begin{tabular}{|l|l|l|}
\hline Year & Cash Flow & Cumulative Cash Flow \\
\hline Investment (2015) & $10,000,000$ & $-10,000,000$ \\
\hline 2015 & $5,927,762$ & $-4,072,238$ \\
\hline 2016 & $4,564,448$ & 492,210 \\
\hline 2017 & $2,096,120$ & $2,588,330$ \\
\hline \multicolumn{2}{|l}{ Payback Period: 23 Months } \\
\hline
\end{tabular}

\section{Appendix 4}

Competitor Analysis for the year 2017

\begin{tabular}{|l|l|l|}
\hline Ratios & Motor Manufacturers & Simba Manufacturer \\
\hline ROCE & $2.8 \%$ & $14.7 \%$ \\
\hline Current Ratio & 3.0 & 0.85 \\
\hline Profit Margin & $24.7 \%$ & $43.4 \%$ \\
\hline Debt Ratio & 0.52 & 0.82 \\
\hline
\end{tabular}

\section{Appendix 5}

\section{SWOT Analysis}

\begin{tabular}{|l|l|}
\hline Strengths & $\begin{array}{l}\text { 1. The company is able to provide end-to-end suitable farming tools to both medium and } \\
\text { large-scale farmers. } \\
\text { 2. The tools provided by the company are quality designed and appropriate for the } \\
\text { environment of the country. } \\
\text { 3. The company has a research and development unit that comes up with innovative [projects } \\
\text { to undertake for its profitability. }\end{array}$ \\
\hline Weaknesses & $\begin{array}{l}\text { 1. The company has limited capital to execute its projects } \\
\text { 2. The company faces lack of government support in terms of material and technological } \\
\text { support which would have otherwise created investment more accessible. }\end{array}$ \\
\hline Opportunity & $\begin{array}{l}\text { 1. The agriculture industry in Tanzania is continuously growing therefore providing wider } \\
\text { adaptability of farmers to the machines that the company produces. }\end{array}$ \\
\hline
\end{tabular}




\begin{tabular}{|l|l|}
\hline Threat & $\begin{array}{l}\text { 2. Agriculture is the backbone of the economy of Tanzania that makes investment more } \\
\text { volatile }\end{array}$ \\
$\begin{array}{l}\text { 1. Government restriction and change in policies affects the company's decisions and } \\
\text { operations. } \\
\text { 2. Inflation status in Tanzania causes the company to make decisions with precaution in order } \\
\text { to avoid negative impacts. }\end{array}$ \\
\hline
\end{tabular}

\section{Appendix 6}

\section{Budgeting}

\begin{tabular}{|l|l|l|l|}
\hline \multirow{2}{*}{ Details } & Jun-2017 & Jun-2017 & \multirow{2}{*}{ Variance } \\
\cline { 2 - 3 } & Actual & Budget & \\
\hline Revenue & $59,470,769$ & $87,972,000$ & $(28,501,231)-3 \%$ \\
\hline Short term rentals & $1,611,360$ & 312,000 & $1,299,360$ \\
\hline Long term rentals & $6,642,657$ & $27,660,000$ & $(21,017,343)$ \\
\hline Hire Purchase/outright sales & $21,216,752$ & $60,000,000$ & $(38,783,248)$ \\
\hline Cost of Sales & - & $25,550,000$ & $(25,550,000)$ \\
\hline Cost of Sales & - & $25,550,000$ & $(25,550,000)$ \\
\hline Gross Profit & $59,470,769$ & $62,422,000$ & $(32,951,231)$ \\
\hline Other income & - & - & - \\
\hline Other Income & & - & - \\
\hline Operating expenses & $44,138,771$ & $38,552,179$ & $42,823,6205 \%$ \\
\hline Other expenses & 386,500 & 232,755 & 153,745 \\
\hline Advertising \& promotion & - & 838,719 & $(838,719)$ \\
\hline Audit \& consulting fees & - & 676,875 & $(676,875)$ \\
\hline Bank charges & 664,406 & 373,139 & 291,267 \\
\hline Client set ups & - & 31,500 & $(31,500)$ \\
\hline Electricity and water & $1,417,364$ & $1,611,256$ & $(193,892)$ \\
\hline Courier \& postage & - & 8,750 & $(8,750)$ \\
\hline Depreciation & $2,323,969$ & $2,535,637$ & $(211,668)$ \\
\hline Legal fees & - & 30,476 & $(30,476)$ \\
\hline Insurance & $11,034,605$ & $1,236,261$ & $9,798,343$ \\
\hline Levies & - & 113,750 & $(113,750)$ \\
\hline Motor vehicle - petrol \& oil & $1,450,000$ & $2,235,625$ & $(785,625)$ \\
\hline $\begin{array}{l}\text { Motor vehicle - repairs \& } \\
\text { maintenance }\end{array}$ & $4,604,300$ & $3,504,371$ & $1,099,929$ \\
\hline $\begin{array}{l}\text { Motor vehicle - insurance \& } \\
\text { license }\end{array}$ & - & 120,750 & $(120,750)$ \\
\hline Printing \& stationery & & 254,415 & $(254,415)$ \\
\hline Salaries \& wages employees & $22,257,900$ & $24,747,900$ & $(2,490,000)$ \\
\hline Profit Before Tax & $(15,332,058)$ & $23,869,821$ & $(1,611,921)-7 \%$ \\
\hline
\end{tabular}

Source: Motors Manufacturers Management

\section{Acknowledgement}

All thanks to The Almighty for giving me the ability of completing this review.

I would like to give special thanks to my friends and family who have provided me with continuous support throughout this review.
Special thanks to the Management of Motor Manufacturers (T) LTD and Auditor, Mr. Denis Demarco for providing information and financial data that was used for this review. 


\section{Reference}

[1] Walsh, C. (2003) Key Management Ratios (Third Edition) Harlow, UK: Pearson Education. Arnold, G. (2005) Handbook of Corporate Finance, Harlow, UK: Pearson Education.

[2] http://www.ieng-group.com/

[3] http://www.globdev.org/files/ProceedingsThird\%20Annual\%20SIG\%20Globdev\%20Worksho p/24-PAPER-Dedrick-Kraemer-Shih-IT-and-

Productivity.pdf

[4] http://www.vvenkatesh.com/wp-

content/uploads/2015/11/Venkateshetal_POM_2010. pdf

[5] http://faculty.usfsp.edu/gkearns/Articles2/benchm arking\%20IT\%20benefits.pdf

[6] http://www.hrmars.com/admin/pics/1576.pdf

[7] https://www.ncbi.nlm.nih.gov/pmc/articles/PMC4 084908/

[8] http://www.candor-holdings.com/equities/wpcontent/uploads/sites/2/2016/02/types_of_financial_r atios_19mar_2012.pdf
[9] https://www.coursehero.com/file/p1qis61/27-

Definition-of-Ratio-Ratios-has-been-defined-by-

different-authors-in-many/

[10] https://www.linkedin.com/pulse/budgetingeducational-management-basil-ezeugo

[11] http://conferinta2013.academiacomerciala.ro/_V

OLCONF2013PDF/volumconferinta/PURPOSE\%20

FOR\%20BUDGETING\%20-

\%20LITERATURE\%20REVIEW_pintea.pdf

[12] http://www.iiakm.org/ojakm/articles/2015/volum e3_3/OJAKM_Volume3_3pp17-26.pdf

[13] https://intranet.ecu.edu.au/data/assets/pdf_file/00 10/357193/Benchmarking-Literature-Review.pdf [14] http://www.proz-

x.com/stephanlangdon/Library/CESACORE/Prentice $\% 20 \mathrm{Hall} \% 20$ Exploring\%20Corporate $\% 20$ Strategy $\%$ 208th.pdf

[15] http://www.cek.ef.uni-lj.si/magister/torteska976B.pdf

[16] https://esa.un.org/techcoop/documents/pn_invest menttechnologypolicynote.pdf 


\title{
Implications of Water Development Projects on Community Welfare; The Case of Eloumden I Mbankomo Sub Division, Mefou and Akono Division
}

\author{
Roosevelt \\ MBA Project Management, Texila American University \\ E-mail: mbaroosevelt@gmail.com
}

\begin{abstract}
Global trends like desertification, urban growth, and economic restructuring are making water increasingly scarce and water access increasingly inequitable in cities around the world. While much is being done to extend water provision systems to most communities, the roots of water scarcity are complex and difficult to resolve. Today, as communities face water scarcity challenges, research is needed to help mitigate its impact on the environment and human welfare. The aim of this research is to establish the implication of water development projects on community welfare in the Eloumden I community through determining the different waters sources, knowing the causes of water supply problems in the Elounden I community and examining the various health related hazards caused by water crisis in this community. The research performed participant-observation, direct observations, and survey interviews in an impoverished, water-scarce neighborhood in Elounden I community. The study contains a thorough discussion of the definition and operationalization of the "community water scarcity" concept, including water provision, water sources, and the environmental impact. The data indicate that water scarcity greatly affect the health situation of the population of this community. When people are first hit by severe water scarcity, the health concerns become more intense.
\end{abstract}

Keywords: Water, Development Projects, Community Welfare1 General.

\section{Introduction}

\section{Background to the Study}

Water is a basic need, an essential resource for survival to secure good health and therefore all access to safe drinking water is right to all. People need water for various domestic purposes like drinking, cooking, sanitation, and irrigation. Besides domestic use, people also need water for other diversified livelihood activities including livestock, gardening, cropping, food processing, aquaculture and fisheries (Soussan 2003; Kopper et al. 2006). In rural and peri- urban areas of developing countries. People around the world face the problem of water scarcity. Scarcity of water forced the people to use unsafe water for drinking and other domestic purposes (WHO, 2009). About 1.7 billion people in developing countries have no access to safe drinking water (Health UNICEF, 2013).

As a result, about $50 \%$ of population in the developing countries suffered from water- borne diseases such as diarrhea, cholera, ascaris, hookworm (Murcoot, S., 2001). About 10 million people die each year due to intervention of some 500 million new cases of waterborne diseases (Snyder, J. D., Merson. M. H., 1982). When people do not have access to safe water supply and sanitation, there will be higher risk in their health condition. Diarrheal infection alone is responsible for 1.8 million deaths a year worldwide, of which $90 \%$ are children under age of five (WSSCC, 2010). Like water, sanitation is also a basic way to ensure healthy life. Parallel to water, sanitation is a serious health risk and affront to human dignity. Sustainability of water supply system depends on social acceptability, social viability and technical and environmental sustainability.

While the world's population tripled in the $20^{\text {th }}$ century, the use of renewable water resources has grown six-fold. Within the next fifty years, the world's population will increase by another 40 to 50 percent. This population growth coupled with industrialization and urbanization will result in an increasing demand for water and will have serious consequences on the environment. (World Water Council, 2014). In spite of the 
importance and apparent abundance of water, most of sub- Saharan Africa faces a serious water scarcity problem (Obed Fung, 2013).

Africa faces huge challenges with multiple issues that adversely affect public health. One major challenge is the ability for both rural and urban Africans to access clean water supply.

The situation of access to clean water and sanitation in rural Africa is even more dismal than the previous statistics imply. The WHO (2006) stated that, in 2004, only $16 \%$ of people in subSaharan Africa had access to drinking water through a household connection (an indoor tap or a tap in the yard). Not only is there poor access to readily accessible drinking water, even when water is available in these small towns, there are risks of contamination due to several factors. When wells are built and water sanitation facilities are developed, they are improperly maintained due to limited financial resources. Water quality testing is not performed as often as is necessary, and lack of education among the people utilizing the water source leads them to believe that as long as they are getting water from a well, it is safe. Once a source of water has been provided, quantity of water is often given more attention than quality of water (Awuah et al. 2009).

There are limited sources of water available to provide clean drinking water to the entire population of Africa. Surface water sources are often highly polluted, and infrastructure to pipe water from fresh, clean sources to arid areas is too costly of an endeavor. Groundwater is the best resource to tap to provide clean water to the majority of areas in Africa, especially rural Africa, and groundwater has the benefit of being naturally protected from bacterial contamination and is a reliable source during droughts. However, the high costs associated with drilling for water, and the technical challenges in finding sources that are large enough to serve the population in need, present challenges that limit tapping the resource. Groundwater is not a safe resource, either, when it comes to providing clean water. There may be contamination of the water with heavy metals, and bacteria may be introduced by leaking septic systems or contaminated wells. For these reasons, it is important that groundwater be monitored frequently, which is costly and requires technical abilities that may not be present in rural areas (Awuah, et al., 2009).
Here are some African statistics to assert the above which $6 \mathrm{~km}$ is the average distance African women must walk in order to collect water. Also, 20 liters of water is the average weight that African women carry on their heads (elena96, 2017).

Over the last decade, the water crises in Elundem I community has worsened as rapid urbanization into Cameroons capital Yaoundé, and other towns such as Douala and Buea have rendered the existing infrastructure extremely inadequate. According to a report by Anthony B. Ndah and XiongzhiXue, for a country endowed with freshwater sources, only an estimated $40 \%$ of Cameroon's population has access to portable water. Majority of those without portable water turn to wells, rivers and lakes for drinking water whose quality, for the most part, is usually compromised by their proximity to biological and industrial waste. Though UNICEF and the World Health Organization (WHO) recently celebrated the attainment of the 2015 Millennium Development Goal (MDG) target of having the proportion of people with access to safe drinking water, Cameroon unfortunately did not meet these goals.

\section{Statement of the Problem}

Some communities in Yaoundé and Cameroon in general stay without water for about a month; or could have a non-consistent water flow; water flows only a few hours, usually at night.

Taps have run dry in most parts of the city. Those who cannot go to regularly supplied places like military barracks have turned to wells, streams and springs. Others are forced to drive far out of town to fetch clean water (Eugene Nforngwa, 2014). Consequently, local authorities have failed to provide neighborhoods with adequate utilities, services, and infrastructure.

Water like everywhere in the world, is becoming both a scarce and a crucial resource; particularly because both people and industries need water and electricity for survival. Eloumden I community is not an exception, as many households do not receive a regular supply of water. The problem is escalating at an alarming rate as the number of households in the Community increases rapidly. These developments therefore, call for an investigation of the impact of water shortage on the health situation of members of the households in the community. 


\section{Objective of the Study}

\section{Main objective}

The main objective of this work is to establish the implication of water development projects on community welfare in the Eloumden I community.

\section{Specific objectives}

- To determine the different waters sources

- To know the causes of water supply problems in the Elounden I community.

- To examine the various health related hazards caused by water crisis in this community

\section{Research Questions}

\section{Main research question:}

- What is the intensity of water crisis on the health situation in the Elounden I community?

\section{Specific research questions}

- What are the different water sources in the Eloumden I Community?

- What are the causes of water supply problems in Eloumden I community?

- What is the various health related hazards caused by water crisis in this community?

\section{Scope of the Study}

The present study assesses potable water resources and their suitability for drinking with the challenges faced in water supply management. This study was carried out between, August and October 2020. The study was centered in North East of Mbankomo sub Division specifically at Eloundem I which is composed mostly of new residential units. Population Sampling and data collection, was done following a convenience sampling system. This research is based on qualitative and quantitative data collection in Eloundem I. Eloundem I is not an isolated case, but represents a broader national problem of water crisis. This research therefore only focuses on Eloundem I, located in North East of Mbankomo sub Division. Only water scarcity and the health situation of the community is taken into account and does not include aspects of community life.

\section{Research Localization}

Located in the Mefou Akono Division, Mbankomo sub division, Eloumden I am a village half nested in the city of Yaoundé, this because of urbanization, it is the border village of the Mfoundi Division and that of Mefou Akono through the sixth Subdivisions of Yaoundé. It is an industrial village that deals with quarries the produce construction materials for civil engineering like the Arab contractor Egyptian firm which is the leader. They hire young people in this locality and are responsible for several road works. We also have the Chinese wood processing companies (kanap wood), mineral water treatment companies (valclair) and many others. This thus facilitates the reduction of the unemployment rate as well as the development of infrastructural Development. 


\section{Map of Eloundem I Community}

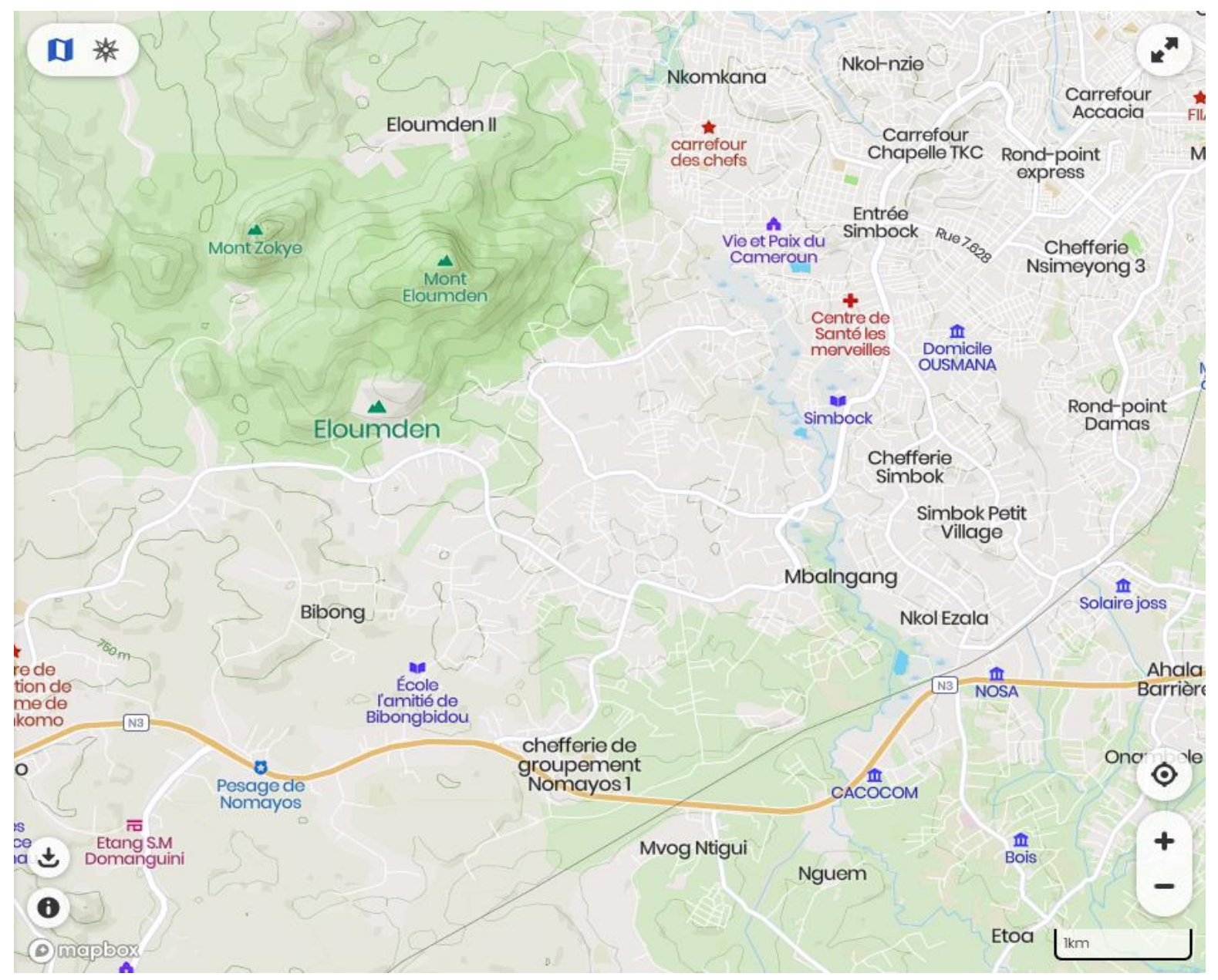

Source: Author adapted from Mapcarta (2020)

\section{Literature Review and Theoretical Framework}

Water scarcity is as a result of an imbalance between the supply of and demand for water sources in a geographical area. A limited or inadequate water supply is one of the toughest issues facing the world's poorest countries, but the populations of these countries are not the only ones to endure the burden of water scarcity. As Levy and Sidel correctly pointed out, distribution in water-strained settings is the source of numerous conflicts globally.

To begin, water crisis or water scarcity as stated by Jaeger, W. K, et al. (2013: Pp1), may appear to be a simple concept, but it can be difficult to apply to complex natural-human systems. While aggregate scarcity indices are straightforward to compute, they do not adequately represent the spatial and temporal variations in water scarcity that arise from complex systems interactions. The uncertain effects of future climate change on water scarcity add to the need for clarity on the concept of water scarcity. Starting with a simple but robust definition, the marginal value of a unit of water they highlight, they highlight key aspects of water scarcity and illustrate its many biophysical and socioeconomic determinants. They make four central observations. Firstly, water scarcity varies greatly across location, time, and a multitude of uses that are valued either directly or indirectly by society. Secondly, water scarcity is fundamentally a normative, anthropocentric concept and, thus, can and should be distinguished from the related, purely descriptive notion of water deficit. Thirdly, the ability to understand and anticipate changes in water scarcity requires distinguishing between the factors that affect the value or benefits of water from those affecting the costs of transforming water in space, time and form. Finally, the robust and rigorous definition of water scarcity will facilitate better communication and understanding for policymakers and scientists. 
Chévarrro Jimena (2015) explains the history of the human right to water and examines its main content and the obligations that derive from this right. To her, the main purpose of the recognition of the human right to water is to guarantee everyone access to sufficient, safe and affordable drinking water to satisfy personal and domestic uses. She discusses on whether the human right to water is recognized as a derivative right or as an independent right at three levels: universal, regional and domestic.

Chellaney Brahma (2013) sketches a bleak picture of water scarcity in Africa, Asia, and the Middle East, regions also struggling with unstable governments and rapidly growing populations. What he calls "water stressed conditions" are also appearing in developed countries, such as Spain, Australia, and South Korea. Even the deep-water aquifers that support modern agriculture in North America are dwindling. But will the social and environmental stresses of water shortage lead to conflict and armed violence? On that question, Chellaney is speculative. To him, conflicts over water have already embroiled states along the Tigris Euphrates basin, in the Middle East, and the war in Darfur has been partly caused because of water shortages. He makes it clear that such conflicts will become more common as water begins to be "used as a weapon".

Marq de Villiers (2015) agrees that water problems persist but argues that they are more localized than global, and that local issues such as water shortages, pollution, ownership, and distribution are all "more tractable, easier to solve, not harder" than worldwide ones. In five sections, he addresses water issues with equal parts caution and confidence. He writes that the state of groundwater, for example, is "dire" but hardly catastrophic, depending on the region. The same goes for the world's rivers, which are in big trouble, but not so far gone that they cannot be saved.

Marq de Villiers (2003) describes the ecological damage incurred by the use and abuse of water sources. Through pollution, diversion, and degradation, industrialization of the world has taken a heavy toll on water quality. To him, "Humans consume water, discard it, poison it, waste it, and restlessly change the hydrological cycles, indifferent to the consequences: too many people, too little water, water in the wrong places and in the wrong amount. The human population is burgeoning, but water demand is increasing twice as fast".

\section{The Cameroon WASH Institutional Framework}

Water governance has been described as the range of political, social, economic and administrative systems that are in place to develop and manage water resources and the delivery of water services at different levels of the society (Pittman, 2008). Hence, improving governance in the water sector is not only about government systems and services delivery. Rather, it encompasses a much broader range of factors including engaging civil society, non-state agents and their relationship to government.

According to the Water Partnership Program (WPP) of the African Development Bank (ADB), sustainable services in water governance are not achieved without the involvement of other stakeholders and particularly water users in the development of policies and laws for sector development (WPP-ADB, 2008). The overall purpose of a sector policy is to serve as the means for establishing and maintaining the enabling environment necessary for sector development (Mogranahan et al, 2006).

In terms of legislation, the water sector in Cameroon is governed by decree $\mathrm{n}^{\circ} 98 / 005$ of 14 April 1998. Masanga, (2014) however argues that, the 1998 national water law is limited as it was not elaborated within the framework of integrated water resource management. This law, according to this scholar, failed to address some of the key principles of sustainable water resource management like the management of water in hydrological basins, effective stakeholder participation and economic value of water.

Nonetheless, in Cameroon, the WASH sector has undergone a series of reforms aimed at improving water governance and promoting effective service delivery. Among the reforms undertaken by government to redress this situation was the privatisation of the then National Water Corporation (SNEC) that was launched in 1999 and concluded in 2008. It was expected that privatization was going to play an increasingly important role in the provision, rehabilitation and maintenance of infrastructure.

The WASH sector is divided in two subsectors. Notably, the urban sub-sector (urban areas) and the rural sub-sector (for rural areas). 
Most of the reforms carried out in this sector fall under the water sector; mostly in the urban water supply sub-sector. In the main time, there exists no institutional structure particularly responsible of the sanitation sub-sector (CSO, 2015)

The rural water supply sub-sector is placed under the direct supervision of the Ministry of Water Resources and Energy (MINEE), through its Directorate of water supply and hydrology (DHH). Without any specific guidelines or national policy in respect with sanitation, the activities of the DHH focus mainly on the construction of water supply facilities and organisation of the supply of drinking water in rural areas (CSO, 2015).

As reported in the Growth and Employment Strategic Paper (GESP), within the framework of the urban water supply policy letter of 2007, the government of Cameroon had adopted the publicprivate partnership policy in the urban areas.

The implementation of this policy is the responsibility of the state-owned company; Cameroon Water Utilities Corporation (CAMWATER), with supervision from the SubDirectorate of urban water supply and sanitation (DEAU). Camwater was created in December 2008, to replace the defunct Société National des Eaux du Cameroun (SNEC). The efforts of Camwater were to be complemented by la 'Camerounaise des Eaux' (CDE), a Moroccan private operating company through the signing of a lease agreement with Camwater in April 2008. CDE was charged with the responsibilities of producing, distributing, maintenance of infrastructure and marketing of safe drinking water up till April 30, 2018 when this contract comes to an end (GESP).

In spite of the putting in place of the required building blocks for the institutional framework, in the WASH sector, water experts hold the fact that, there exist no formal national water policy for the integration, application and enforcement of water legislation (Masanga, 2014). As a result, Cameroon is still unable to ensure regular, adequate and sustainable water and sanitation provision to a greater proportion of its citizens. The 2015 Cameroon country status overview (CSO) published by AMCOW reported that, Cameroon still lack an operational programmatic approach that would not only enhance the conduct of proper needs assessment, but also would enable the establishment of plans based on priority criteria; thus, leading to a harmonization plan on the use of finances (CSO, 2015). The Cameroon WASH institutional framework consequently suffers from a certain number of road blocks among which;

- Large number of sector players leading to fragmentation, over lapping of responsibilities and poor coordination of operations.

- The transfer of power in favour of councils has not been accompanied by adequate allocation of financial resources to enable them effectively assume the duties entrusted them.

- Limited coordination between the different ministries involved in the sector and the other asset holding company like Camwater.

- The problem of ownership of facilities and responsibilities for their maintenance and renewal still yet to be resolved as the decentralization process in Cameroon is on a slow pace, with the roles of the councils in the sector that remain largely theoretical. As such, the demand responsive approach pruned in the national water supply and sanitation (WSS) policy for rural areas remains limited.

- The private sector is not particularly active in the rural areas and only a few numbers of NGOs are actually involved in the construction of tertiary services.

- The National Water Committee (CNE) created by decree to coordinate the water subsector activities is not yet operational.

- Corruption and embezzlement of funds (CSO, 2015).

\section{Theoretical framework}

\section{The Theory of Change}

Change in theory is based on an approach that depends on the underlying problem, the context and assumptions. However, Taplin et al think that, at its very heart, a theory of change spells out initiative or program logic. According to these scholars, a theory of change defines long-term goals and then maps backward to identify changes that need to occur earlier, known as preconditions. The identified changes are then mapped graphically in causal pathways of outcomes, showing each outcome in logical relationship to all the others. While interventions, which are the activities and outputs of any sort, are mapped to the outcomes pathway to show 
what stakeholders think it will take to effect the change, and when (Taplin et al, 2013).

The essence of any project is to take a people from a less desirable condition A to a more desirable one B. That is, bring about a positive change in the lives of the beneficiaries. Simply put, the idea behind every development intervention is that, by undertaking an action $\mathrm{X}$, it will lead to the achievement of progress Y. Based on the premise that every development intervention is expected to positively impact the livelihood of communities, an underlying theory of change will clearly articulate the logic between the intended activity (the 'if 'part), and the expected change it will generate (the 'then' part) (Care, 2012).

Just like a logical framework describes the hierarchical logic between activities, and their expected outcomes, a grounded theory of change offers a clearer picture of results intended to emanate from an action. In this perspective (Colby et al, 2013) holds that, a well-articulated theory of change provides a working model against which testable hypotheses and assumptions regarding how the planned activities will best contribute to achieving the desired results.

The water and sanitation sector and more especially the rural WASH sector is a complex adaptive system consisting of multiple actors and relationships, all of which need to work together effectively for success to be achieved. In this light, Shouten stresses that, at the heart of a given approach to change, is a vision of how the rural water sector needs to function if sustainable water and sanitation services are to be provided, and a set of guiding messages intended to inspire stakeholders to start creating change in their own context (Shouten et al, 2013).

Change is all about people; there is therefore a need to adequately identify the actors to work with in any community development intervention. Moreover, projects that spring up from contextual realities based on community analysis and assessment, and proper identification of relevant stakeholders (inputs) are more likely to bring about the expected change. Nonetheless, most WASH supply projects focus on the 'hardware' that is, the physical infrastructure, ignoring the knowledge and behaviours aspects that constitute the 'software', and upon which the achievement of project goal, to create the expected change depends to a greater extend. Consequently, project end up building water and sanitation infrastructure instead of providing water (Moriarty et al, 2013).

\section{Methodology}

\section{Population}

Eloundem I have an estimated total population of $\mathbf{1 8 , 0 0 0}$ people. The unit of analysis was the individual households and water providers while the unit of observation which was the target population comprised of the respondents from the sample survey. Simple random sampling and purposive sampling was used to obtain a sample from a sampling frame of all the households in the study area.

\section{Sample and Sampling Procedure}

The sample size given that the target population was 18,000 at a confidence interval of $95 \%$ and the error margin of $5 \%$, the sample population was 100 respondents (Fisher et al., 2008). As earlier noted, the water sector was selected due to the basic role the resource plays in our lives. The unit of analysis was individual households while the unit of observation was the respondents from the sample survey. Simple random sampling was used to obtain a sample from a sampling frame of all the households in the study area. The researcher selects who to be included in the study based on their ability to provide necessary data but most importantly for those who are willing and available. The rationale for choosing this approach was that the researcher was seeking knowledge about; water crisis in the Elounden I community which the respondents would provide by virtue of their experience.

\section{Data Collection Methods and Instruments}

In this study, both primary and secondary data were collected. Primary data provided the researcher with first-hand information on the subject matter, and this could be attained through observations, interviews as well as questionnaires. On the other hand, the secondary data collection was gotten from existing information from other similar works and related articles.

\section{Questionnaires}

The questionnaires administered to the respondents were divided into five sections. The first section was a letter to the respondent with the 
personal information of the researcher (school, dissertation theme). We had to move from home to home asking the questions ourselves while ticking and filling where necessary. Section 2 was the demographic profile of the respondent, which collected personal information about the respondent such as the gender, level of education (others specify), and number of years living in Elounden I community. Section 3 was to get the opinions of respondents on water crisis in their community. Section 4 sought to get their opinion on the water governance system in Elounden I community. Part 5 tried to know about alternative water sources found in their community.

\section{Interviews}

Here, some water supply actors were interviewed based on their accessibility and availability. Face to face interview was conducted, and main interviews were conducted with Senior Technical Staffs of the SubDepartment of Drinking Water Supply in Urban and Rural Areas in relation to the water crisis. Also, an interview was carried out with .... Still there was an interview with the Chief/Quarter Head of Elounden I community as regards water issues plaguing their community. Answers to the questions were given and the researcher wrote them down as they responded.

\section{Observation}

Observation method was used to determine the impacts of water shortage in Elounden I community. The researcher observed the activities related to water for a period of three months to assess the impacts posed by water shortage in Elounden I community and find out possible solutions to the problems. The observations were recorded in a note book and photographs on activities revolving around the water sites taken during field trips.

\section{Analytical Approach}

The data collected were subjected to inferential statistical analysis which included discussing general characteristics from a sample population. The qualitative method was also used to interpret data from the interviews and social surveys; both made in the Elounden I community, and to water actors. The data analysis was based on the study objectives and research questions. After all data was collected, the researcher identified incomplete or inaccurate responses, which were corrected to clarify the quality of the responses. The responses from the questionnaires, interview schedules and observation schedules were coded into statistical package for social sciences (SPSS) version 20 for analysis. Qualitative data was analyzed using content analysis based on analysis of meanings and implications emanating from respondents' information and documented data. It was summarized into meaningful statements, which were used to supplement the quantitative data to enrich the interpretation of the findings.

\section{Validation of the Results}

Our work is acceptable in the sense that after the qualitative and quantitative analysis being carried out, truths and facts about the water problem in Elunmden I community is brought to light. At the end of the study, results acquired could be replicated and compared to other communities facing similar experiences of water crisis.

Validity is defined as the accuracy and meaningfulness of inferences, which are based on the research results (Mugenda \& Mugenda, 1999). Validity, according to Borg and Gall (1989) is the degree to which a test measures what it purports to measure. All assessments of validity are subjective opinions based on the judgment of the researcher (Wiersma, 1995). Again, according to Borg and Gall (1989) content validity of an instrument is improved through expert judgment. As such, the researcher sought assistance of the supervisors, who, as experts in, research, helped improve content validity of the instrument.

\section{Presentation of Results and Discussion}

In any scientific research, the data collected from the field requires being treated using appropriate statistical methods which are recognized in the domain of social sciences so as to confirm research questions and explain findings related to the study. In our work, we used the descriptive and inferential statistical analysis so as to understand our research.

\section{Sources of Water}

In the study, the first objective was to assess the sources of water in Eloundem I community. The first research question sought to achieve the objective by finding out the sources of water at Eloundem I community. The following water 
sources were identified in Eloundem I community Main sources of water for the households were; piped water from boreholes, shallow wells and running stream water. The water sources information is represented in the figure below.

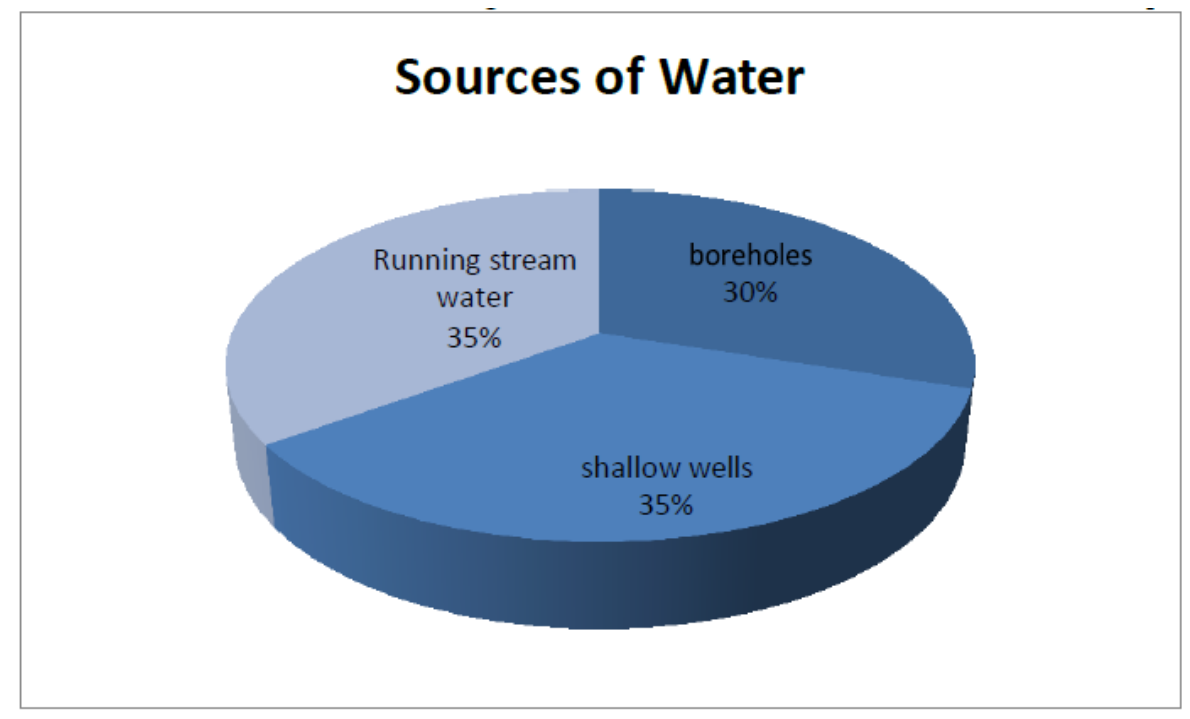

Figure 4.1. Sources of Water in Eloundem I community

Figure 4.1 above illustrates the proportions of the respondents who use the different sources of water in the research area. From the figure 4.1 above, $35 \%$ get their daily water from running streams around the community, $35 \%$ obtain the water from shallow wells, $30 \%$ from boreholes. The respondents depending on the piped boreholes for water supply spend some amounts of money as charges for the water. Most of them pay for water per 20 litter containers, $70 \%$ have the charges included in the rent and spend 1500FCFA per month on water. Based on their varied income, this resulted to use of much money on water since they spent extra cost when the water is not available in the taps by buying from water vendors and water kiosks. The income of most respondents was very little. Employed (33.6\%) lowest income was 30,000FCFA per month and the highest income was above 300,000 FCFA per month. For the business persons (59.4), the lowest income was 50,000 FCFA per month and the highest income 500,000 FCFA per month which varied according to the market trends and the health of the economy. The other $7 \%$ of the respondents were unemployed and paying the monthly water charges as well as buying water was very expensive for them. The respondents agreed that acquiring water was expensive for them and was evident from the charges paid for the water.

The figure below shows an improvised water collection point.

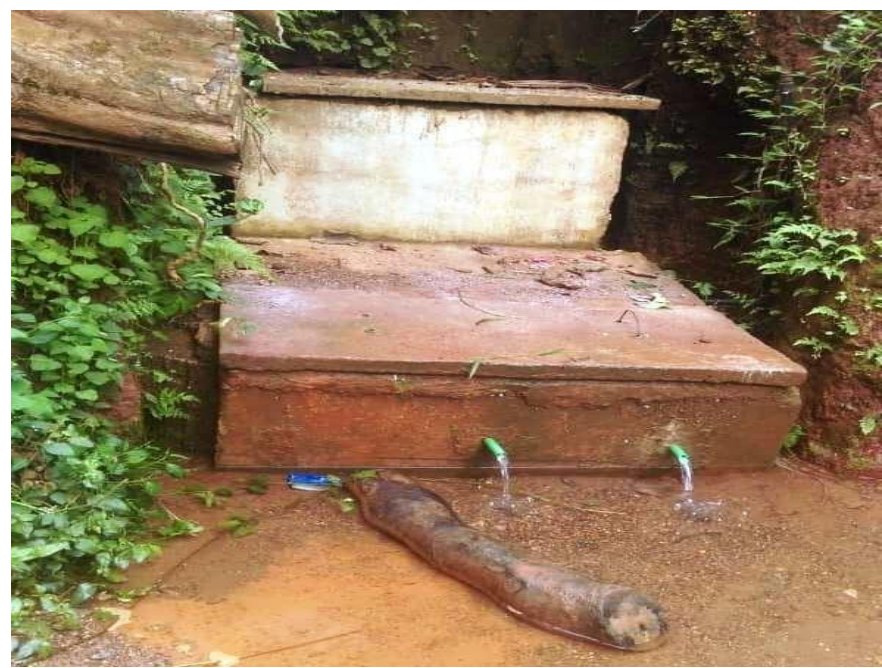

Plate 4.1. Plate indicating an improvised water collection point (Photograph; 17/ 09/2020) 


\section{Causes of Water Supply Shortage}

The second objective of the study was to identify the causes of water supply shortage in Eloundem I community. The second research question sought to find out the causes of water supply in Eloundem I community. The possible main cause of water supply problems is the unexploited water resources of this area.

From research there exist areas with spring water with production volume of about 20 liters per second. Meaning within one minute five families can collect water if this source is been developed but unfortunately nothing is been done to exploit such a lofty resource.

\section{Health and Socio-Economic Effects of Water Crisis at Eloumden I}

The third objective of the study was to evaluate Health and Socio-Economic impact of Water Crisis at Eloumden I. The third research question sought to find out the Health and SocioEconomic Effects of Water Crisis at Eloumden I.

The research investigated the water related diseases in Eloumden I. The diseases identified were diarrhea, Typhoid, Malaria and Dysentery and their effect on the households were categorized in terms of employed, business persons and the unemployed. The results obtained were represented in the table below.

Table 4.4. Water borne diseases related to water in Eloumden I.

\begin{tabular}{|l|l|l|l|l|l|l|l|l|l|l|l|}
\hline Occupation & \multicolumn{2}{l}{ No disease } & \multicolumn{2}{l}{ Diarrhea } & \multicolumn{2}{l|}{ Typhoid } & \multicolumn{2}{l|}{ Malaria } & \multicolumn{2}{l|}{ Dysentery } \\
& Freq & $\%$ & Freq & \% & Freq & \% & Freq & \% & Freq & \% \\
\hline Employed & 25 & 53 & 2 & 6 & 10 & 24 & 5 & 10 & 3 & 7 \\
\hline Business Persons & 15 & 50 & 5 & 18 & 3 & 10 & 5 & 18 & 2 & 4 \\
\hline Unemployed & 10 & 40 & 5 & 20 & 1 & 4 & 8 & 32 & 1 & 4 \\
\hline
\end{tabular}

Source: Field survey 2020

Table 4.4 above indicates that, $53 \%$ of the employed respondents said that there were no cases of water borne related diseases, $6 \%$ of the employed said there were cases of diarrhea, $24 \%$ had typhoid, $10 \%$ suffered from Malaria, $7 \%$ for dysentery and there were no cases of cholera in this area. According to the business persons, 50\% of them said there were no cases of diseases, $18 \%$ said they had experienced diarrhoea, 10\% suffered from typhoid, $18 \%$ from malaria and $4 \%$ said there were cases of dysentery. Unemployed respondents had almost similar responses with $40 \%$ saying there were no cases of water related diseases, $40 \%$ said there were cases of diarrhoea $4 \%$ suffered from typhoid, $32 \%$ from malaria and
$4 \%$ also confirmed that there were cases of dysentery. Due to reduced quantities of drinking water, some respondents said that they were forced to take chances, buy and consume water which they were not sure of the sources and at times is not fit for consumption leading to the mentioned water borne diseases (diarrhoea and cholera). This has impacted negatively on the health of some members of the population resulting to low output in terms of labour. They may not perform their duties as expected hence reduced output in production which negatively affects the economy and development of Eloumden I.

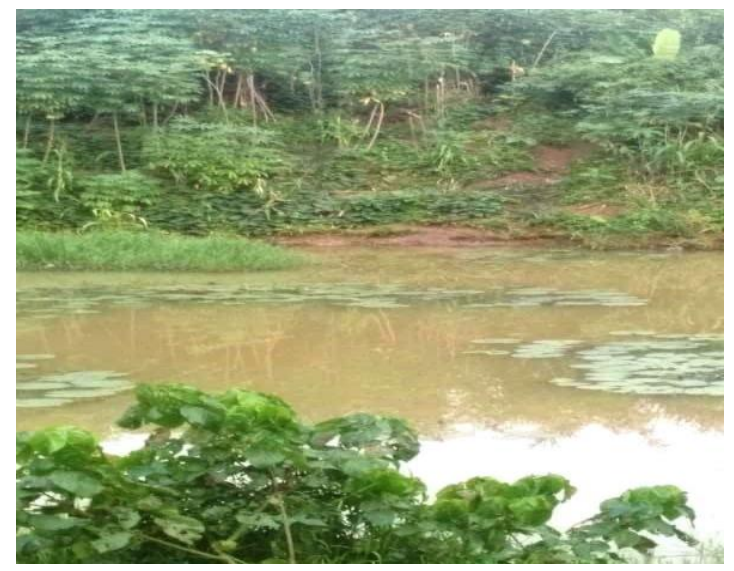

Plate 4.3. Plate indicating water source which doubles as a breathing ground for mosquitoes (Photograph; 17/ 09/ 2020) 


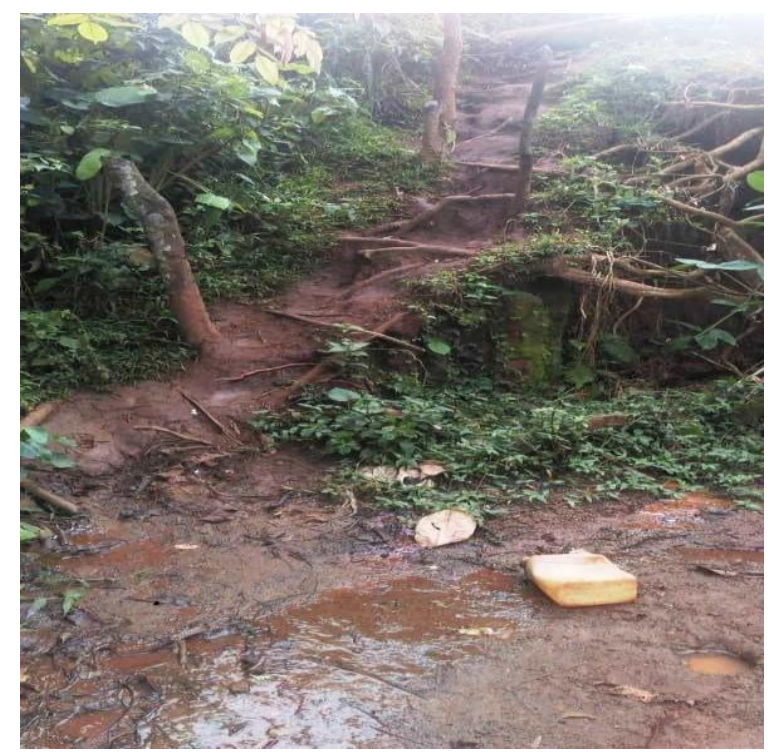

Plate 4.3. Plate showing accessibility to water collection point (Photograph; 17/ 09/2020)

From the analysis, $96 \%$ of the respondents said there was poor sanitation and low standards of cleanliness while $4 \%$ said that there was no effect of water supply shortage on the sanitation of their residential areas. These results are with line with those of water shortage by Kimani et al., (2007) that water has a major effect on the sanitation of an area especially in the urban areas.

\section{Recommendations and Conclusion \\ Recommendations}

Based on the analysis of the study, the researcher wishes to make the following recommendations;

Water actors should involve the community to aid in water maintenance, development programmes and water provision projects. Members of the community should come up with other ideas to supplement the current water sources and make communal contribution to support that e.g. drilling more boreholes, wells and implementing any water conservation techniques that may be beneficial.

The government should organize more capacity building programmes for both water actors and the households (members of the community) to equip them with adequate skills and abilities to handle any issues that are related to water.

The households should embrace maximum use of roof water harvesting in most buildings so as to collect a lot of water during the rainy seasons.

The study mainly evaluated the water crisis on health situation in the EloumdenI community. The researcher recommends further research on:
- The impacts of water crisis on health situation on other areas in the country other than evaluate the water crisis on health situation in the EloumdenI community.

- The strategies being employed by the government to develop water facilities in EloumdenI community and other parts of the country.

- A case study of an area that has well exploited water resources to use as a model in the case of Eloundem I.

\section{Conclusion}

The study established that the respondents had adaptive measures to ensure that water is available despite the problems in water supply. This is possible mainly by expiating the available springs along the slopes of mount Eloundem. Others depend on borehole water and shallow well which supplement the water supplied from other sources. This ensures that the daily activities that require water are not severely affected and the health situation of this area is ameliorated.

The first objective was to assess the main sources of water. From the findings it was noted that the sources of water were three mainly, of which most of them were unhealthy. With $75 \%$ of them using water from sources judged uncertain and unhealthy. This showed that there was a major problem of water.

The second objective was to investigate the causes of water supply crisis. The study established main cause of water supply problems is the unexploited water resources of this area. 
The third objective was to investigate the health and socio-economic impacts of water crisis. The study established that a lot of money was spent community members that contracted disease from unhealthy water sources. This has affected the health of the individuals and a lot of finances used on the treatment would have been used for development. There were also conflicts related to water. This has socially affected the members of the community. In the study, females are the most affected members of the community in water collection activities since they are involved in home chores. This negatively affects them since they have few chances for decision making and involvement in other development activities.

\section{References}

[1] Alcamo, J., et al. (2007). Future long-term changes in global water resources driven by socioeconomic and climatic changes, Hydrological Sciences, 52, pp. 247- 275.

[2] Antao, C.et al. (2007). An integrated water, sanitation and health strategy for the municipality of Ruiru, Kenya. School of International and Public Affairs (SIPA), Columbia University, New York.

[3] Balance, T. and S. Tremolet, (2005). Private sector participation in urban water supply in SubSahara Africa, quoted in: Agro Paris Tech and Group SUEZ: Management Contracts in Developing Countries, pp .8-9.

[4] Barkatullah, N. (1999). Pricing, Demand Analysis and Simulation: An Application to a Water Utility.

[5] Barlow, M., (1999). The water crisis and the commoditization of the world's water supply. Special report International Forum on Globalization Sausalito: CA.

[6] Bouwer, H., (2002). Intergrated Water Management for the 21st Century. Problems and solutions.

[7] Burrows, et al. (2004) Water and Sanitation: The Education Drain. Brooks, N. and Sethi, R., (1997). The Distribution of Pollution: Community Characteristics and Exposure to Air Toxics Journal of Environmental Economics and Management, 32, 233-250.

[8] Bryan, E. et al. (2009). Adaptation to Climate Change in Ethiopia and South Africa: Options and Constraints Environmental Science and Policy, 12 (4). [9] Catherine Dion (1998). "Monitoring of Pollution Regulation: Do Local Conditions Matter?" Journal of Regulatory Economics; 13: 5-18.

[10]Chartres, C. and Varma, (2010). Out of water. From Abundance to Scarcity and How to Solve the
World's Water Problems USA: FT Press.

[11] Channing L. Bete Co. Inc., (1981). The ABC's of Water Conservation.

[12]Choldin, H., (1978). Urban density and pathology. Annual Reviews, Sociology, Vol 4, pp 91113.

[13]DFID, United Nations Development Programme (UNDP) and World Bank (W.B)., (2002) Linking Poverty Reduction and Environmental Management: Policy Challenges and Opportunities, Discussion document prepared for World Summit on Sustainable Development.

[14]Diwakar $\mathrm{H}$ and $\mathrm{N}$ Nagaraj (2002), Impact of Water Pollution on Food Security and Environment: Bearing the Brunt, Wasteland News, August-October. [15]Euromonitor Global Market Research Blog, (2010).

[16] European Commission (2007b). Water Scarcity and Droughts. Second Interim Report. DG Environment, June 2007.

[17]European Commission (2007c). Addressing the challenge of water scarcity and droughts in the European Union. Communication from the Commission to the Council and the European Parliament, COM (2007)414.

[18] Fisher, A., Corbet, A.., and Williams, C. (2008). The relation between the number of species and the number of individuals in a random sample of an animal population." Journal of Animal Ecology, 12: 42, 58. 763, 764.

[19]Food and Agricultural Organization (FAO) and Jim Kundell., (2008). Water Profile of Kenya, in: Cutler J. Cleveland (eds.) Encyclopedia of Earth Washington, DC: Environmental Information Coalition, National Council Science and the Environment.

[20] Gleick, Peter., (1993). Water in Crisis. New York: Oxford University Press

[21] Gleick, P., (1999). The world's water, the biennial Report on water Resources. Washington DC: Island Press.

[22] Government of Karnataka, (2000). Rural Water Supply and Sanitation in Karnataka-Strategy Paper 2000-2005, Rural Development and Panchayat Raj Department, Bangalore. Government of Karnataka, (2001). Study on Rapid Sector Assessment in Karnataka, Project Planning Monitoring Unit, Rural Development and Panchayat Raj Department, Bangalore.

[23] Government of Karnataka, (2002-03). Annual Report on Rural Development and Panchayat Raj Department: Bangalore.

[24] Government of Karnataka, (2002)). Report of the 
High-Power Committee (HPC) for Redressal of Regional Imbalances, Bangalore.

[25] Government of Karnataka, (2004), State of Environment Report and Action, Department of Ecology, Environment and Forest: Bangalore.

[26] Gray, H., and Alde, M., (2007). Are Rural-Urban Migration and Sustainable Development Compatible in Mountain Systems Mountain Research and Development Vol 27(2), pp 119-123. Herrero, M., Ringler, J., Van de Steeg, P., Thornton, T., Zhu, E., Bryan, A., Omolo, J. Koo, A, Notenbaert., (2010). Kenya: Climate variability and climate change and their impacts on the agricultural sector, ILRI report to the World Bank for the project "Adaptation to Climate Change of Smallholder Agriculture in Kenya.

[27] Hoekstra, A., and Chapagain, A., (2007) Water footprints of nations: water use by people as a function of their consumption pattern. Water Resource Management, 21, pp. 35-48.

[28] Intergovernmental Panel on Climate Change, (2001): Impacts, Adaptation and Vulnerability. Janakarajan, S., (2002). Conflicts over the Invisible Resource: Is there a Way Out? in Moench, M., Elizabeth Caspari and Ajay Dixit (eds.) Rethinking the Mosaic: Investigations into Local Water Management, published by NWCF and ISET: USA.

[29] Joshi, D. and Fawcett, B., (2001). "Water Projects and Women's Empowerment" Paper for 27th WEDC Conference: People and Systems for Water, Sanitation and Health, Lusaka, Zambia.

[30] Joyce, J., Granit, J., Hall, D., Haarmeyer, D., Lindstorm, A., (2010). The impact of global Financial Crisis on financial flows to the water sector in Sub Saharan Africa. New York: Oxford University Press. [31] Kaluli, J., Wangeci., C and P. G., (2009). Home Biomechanical and Environmental Engineering Department, Jomo Kenyatta University of Agriculture and Technology, Nairobi, Kenya.

[32] Kandji, S., (2006). Drought in Kenya: Climatic, Economic and Socio- Political Factors, New Stand points (November-December), pp. 17-19.

[33] Karanja, G., and Fissiha T., (1990) Soil and Water Conservation in Bibliography with Annotations (Nairobi, Kenya: University of Nairobi, Department of Agricultural Engineering; and Stockholm, Sweden: Swedish Agency for Research Cooperation with Developing Countries (SAREC)).

[34] Karanja, J., and Ng'ang'a E., (2008). Sanitation and Hygiene in Kibera Slums, Nairobi: Women Concerns and Nurses Promotional Tools.” Roskilde University, Denmark.

[35] Karanja, J., (2011). Improving water provision in Nairobi through control of non- revenue water Global
Water Summit 2011. Global Water Intelligence. pp.212-213.

[36] Kenya Population and Housing Census, (2009). Ruiru District, Kiambu County.

[37] Kimani, M., Wangui, E., and. Ngindu., A (2007). Quality of Water the Slum Dwellers Use: The Case of a Kenyan Slum, Journal of Urban Health: Bulletin of the New York Academy of Medicine, Vol. 84, No. 6 (November), pp. 829-838.

[38] Kothari, C.R., (2004) Research Methodology, Methods and techniques, New Age International (P) Ltd.

[39] Krejcie and Morgan, (1970). Determining sample size for Research Activities Educational and Psychological Measurement, vol.30, pp.607-610.

[40] Malesu, M., Oduor, A., and Odhiambo, J., (2007). Green Water Management Handbook, Rainwater harvesting for agricultural. Production and Ecological sustainability. World Agro- forestry centre.

[41] Marble, K., and Sheard, R., (1999). A Guide to Residential Water Conservation.

[42] Martin, K. and Acuna, C., (2002). SPSS for Institutional Researchers." Lewisburg, Pennsylvania: Bucknell University Press.

[43] MENA Report., (2007). Making the most out of scarcity, accountability for Better Water Management in the Middle East and North Africa.

[44] Mogaka, H.; Gichere. S.; Richard D.; and Rafik Hirji (2006). Climate Variability and Water Resources Degradation in Kenya: Improving Water Resources Development and Management (Washington, DC: The World Bank, World Bank Working Paper, No. 69).

[45] Molden, D., (2008). Water Security for food security; "Findings of the Comprehensive assessment Sub- Saharan Africa," Africa world water week, Tunis pp 20.

[46] Moriasi, D., (2007). Hydrologic and Environmental Impacts of Conservation Practices in Oklahoma Agricultural Watersheds. United States Department of Agriculture, Agricultural Research Service. P.1.

[47] Murray, C., and Lopez A., (1996). The Global Burden of Disease: A Comprehensive Assessment of Mortality and Disability from Diseases, Injuries and Risk Factors In 1990 and Projected to 2020. Cambridge, Massachusetts: Harvard School of Public Health.

[48] Naumann, M. (2003) Current Status of Water Sector in the Czech Republic, Working Paper Nealis, J., (2010). Ruiru District Population booklet.

[49] NEMA. (2010). Water availability and management in Kenya." Booklet. 
[50] Ngigi, A., and Macharia D., (2006). Kenya: Water Sector Policy Overview Paper, IT Power East Africa. [51] Nyangeri, E., and Ombongi, S., (2007). History of Water Supply and Sanitation in Kenya in Juuti, Katko and Vuorinen. (Eds) Environmental History of Water (IWA Publishing, 2007), Section until Kenyan independence: pp 271-280.

[52] Ofwat., (2006) Security of supply, leakage and the efficient use of water: 2005/6 report, UK. Orodho, A. (2002). Participation trends in secondary school Education in Kenya. Emerging scenario and policy directions. Kenyatta University: Nairobi.

[53] Postel,. L., Daily. C., and Ehrlich, P., (1996). Human appropriation of renewable fresh water. Science pp 271-785.

[54]PPD Consultants Ltd. (2007), Ruiru-Juja Water and Sewerage Company Ltd. Three Year Transitional Business Plan, Nairobi.

[55] Policy Development and Studies Branch, (2010). Water scarcity and humanitarian actions, key emerging trends and challenges OCHA Occasional Policy Briefing Series No. 4.

[56] Polit, F., (1995). Nursing Research Principles and Methods. United Nations Development Programme (UNDP), Human Development Report Millennium Development Goals. A Compact among Nations to end Human Poverty, published by UNDP.

[57]Rajamarthanda (1998), Behavior of Depth to Water Level between 1978 -97 in Karnataka State, Department of Mines and Geology, Bangalore.

[58]Redhouse, D. P., Roberts and R., Tukai., (Water Aid, 2004a). Every One's a Winner: Economic Valuation of Water Projects. Discussion Paper. August.

[59] Revenga, C., Johnson, N., and Echeverria, J., (2001). Managing water for people and nature Science. 292 (May 11), 1071-1072.

[60] Sherri, J., (2009) Research methods and Statistics, A Critical Thinking Approach. USA, Wards worth: Cengage Learning.

[61] Smakhtin, V., Revenga, C., and Döll, P., (2004) Taking into account environmental water requirements in global-scale water resources assessments. Comprehensive Assessment Research Report 2. Colombo, Sri Lanka: Comprehensive Assessment Secretariate.
[62] Sobel, J., (2004) Pathogen-Specific risk factors and protective factors for acute Diarrhoeal illness. The Chicago Press. London.

[63] Wafula, P., (2010) Lack of Investment in Water Sector Leaves Kenyan Towns Parched, Business Daily Nairobi, Kenya: Nation Media Group, p. 2.

[64] Wambua, S., (2004). Water Privatization in Kenya. Global Issue Paper, Heinrich Boll Foundation, No.8 pp. 12-15.

[65] Water Aid., (2001). Looking Back: The Longterm Impacts of Water and Sanitation Projects. Water Aid. (2005). National Water Sector Assessment, Madagascar.

[66] Water Aid. (2006a). Country Information, Madagascar.

[67] Water Aid. (2006b). Wider Impacts of Water, Sanitation and Hygiene Education Projects. Issue Sheet.

[68] Water and Sanitation Program - Africa (2007). Citizen Report Card for Water in Urban Areas. Nairobi.

[69] White, G., (1999). Drawers of Water Domestic water use in East Africa. London The University of Chicago Press.

[70] World Health Organization and UNICEF, (2012). Progress on drinking water and sanitation: United States:

[71] World Bank., (2001) World Development Report 2000/2001: “Attacking. Poverty.” Washington, DC

[72] World Health Organization (2012) United Nations International Children's Emergency Fund (UNICEF), (2012). Joint Monitoring Programme for Water Supply and Sanitation.

[73] Winpenny, J., (2011). Financing water security for economic growth in Africa. A paper for the African Development Bank. July 2011 pp. 39.

[74] World Bank, (1996). African water resources: Challenges and Opportunities for sustainable Development. World Bank Technical Paper No. 331. 


\title{
A Critical Analysis of the Effects of Strategic Management on Small Scale Businesses; A case study of Patent Medicine Stores in Abuja, Nigeria
}

\author{
Akinsola Fadeyi \\ Master in Management, Texila American University \\ E-mail:akinsola@outlook.com
}

\begin{abstract}
The impact of strategic management in businesses cannot be over-emphasised irrespective of the size or nature of the business. The strategy provides the key to success in today's changing business environment; hence, the success of a business can be traced to a well-pronounced factor, which is strategic management. As expressed by Jauch (2015), strategy formulation is a grand plan to be followed to achieve a set objective in small-scale businesses. For improved profitability and sustainability, small-scale businesses need to manage their operations intentionally.

To utilise the limited resources effectively for higher profitability, small-scale businesses need a strategy; when resources are finite, when there is uncertainty about competitive strength and behaviour, when decisions must be coordinated between far places and overtime, and when there is uncertainty about control of initiative Miller (2013). However, the study critically analysed the effect of strategic management on small-scale businesses of Patent Medicine Stores in Abuja, Nigeria, especially in the 21st century. The methodology comprises the research and questionnaire design, data collection and data analysis techniques. The researcher was able to retrieve 53 questionnaires out of 70 and test the hypothesis using the chi-square method. From the result after the research, the researcher discovered that strategic management has a great effect on small-scale businesses of patent medicine stores in Abuja, Nigeria.

Conclusively, business owners and managers must formulate policies and strategies if their businesses must continue to exist, serve and sustain competition.
\end{abstract}

Keywords: Management, Strategy, Business, and Strategic Management.

\section{Introduction}

The structure of a building is determined by its foundation and not by its façade; this is the same with businesses. The success of a business does not just boil down to the availability of resources, but it can be attributed more to proper management of all available resources. A wellstructured and feasible strategic management makes goals easily achievable, thereby meeting customer needs perfectly. Coordination and administration of tasks to achieve a plan can be traced to management; thus, management is an administrative activity that includes setting the organisation's strategy and coordinating the efforts of staff to accomplish objectives through the application of available resources. Furthermore, strategic management involves the identification and description of the techniques that managers can apply to achieve better performance and gain a competitive advantage for their organisation. An organisation has a competitive advantage if its profitability is higher than the average profitability of related companies within its industry and marketspace. To summarise, a strategic decision is crucial for the growth of any organisation.

Currently, in Nigeria, many small-scale businesses are not economically viable. This has resulted from poor management and a lack of innovation. A business that has a deficiency in creativity, planning, decision and excellent strategic management is bound to shut down Okanlahan (2018). Patent medicine stores (commonly referred to as chemist) are small stores or shops where drugs are sold over the counter. Many of the stores are owned by individuals who have the pharmaceutical knowledge and qualifications to run a chemist but lack business management skills. Giving control of businesses to non-strategic managers is a significant reason for the failed businesses. 
Thus, owners are advised to dedicate required efforts in addressing these business gaps.

Another challenge that patent medicine stores face is the employment of incompetent workers due to financial constraints. O'level holders are being employed because they are affordable. Few medicine stores owners can no longer operate because of this act; the wrong drugs had been administered because amateurs are running the stores in the absence of competent hands. To correct this, other patent medicine stores have learnt from the gap and improved their service delivery. Amid all these, some stores still lag in strategic business management and thus, struggle in the competitive market.

For short term and long-term goals, actualisation managers or owners of small-scale businesses must see the importance of planning and put into consideration supporting factors that will contribute to the growth of the business. Small stores can expand; it all depends on how well it is managed (Hann K.O., 2020). A few factors that aid the growth of patents medicine stores in Abuja, Nigeria include; marketing techniques, innovation, technological development, business structure and administration. If these factors are not put in place, the business profitability will diminish hence, leading to the dissolution of the business.

While management is essential to any business, some stores have excellent knowledge of strategic management but lack application. To solve this, a professional can be employed, but only a few stores can afford this solution. Hence, to thrive as a patent medicine store owner, it is crucial first to acquire the right knowledge of the business, starting with the necessary technical foundation. It is also required to possess current management skills and formulate worthy goals that will sustain the business and engage qualified staff.

This study critically analyses the effect of strategic management on small-scale businesses of Patent Medicine Stores in Abuja, Nigeria. It reviews the impact strategic management has on the patent medicine stores in the same location. In the process of determining where a business will be in 3 to 5 years or more, the manager tends to have futuristic goals and works towards achieving them. Since this is planned, many dreams are cut short because of resources and few other threats.
While some other stores face market instability, there are records of other patents stores that are thriving and expanding.

\section{Empirical Framework}

One of the recent conceptual studies in Nigeria (Ujunwa \& Modebe, 2012) advocated for the adoption of strategic management approach in ensuring capital market efficiency following the perceived pivotal role the capital market in economic development. The strategic measure they reviewed ranged from effective regulation to achieving favourable macroeconomic environment. They posited that these strategies will not only promote the efficiency of the capital market but will leverage the role of the capital market in promoting economic growth.

Bob Johnson (2005) argued with few colleagues on the possible effect that strategy has on business productivity. He explained that a business that is not strategically managed would face a great fall. From his findings, he realised many SME businesses run their business ontrend and are limited because only a few are open to change and upgrade in ways and manners of operation.

Askarany and Yazdifar (2012), investigating the diffusion of six proposed strategic management tools of the past few decades through the lens of organisational change theory, examined the relationship between the adoption of these techniques and organisational performance in both manufacturing and nonmanufacturing organisations in New Zealand. The findings suggest a significant association between the diffusion of these relatively new strategic management tools and organisational performance.

Hypotheses are formulated to establish some facts.

$\mathbf{H}_{0}$; the perception of patent medicine business owners has no significant effects on their business.

$\mathbf{H}_{0}$; the perceptions of PM business owners have no significant effect on the adoption of strategic management.

$\mathbf{H}_{0}$; Strategic Management has no significant effect on Patent Medicine Stores in Abuja, Nigeria. 


\section{Methodology}

A research methodology is a general orientation or the research process framework to conduct research. A research methodology is available in two different categories: quantitative research and qualitative research (Gadafi, 2017).

For emergency and acute conditions, the medicine stores known as patent are recognised in Nigeria. To reduce the burden of disease and mortality, Africa is increasingly recognising the vital role that drug retailers play in delivering primary healthcare services. In Nigeria, owneroperated drug retail outlets known as patent and proprietary medicine vendors (PPMVs) are the leading source of medicines for acute conditions. A greater understanding of the role of PPMVs and the quality of care they provide is needed to inform ongoing national health initiatives that aim to incorporate PPMVs as a delivery mechanism.

Abuja, the federal capital territory of Nigeria has been chosen as the case study with six local governments. For this study, the sampled population of 21 patent medicine stores with 61 respondents were selected in the Bwari Local Government in the following areas;

Table 1. Sample population (Bwari Local Government)

\begin{tabular}{|l|l|l|l|}
\hline S/N & Location & Numbers of Stores & Respondents \\
\hline 1 & Camp & 2 & 5 \\
\hline 2 & Dawaki & 3 & 12 \\
\hline 3 & Dutse & 3 & 5 \\
\hline 4 & Kogo & 4 & 10 \\
\hline 5 & Kubwa & 6 & 20 \\
\hline 6 & Ushafa & 3 & 9 \\
\hline & TOTAL & $\mathbf{2 1}$ & $\mathbf{6 1}$ \\
\hline
\end{tabular}

A descriptive survey design was used for this study to collect detailed and factual information that describes the subject matter. Data was compiled based on the concepts defined in the research model, and hypotheses were tested. The instrument used for data collection was questionnaires, and each question was directed at getting the perception of the respondents on the application of strategic management and its effect on business growth and development.

Questionnaires are extremely flexible and could be used to gather information concerning almost any topic, from small to a large number of people (Moore, 1987 cited in Olatokun and Gbinedion, 2009). The hypotheses testing was carried out with chi-square.

\section{Results}

\section{Chi-square}

Percentage analysis was used to answer the two (2) research questions raised while chisquare $\left[X^{2}\right]$ inferential statistics were applied to test all the research hypotheses at $\square=0.05$ level of significance. According to Ali (2006), sighted in Ismael (2020), "chi-square $\left(x^{2}\right)$ test was used in data analysis or treatment if such data are discrete and the variances are independent or unrelated to one another." Furthermore,
Ogblechi (2013) elaborated on the conditions and merits of applying chi-square statistics to data analysis; thus; the chi-square test is most appropriate where a study is of a non-parametric statistical nature. It is used for treating data consisting of frequency counts. It permits the researcher to determine whether a significant difference exists between the observed number of cases falling into each category and the expected numbers based on the null hypotheses. The fundamental question answered by the chisquare test analysis is whether the frequencies observed in a sample deviated significantly from theorised population frequencies.

Percentage calculation was based on the mathematical relation/formula:

Percentage $(\%)={ }^{\mathrm{x}} / \mathrm{N} * 10 \% / 1$

Where:

$X=$ Number of Responses in favour/against each item

$N=$ Total number of Respondents

$100=$ Constant

$*$ Symbol for multiplication

The chi-Square calculation was carried out using the formula:

$$
\text { Chi-Square }\left(X^{2}\right)=\frac{\sum\left(f_{o}-f_{e}\right)^{2}}{f_{e}}
$$


Where: $X^{2}=$ Chi-Square

fo $=$ Observed frequencies

$f e=$ Expected frequencies

\section{Research decisions were made based on the following criteria}

[a] If percentage value of $x$, that is $(x \%) \geq 50$, then item is accepted or agreed with as being "true" and

[b] If percentage value of $x$, that is $(x \%)<50$, then item is rejected or disagreed with and therefore regarded as "false." [c] If the value of $X^{2}$-Calculated is greater than $\mathrm{X}^{2}$-Tabulated, that is $\left[\mathrm{X}^{2}\right.$-Cal.> $\mathrm{X}^{2}$-Tab. $]$, then $\mathbf{H}_{\mathbf{o}}$ would be rejected/ignored, and consequently, $\mathbf{H}_{1}$ would be accepted.

[d] If the value of $X^{2}$-Tabulated is greater than or equal to $\mathrm{X}^{2}$-Calculated, that is $\left[\mathrm{X}^{2}-\mathrm{Tab} . \geq\right.$ $\mathrm{X}^{2}$-Cal.], then $\mathbf{H}_{\mathbf{0}}$ would be accepted, and consequently, $\mathrm{H}_{1}$ would be rejected/ignored.

Note: $\mathbf{H}_{\mathbf{0}}=$ Null Hypothesis and $\mathbf{H}_{\mathbf{1}}=$ Alternative Hypothesis.

\section{Section 1: Perception of patent medicine store owners to business}

Q1. The following is a list of possible ways patent medicine store owners may view a business. Using the scale below, please indicate the extent of your agreement or disagreement with the statement below.

Table 2

\begin{tabular}{|l|l|l|l|l|l|l|}
\hline Perception & \multicolumn{2}{|l|}{ Disagree } & \multicolumn{2}{l|}{ Agree } & Remark \\
\hline a. My business is majorly established to make profit & 12 & 19.7 & 49 & 80.3 & Agree \\
\hline $\begin{array}{l}\text { b. My business is run for charity as my goods are to save } \\
\text { lives }\end{array}$ & 53 & 86.9 & 8 & 13.1 & $\begin{array}{l}\text { Disagre } \\
\text { e }\end{array}$ \\
\hline $\begin{array}{l}\text { c. My business is established to make a profit and to fulfil } \\
\text { social responsibility }\end{array}$ & 28 & 45.9 & 33 & 54.1 & Agree \\
\hline & 93 & & 90 & & \\
\hline AVG & 31 & & 30 & & \\
\hline
\end{tabular}

\section{Section 1: Perception of patent medicine store owners on strategic management}

Q1. The following is a list of possible ways patent medicine store owners may view strategic management. Using the scale below, please indicate the extent of your agreement or disagreement with the statement below.

Table 3

\begin{tabular}{|l|l|l|l|l|l|}
\hline Perception & \multicolumn{2}{l|}{ Disagree } & \multicolumn{2}{l|}{ Agree } & \\
\hline $\begin{array}{l}\text { a. Strategic management involves excellent planning and } \\
\text { controlling of business activities that will improve profitability } \\
\text { thus; it is essential for business survival }\end{array}$ & 71.5 & 54 & 88.5 & Agree \\
\hline $\begin{array}{l}\text { b. Strategic management is not a priority when the owner has the } \\
\text { resources to fund the business. }\end{array}$ & 21 & 34.4 & 40 & 65.6 & Agree \\
\hline $\begin{array}{l}\text { c. Strategic management is expensive to adopt as a business } \\
\text { owner, thus, a traditional method of running the business help } \\
\text { sustainability }\end{array}$ & 34 & 55.7 & 27 & 44.3 & Disagree \\
\hline & 62 & & 121 & & \\
\hline AVG & 20.7 & & 40.3 & & \\
\hline
\end{tabular}




\section{Section 3: The effect of strategic management on Patent medicine stores in Abuja, Nigeria}

Q3. The following is a list of how strategic management can affect patent medicine stores

Table 4

\begin{tabular}{|l|l|l|l|l|l|}
\hline Trust & \multicolumn{2}{l|}{ Disagree } & \multicolumn{2}{l|}{ Agree } & Remark \\
\hline $\begin{array}{l}\text { a. Patent Medicine stores are assured of expansion and improved } \\
\text { profitability with excellent strategic management }\end{array}$ & 4 & 6.6 & 57 & 93.4 & Agree \\
\hline $\begin{array}{l}\text { b. Effective decision and efficient performance is the result of } \\
\text { strategic management }\end{array}$ & 14 & 23.0 & 47 & 77.0 & Agree \\
\hline $\begin{array}{l}\text { c. Patent medicine store rightly applying strategic management stays } \\
\text { long in business }\end{array}$ & 8 & 13.1 & 53 & 86.9 & Agree \\
\hline $\begin{array}{l}\text { d. Good strategic management of medicine stores rightly appraise and } \\
\text { promote the medical knowledge of the owner }\end{array}$ & 16 & 26.2 & 45 & 73.8 & Agree \\
\hline & 42 & & 202 & & \\
\hline & 10.5 & & 50.5 & & \\
\hline
\end{tabular}

Source: Researcher's fieldwork (2020)

NOTE: Data in Tables were generated by using percentage calculations as follows:

For Item 1: Agree $=[a / 61] \times 100 \%=a \%$

Disagree $=[a / 61] \times 100 \%=a \%$

N.B:

(1) Sample size $=61$

(2) The calculation was applied to all data generated in each case in each table

\section{Discussion}

The Tables above provided the data for answering research question one, two and three. All the items relating to perceptions towards business and strategic management were accepted except the second $\left(2^{\text {nd }}\right)$ and third $\left(3^{\text {rd }}\right)$ item in question one and two, respectively. The relative effects of the items are as follows: businesses are mainly established to make a profit (80.3\%); businesses are not run for charity (86.9\%); businesses are established to make a profit and also to fulfil social responsibility $(54.1 \%)$. All items relating to the perception of strategic management are as follows; strategic management involves excellent planning and controlling of business activities that will improve profitability; thus, it is essential for business survival (88.5\%). Strategic management is not a priority when the owner has the resources to fund the business. (59.0\%),
Strategic management is not expensive to adopt as a business owner; thus, the traditional method of running the business does not help sustainability $(60.7 \%)$; the items relating to the effect of strategic management are as follows; Patent Medicine stores are assured of expansion and improved profitability with excellent strategic management (93.4\%). Effective decision and efficient performance are the result of strategic management $(77.0 \%)$. Patent medicine store rightly applying strategic management stays long in business (86.9\%) and good strategic management of medicine stores rightly appraise and promote the medical knowledge of the owner (63.8\%).

\section{Test of Research Hypotheses}

$\mathrm{H}_{\mathbf{0}}$; the perception of patent medicine business owners does not have a significant effect on their business

Table 5. Test of $\mathrm{X}^{2}$ Computations for $\mathrm{H}_{0}$, Inference and Decision Made (Data Extracted from Table 1).

\begin{tabular}{|l|l|l|l|l|l|}
\hline Responses & Fo & Fe & $(\mathbf{f o}-\mathbf{f e})^{\mathbf{2}}$ & $(\mathbf{f o - f e})^{\mathbf{2}} / \mathbf{f e}$ & Inference \\
\hline Agree $[\%]$ & 31 & 30.5 & 0,25 & 0.008 & \multirow{2}{*}{${ }^{2}$-Cal $>\mathrm{X}^{2}$-Tab } \\
\cline { 1 - 5 } Disagree [\%] & 30 & 30.5 & 0.25 & 0.008 & \\
\hline Total & 61 & 61 & - & 0.016 & DECISION \\
\cline { 1 - 3 } $\mathrm{X}^{2}$-Calculated $=0.016$ & \multicolumn{2}{|l}{$\mathrm{X}^{2}$-Tabulated $=3.84$} & Reject $\mathrm{H}_{0}$ \\
\hline
\end{tabular}




\begin{tabular}{|l|l|l|}
\hline NOTE: $\mathrm{DF}=1$ & $\alpha=0.05$ & Accept $\mathrm{H}_{1}$ \\
\hline
\end{tabular}

Source: Researcher's fieldwork (2016)

Table 12 showed that $\mathrm{X}^{2}$-Calculated $=0.016$ while $X^{2}$-Tabulated $=3.84$ (Minium, King \& Bear, 1993). This gave the inference $\left[X^{2}-\right.$ Cal.> $\left.X^{2}-T a b.\right]$. We, therefore, rejected the alternate hypothesis $\left(\mathrm{H}_{1}\right)$ which states, "the perception of patent medicine business owners does have a significant effect on their business" and accepted the null hypothesis $\left(\mathrm{H}_{0}\right)$ which states "the perception of patent medicine business owners does not have a significant effect on their business." This result empirically seems to be argued as it is a general notion that personality has a lot to do with your business. Thus, the rejected alternate hypothesis should be accepted, and the null hypothesis rejected. The researcher suspects that an item needs to be deleted to get this fact. Thus, this is open to further practical and empirical research or findings.

$\mathbf{H}_{0}$; the perceptions of patent medicine business owners have no significant effect on the adoption of strategic management

Table 6. Test of X2 Computations for H02, Inference and Decision Made (Data Extracted from Table 2)

\begin{tabular}{|c|c|c|c|c|c|}
\hline Responses & fo & $\mathbf{F e}$ & $(\mathbf{f o}-\mathbf{f e})^{2}$ & $(\mathrm{fo}-\mathrm{fe})^{2} / \mathrm{fe}$ & Inference \\
\hline Agree [\%] & 20.7 & 30.5 & 96.04 & 3.15 & \multirow[t]{2}{*}{$\mathrm{X}^{2}-\mathrm{Cal}>\mathrm{X}^{2}-\mathrm{Tab}$} \\
\hline Disagree [\%] & 40.3 & 30.5 & 96.04 & 3.15 & \\
\hline Total & 61 & 61 & - & 6.30 & DECISION \\
\hline \multicolumn{3}{|c|}{$\mathrm{X}^{2}$-Calculated $=6.30$} & \multicolumn{2}{|c|}{$\mathrm{X}^{2}$-Tabulated $=3.84$} & \multirow{2}{*}{$\begin{array}{l}\text { Reject } \mathrm{H}_{0} \\
\text { Accept } \mathrm{H}_{1}\end{array}$} \\
\hline \multicolumn{3}{|l|}{ NOTE: $\mathrm{DF}=1$} & \multicolumn{2}{|l|}{$\alpha=0.05$} & \\
\hline
\end{tabular}

Source: Researcher's fieldwork (2016).

Table 13 showed that $\mathrm{X}^{2}$-Calculated $=6.30$ while $\mathrm{X}^{2}$-Tabulated $=3.84$ (Minium, King \& Bear, 1993). This gave the inference $\left[X^{2}-\right.$ Cal.> $X^{2}-$ Tab.]. We, therefore, rejected the null hypothesis (Ho) which states that " $\mathbf{H}_{\mathbf{0}}$; the perceptions of patent medicine business owners have no significant effect on the adoption of strategic management" and accepted the alternative hypothesis $\left(\mathrm{H}_{1}\right)$ which stated that " $\mathbf{H}_{\mathbf{0}}$; the perceptions of Patent Medicine business owners have a significant effect on the adoption of strategic management."

$\mathbf{H}_{0}$; Strategic Management has no significant effect on Patent Medicine Stores in Abuja, Nigeria.

Table 7. Test of $\mathrm{X}^{2}$ Computations for $\mathrm{H}_{02}$, Inference and Decision Made (Data Extracted from Table 2)

\begin{tabular}{|c|c|c|c|c|c|}
\hline Responses & fo & $\mathrm{Fe}$ & $(\mathrm{fo}-\mathrm{fe})^{2}$ & $(\mathrm{fo}-\mathrm{fe})^{2} / \mathrm{fe}$ & INFERENCE \\
\hline Agree [\%] & 10.5 & 30.5 & 400 & 13.11 & \multirow[t]{2}{*}{$\mathrm{X}^{2}-\mathrm{Cal}>\mathrm{X}^{2}-\mathrm{Tab}$} \\
\hline Disagree [\%] & 50.5 & 30.5 & 400 & 13.11 & \\
\hline Total & 61 & 61 & - & 26.22 & Decision \\
\hline \multicolumn{3}{|c|}{$\mathrm{X}^{2}$-Calculated $=26.22$} & \multicolumn{2}{|c|}{$\mathrm{X}^{2}$-Tabulated $=3.84$} & \multirow{2}{*}{$\begin{array}{l}\text { Reject } \mathrm{H}_{0} \\
\text { Accept } \mathrm{H}_{1}\end{array}$} \\
\hline \multicolumn{3}{|c|}{ NOTE: $\mathrm{DF}=1$} & \multicolumn{2}{|l|}{$\alpha=0.05$} & \\
\hline
\end{tabular}

Source: Researcher's fieldwork (2016)

Table 13 showed that $\mathrm{X}^{2}$-Calculated $=26.22$ while $\mathrm{X}^{2}$-Tabulated $=3.84$ (Minium, King \& Bear, 1993). This gave the inference $\left[X^{2}-\right.$ Cal.> $\left.X^{2}-T a b.\right]$. We, therefore, rejected the null hypothesis (Ho) which states "strategic management has no significant effect on patent medicine stores in Abuja, Nigeria" and accepted the alternative hypothesis $\left(\mathrm{H}_{1}\right)$ which stated, "strategic management has a significant effect on patent medicine stores in Abuja, Nigeria."

\section{Conclusion}

The use of the newest technologies in businesses today has made the market highly 
competitive. Thus, any patent medicine store that fails to upgrade and serve as a strategic system for ensuring an efficient and trustworthy distributor or retailer certainly has no future. Strategic management enables easy decision making, flexible control and planning of resources to yield result. From the findings, it was observed that $87 \%$ of the respondents appreciate the value of strategic management and practically applied it. $67 \%$ of the respondents in Kubwa approved the adoption of strategic management and confirmed its successful result; $48 \%$ of the respondents in Dawaki assumed adopting strategic management is expensive. For the respondents at Ushafa, the researcher observed that they believed in the profession rather than the business. The size of the business is not as big as those who practically adopt strategic management. Thus, the study recommends that a significant percentage of store owners should be educated on strategic management.

Due to the massive increase in the number of patent medicine stores both in rural and in urban areas, it is imperative to conclude that business owners not only require financial backing, but they also need basic training and technological awareness to help improve their businesses. This is because the success of every business will contribute to the development of the economy.

However, it is a sad story that despite the commendable work carried out by most researchers in ensuring a better system; lack of awareness of this pioneering development has influenced the non-adoption of strategic management as such, a larger population of the country that are into similar businesses struggle for success. Concerning this reality, further research is needed to close the gaps observed in the study. Increasing the population to two to three local government areas should present a broader view of this study and provide more opinions.

Finally, the researcher also observed that the level of exposure in these settlements goes a long way in determining the adoption of strategic management thus; proper awareness of the benefit of strategic management in smallscale businesses will curb these challenges. The subsequent studies may look at the understanding of strategic management in business in rural areas.

\section{Reference}

[1] Impact of Strategic Management on Small Scale Business Development (A case study of Assur electronics, Uyo) Retrieved September 2020 from https://projectchampionz.com.ng/2016/08/05/strategi c-management-small-scale/

[2] Career development, (2020) What is Management? Retrieved September 2020 from; https://www.indeed.com/career-advice/careerdevelopment/what-is-management

[3] MSG, (2020) Management study guide; meaning and important concepts; Retrieved September 2020 from

https://www.managementstudyguide.com/strategicmanagement.htm

[4] Naomi B., Jenny L., and Maia S., (2012) A Systematic Review of the Role of Proprietary and Patent Medicine Vendors in Healthcare Provision in Nigeria; Retrieved September 2020 from

[5] https://journals.plos.org/plosone/article?id=10.13 71/journal.pone.0117165

[6] Web sources: https://www.researchgate.net/publication/314834917 _The_Impact_of_Strategic_Management_on_Organi sational_Growth_and_Development_A_Study_of_Se lected_Manufacturing_Firms_in_Anambra_State

[7] https://www.abacademies.org/articles/Analysisof-the-impact-of-strategic-management-on-thebusiness-performance-1939-6104-17-1-163.pdf [8] http://iosrjournals.org/iosr-jbm/papers/Vol7issue1/D0712432.pdf

[9] https://www.strategyskills.com/Articles/Docume nts/evolution.pdf

[10] https://www.answers.com/Q/How_managers_util ize_organizational_resources_efficiently_and_effecti vely_to_achieve_organizational_goals

[11] http://uir.unisa.ac.za/bitstream/handle/10500/196 2/04chapter3.pdf

[12] https://www.thoughtco.com/chi-square-test-fora-multinomial-experiment-3126399

[13] https://www.managementstudyguide.com/strateg y-formulation-vs-implementation.htm

[14] http://rizvihmct.com/wpcontent/uploads/2017/02/Semester-VI-strategicmanagment.pdf

[15] https://www.economicsdiscussion.net/strategicmanagement/what-is-strategic-managementprocess $/ 31761$

[16] https://theintactone.com/2018/12/23/sm-u1topic-2-meaning-nature-scope-and-importance-ofstrategic-management/ 
[17] https://www.torbenrick.eu/blog/strategy/compani es-that-struggle-with-disruptive-change/

[18] https://www.businesswire.com/news/home/2020 0924005354/en/

[19] https://codemint.net/business-administration/theimpact-of-strategic-management-on-performance-ofsmall-and-medium-scale-enterprises-a-studyofkaduna-metropolis/index.html

[20] https://www.retaildive.com/news/crisismanagement-how-two-dtc-brands-found-success-inthe-midst-of-a-pande/579302/

[21] https://www.researchgate.net/publication/314834 917_The_Impact_of_Strategic_Management_on_Org anisational_Growth_and_Development_A_Study_of _Selected_Manufacturing_Firms_in_Anambra_State [22] https://www.semanticscholar.org/paper/A-

Systematic-Review-of-the-Role-of-Proprietary-and-

Beyeler-

Liu/034b8b76af0f7389ba0d7c24aee0b509a648d668

[23] http://uir.unisa.ac.za/bitstream/handle/10500/202 4/07chapter7.pdf

[24] https://yourbusiness.azcentral.com/importanceorganizational-behavior-its-effect

company25410.html

[25] https://study.com/academy/answer/calculate-thep-value-for-the-following-hypothesis-test-at-thealpha-0-05-level-of-significance-the-sample-mean-is102-3-and-the-sample-standard-deviation-is-12-for-asample-of-n-25-h0-mu-105-h1-mu-ne-105.html
[26] https://www.transtutors.com/questions/strategyplans-and-budgets-are-unrelated-to-one-another-doyou-agree-explain-explai-3169523.htm

[27] https://www.surveygizmo.com/resources/blog/int roduction-to-chi-square-test-and-when-to-use-it/

[28] https://www.iedunote.com/strategic-management [29] https://hwperfect.com/homeworkhelp/29-

Homework.html

[30] https://microbenotes.com/null-and-alternativehypothesis/

[31] http://docshare.tips/emerging-trends-in globalbusiness_575b8d19b6d87f09938b481c.html [32] http://www.businessdictionary.com/definition/H 1.html

[33] https://iiste.org/Journals/index.php/JEP/article/vi ew/34631/0

[34] https://www.oracle.com/technetwork/database/bi gdataappliance/overview/bigdatarefarchitecture2297765.pdf

[35] http://shodhganga.inflibnet.ac.in/bitstream/10603 13782/13/13_chapter\%203.pdf

[36] https://www.linkedin.com/pulse/roleinformation-technology-business-success-abid-afzalbutt 


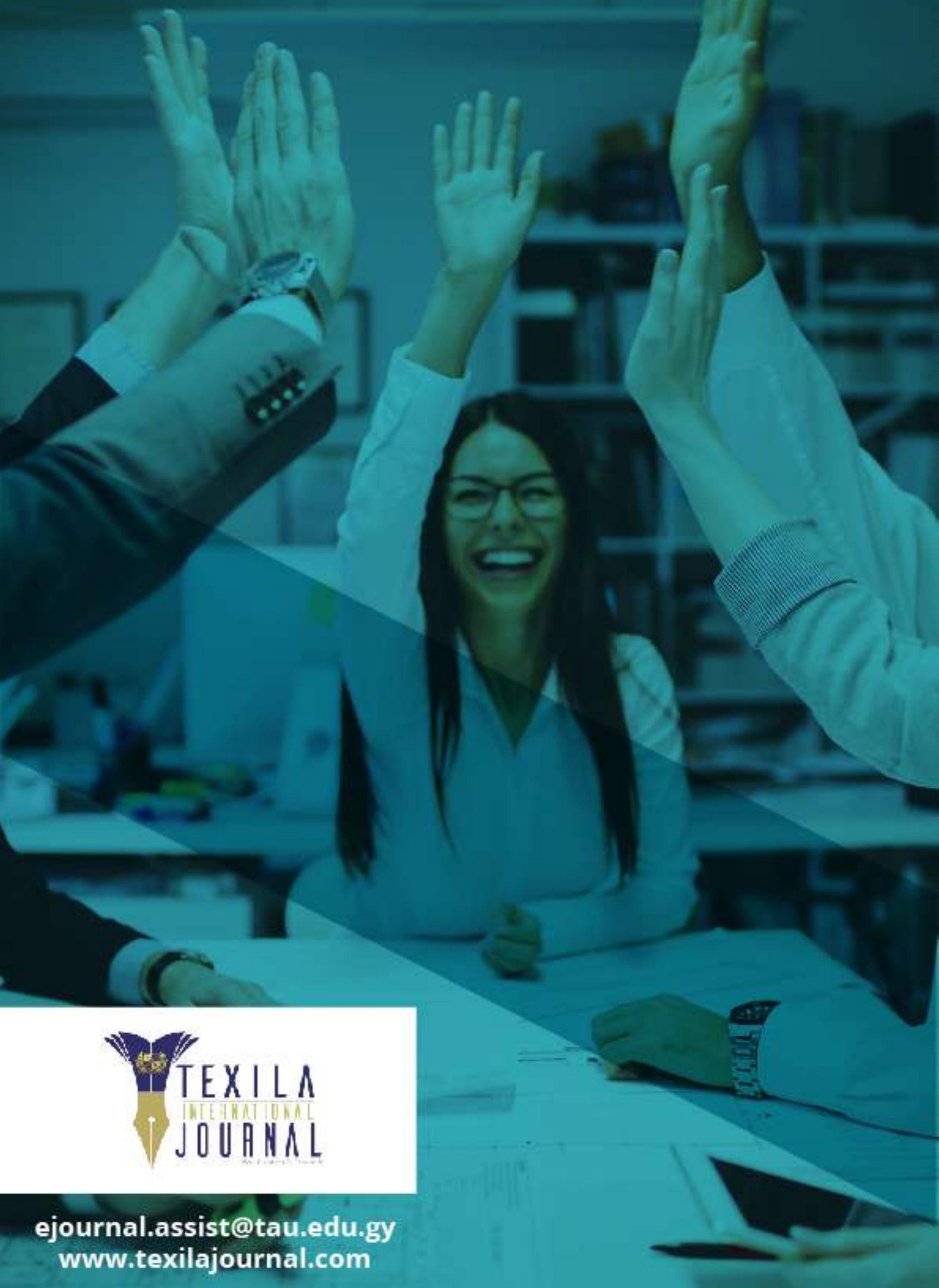

